Escola de Engenharia de São Carlos

Departamento de Engenharia de Transportes

Programa de Pós-graduação em Engenharia de Transportes

VIVIANI ANTUNES GOMES RODRIGUES

Análise do comportamento individual relativo a viagens encadeadas através de variáveis socioeconômicas, participação em atividades e características agregadas das alternativas modais.

São Carlos

2020 



\title{
Análise do comportamento individual relativo a viagens encadeadas através de variáveis socioeconômicas, participação em atividades e características agregadas das alternativas modais.
}

Tese de doutorado apresentada à Escola de Engenharia de São Carlos (EESC/USP) como parte dos requisitos para obtenção do título de Doutor em Ciências, Programa de Pós-Graduação em Engenharia de Transportes.

Área de concentração: Planejamento e Operação de Sistemas de Transportes.

Orientadora: Profa. Dra. Cira Souza Pitombo

\author{
São Carlos
}

2020

EXEMPLAR DEFINITIVO (CORRIGIDO). O EXEMPLAR ORIGINAL ESTÁ DISPONÍEL NA CPG DA EESC-USP. 
AUTORIZO A REPRODUÇĀO TOTAL OU PARCIAL DESTE TRABALHO, POR QUALQUER MEIO CONVENCIONAL OU ELETRŐNICO, PARA FINS DE ESTUDO E PESQUISA, DESDE QUE CITADA A FONTE.

Ficha catalografica elaborada pela Biblioteca Prof. Dr. Sérgio Rodrigues Fontes da EESC/USP com os dados inseridos pelo(a) autor(a).

Eduardo Graziosi Silva - CRB - 8/8907 



\section{FOLHA DE JULGAMENTO}

Candidata: Engenheira VIVIANI ANTUNES GOMES RODRIGUES.

Título da tese: "Análise do comportamento individual relativo a viagens encadeadas através de variáveis socioeconômicas, participação em atividades e características agregadas das alternativas modais".

Data da defesa: 09/12/2020.

Comissão Julgadora

Profa. Associada Cira Souza Pitombo

(Orientadora)

(Escola de Engenharia de São Carlos - EESC/USP)

Profa. Dra. Fabiana Serra de Arruda

(Universidade de Brasília/UnB)

Prof. Dr. Pablo Brilhante de Sousa

(Universidade Federal da Paraíba/UFPB)

Prof. Dr. Pastor Willy Gonzales Taco

(Universidade de Brasília/UnB)

Prof. Dr. Francelino Franco Leite de Matos Sousa

(Centro Universitário Christus - Unichristus/CE)
Aprovada

Aprovada

Resultado

Aprovada

Aprovada

Aprovada

Coordenador do Programa de Pós-Graduação em Engenharia de Transportes:

Prof. Associado Adalberto Leandro Faxina

Presidente da Comissão de Pós-Graduação:

Prof. Titular Murilo Araújo Romero 

Dedico este trabalho aos meus amados pais, José Neri e Yêda, sempre uma referência de amor, força e perseverança.

E aos meus queridos avós Otelvino e Vicência, Geraldo e Augusta, (in memoriam) 




\section{Agradecimentos}

Agradeço a Deus pela vida que habita no interior de todas as pessoas. Por todas as bênçãos recebidas e experiências vividas no decorrer desses anos. Muito obrigada!!

Agradeço ao meu marido Eurípedes por todo amor, carinho, paciência e companheirismo. Ao meu filho Vitor e aos meus enteados Ghabriel e Nathan, por fazerem nossos dias mais alegres e com novas esperanças.

Agradeço à minha orientadora Cira Souza Pitombo por todo ensinamento, orientação, amizade paciência e confiança. Meu respeito e gratidão.

Agradeço à Coordenação de Aperfeiçoamento de Pessoal de Nível Superior (CAPES) pelo apoio à pesquisa.

Agradeço ao amigo Lucas Assirati pelos muitos auxílios no decorrer deste trabalho. Sempre solícito e prestativo.

Aos colegas do Departamento de Engenharia de Transportes, pelos momentos agradáveis, pelo companheirismo e amizade. Agradeço, especialmente, aos amigos Aurenice, Murilo, Samille, Cíntia, Samuel, Thiago e Andressa.

Agradeço à bolsista de Iniciação Científica, Carolina Cerveira, pela participação importante do seu projeto na etapa de caracterização agregada das alternativas.

Meu agradecimento especial à colega Marina Urano Caldas, pela participação fundamental na etapa de redução de parâmetros do Modelo.

Agradeço a cada um dos professores e funcionários do STT, em especial à professora Ana Paula Larocca, aos professores Antônio Nélson Rodrigues da Silva e André Luiz Cunha. Exemplos de profissionalismo, dedicação e responsabilidade com o ensino.

Agradeço à banca examinadora pela participação e contribuições.

Agradeço à Universidade Federal do Triângulo Mineiro (UFTM) e aos colegas do Departamento de Engenharia Civil pelo apoio e incentivo. 


\section{Resumo}

GOMES, V. A. Análise do comportamento individual relativo a viagens encadeadas através de variáveis socioeconômicas, participação em atividades e características agregadas das alternativas modais. 2020. Tese (Doutorado) - Escola de Engenharia de São Carlos, Universidade de São Paulo, São Carlos, 2020.

Nas últimas décadas, a abordagem da demanda por viagens baseadas em atividades ganhou destaque em decorrência da sua melhor caracterização da demanda por viagens, como por exemplo, as decisões simultâneas de aspectos da demanda e a interdependência entre todas as viagens individuais, realizadas ao longo do dia - viagens encadeadas. A modelagem da cadeia de viagens baseia-se em dados relativos a diários de atividades, dados coletados através de coleta passiva (smartphones, por exemplo), ou dados obtidos por pesquisas de Preferência Revelada (PR) e Declarada (PD). Em transportes, uma das principais fontes de dados é a Pesquisa $\mathrm{O} / \mathrm{D}$, que é uma pesquisa de $\mathrm{PR}$ e descreve as escolhas e comportamentos reais dos indivíduos. No entanto, a Pesquisa O/D somente relaciona os dados das escolhas efetivas realizadas pelo entrevistado. Ela não caracteriza as alternativas não escolhidas sendo, por isso, um fator limitante na sua aplicação em modelagens relativas às escolhas dos deslocamentos. Neste contexto, este trabalho investiga o comportamento relativo a viagens encadeadas através de participação em atividades e de características socioeconômicas, para duas amostras, uma de trabalhadores e outra de estudantes, propondo a inclusão de características modais agregadas, obtidas através do algoritmo CART (Classification And Regression Tree) e Pesquisa OD, realizada na Região Metropolitana de São Paulo em 2007. Para realização do objetivo principal, o presente trabalho apresenta alguns objetivos específicos: (1) Classificar os indivíduos em grupos que apresentem similares padrões de viagem, utilizando-se as sequências de motivos e modos de viagem (Variável dependente); (2) Realizar uma caracterização das alternativas modais a partir de dados de PR; (3) Propor um critério para formulação do Modelo Logit Multinomial e redução de parâmetros a serem estimados; (4) Incorporar as variáveis agregadas, obtidas em (2), e mensurar o aprimoramento nas estimativas através de Modelo Logit Multinomial. A característica agregada das alternativas foi os tempos médios de viagens para cinco alternativas modais. Este estudo está associado às seguintes lacunas de pesquisa: (1) a ausência de dados relativos às alternativas em Pesquisa de PR; (2) a falta de um critério para composição das funções utilidade para o caso de grande conjunto de alternativas e muitos parâmetros a serem estimados e (3) modelagem com base na abordagem de demanda por viagens, baseadas em atividades. Levando-se em conta os resultados obtidos, verificou-se a viabilidade do procedimento metodológico proposto considerando as restrições da ferramenta utilizada. Adicionalmente, a modelagem paramétrica apresentou melhoria no modelo a partir da inclusão da variável que caracteriza a alternativa, além de corroborar relações embasadas pela literatura.

Palavras chaves: Viagens encadeadas. Abordagem da demanda por viagens baseada em atividades. Preferência Revelada. Padrões de viagens. Algoritmo CART. 


\begin{abstract}
GOMES, V. A. An analysis of trip-chaining behaviour based on activity participation, socioeconomic variables and aggregated characteristics of modal alternatives 2020. Doctoral Thesis - São Carlos Enginnering School, University of São Paulo, São Carlos, São Paulo, Brazil, 2020.
\end{abstract}

In recent decades, the activity-based approach has gained prominence due to its better characterisation of travel behaviour, such as simultaneous decisions of demand and interdependence aspects among all individual trips, carried out over a day - trip chaining. Trip chaining modelling is based on data related to activity diaries, passive data collection (smartphones, for example), or data obtained by Revealed (RP) and Stated (SP) Preference surveys. In transport, one of the main sources of data is the O/D Survey, which is an RP survey and describes real choices and individual behaviours. However, the O/D Survey only lists the data of the effective choices made by the interviewee. It does not characterise the alternatives not chosen and is, therefore, a limiting factor when applying modelling related to the displacement choices. In this context, this study investigates the trip chaining behaviour considering activity participation and socioeconomic characteristics for two samples; one of workers and another of students, proposing the inclusion of aggregate modal characteristics, obtained from the CART (Classification And Regression Tree) algorithm and OD Survey, carried out in São Paulo in 2007. In order to meet the main objective, this study presents some specific objectives: (1) Classifying individuals into clusters that present similar travel patterns, using trip purpose and travel modes sequences (dependent variable); (2) Carrying out a characterisation of modal alternatives based on RP data; (3) Proposing a criterion for formulating the Multinomial Logit Model and a reduction of parameters to be estimated; (4) Incorporating the aggregated variables, obtained in (2), and measuring the improvement in estimates using the Multinomial Logit Model. The aggregated characteristic of the alternatives was the average travel times for five modal alternatives. This study is associated with the following research gaps: (1) the absence of data, associated to alternatives in an RP survey; (2) the lack of a criterion for utility function composition for the case of a large choice sets and many parameters to be estimated; and (3) modelling based on the activity-based travel demand approach. Taking into account the findings obtained, the feasibility of the proposed methodological procedure was verified regarding the constraints of the tool used. Additionally, parametric modelling improved the model by including the alternative variable and corroborated relationships based on the literature.

Keywords: Trip-Chaining, Activity-based approach, Revealed Preference, Travel patterns. CART algorithm. 


\section{Lista de Figuras}

Figura 1.1 - Síntese dos problemas de pesquisa envolvidos .................................. 29

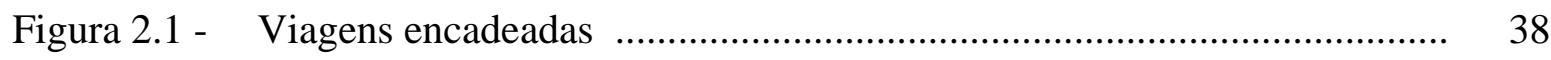

Figura 3.1 - Ilustração de um dendrograma (Método de agrupamento hierárquico) .. 46

Figura 3.2 - Exemplo da estrutura de uma Árvore de Decisão ................................ 49

Figura 3.3 - Algoritmo CART …................................................................. 50

Figura 4.1 - Etapas metodológicas associadas à modelagem paramétrica (exemplo

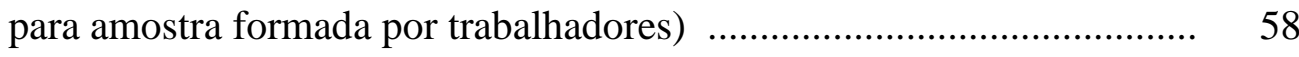

Figura 4.2 - $\quad$ Pesquisa Origem Destino - RMSP 2007 ........................................ 58

Figura 4.3 - Procedimento metodológico …....................................................... 59

Figura 4.4 - Ilustração do procedimento adotado para obtenção dos tempos de viagens médios por modo de transporte ............................................. 62

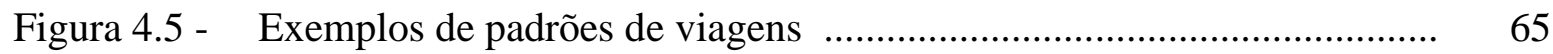

Figura 4.6 - Exemplo do procedimento adotado com a AD para redução do número de parâmetros

Figura 5.1 - Esquema ilustrativo para obtenção dos tempos de viagens por modo de transporte

Figura 5.2 - Mapa do Algoritmo CART - Ramo 1 e Ramo 2

Figura 6.1 - Esquema ilustrativo do procedimento para classificação dos indivíduos

Figura 7.1 - Ilustração das etapas relativas à redução de parâmetros e composição das funções utilidade e modelagem paramétrica

Figura 8.1 - Relação entre os objetivos, lacunas e hipóteses de pesquisa 


\section{Lista de Quadros}

Quadro 3.1 - $\quad$ Síntese do uso de cada ferramenta, associada aos objetivos .............. 55

Quadro 6.1 - $\quad$ Síntese de resultados da literatura, associadas ao presente estudo ..... 91

Quadro 7.1 - Síntese dos resultados, provenientes da etapa paramétrica, encontrados neste trabalho ............................................................. 107 


\section{Lista de Tabelas}

Tabela 4.1 - Variáveis da amostra por indivíduos trabalhadores ................................. 60

Tabela 4.2 - Relação dos motivos e dos modos de viagem na Pesquisa O/D (2007) e classificados neste trabalho ................................................................. 64

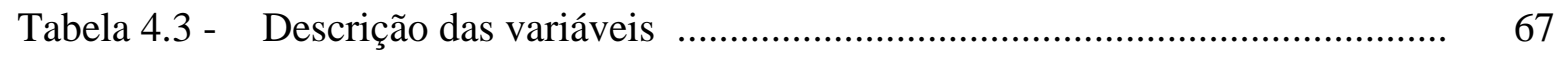

Tabela 5.1 - Variáveis da Amostra ........................................................................ 76

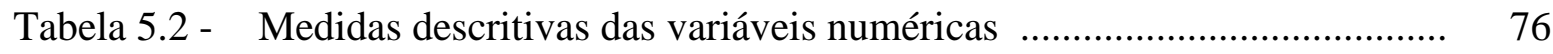

Tabela 5.3 - Frequência das categorias das variáveis categóricas $\quad$............................ 77

Tabela 5.4 - Condições de corte nos nós terminais e tempos de viagens para os 5 modos de transporte

Tabela 6.1 - Descrição dos clusters dos estudantes com padrões de viagens encadeadas similares

Tabela 6.2 - Descrição dos clusters dos trabalhadores com padrões de viagens encadeadas similares

Tabela 7.1 - Variáveis importantes na explicação do comportamento (Amostra de Estudantes)

Tabela 7.2 - Variáveis importantes na explicação do comportamento (Amostra de Trabalhadores)

Tabela 7.3 - Resumo dos resultados das modelagens 108

Tabela 7.4 - Trabalhos que utilizaram combinação de dados de PR e PD 


\title{
Lista de Siglas
}

\author{
AC Análise de Cluster \\ AD Árvore de Decisão \\ CART Classification And Regression Tree \\ GPS Global Positioning System \\ IIA Independência das Alternativas Irrelevantes \\ O/D Origem/Destino \\ PD Preferência Declarada \\ PR Preferência Revelada \\ RMSP Região Metropolitana de São Paulo
}




\section{Sumário}

1

INTRODUÇÃO

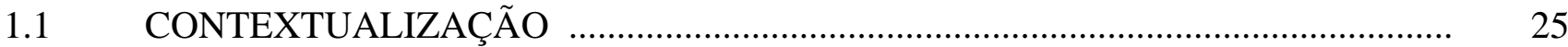

1.2 PROBLEMAS DE PESQUISA E HIPÓTESES ........................................................ 27

OBJETIVOS

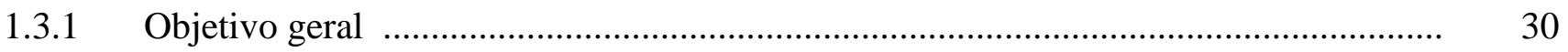

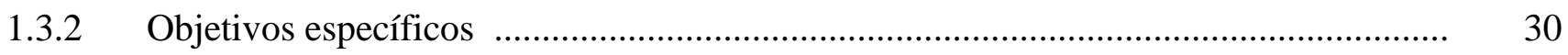

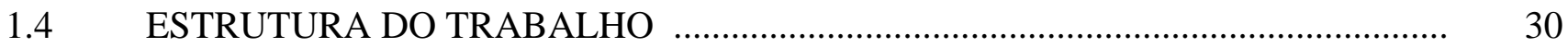

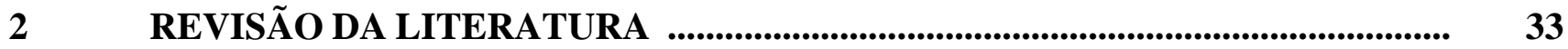

2.1 ABORDAGEM DA DEMANDA POR VIAGENS BASEADAS EM ATIVIDADES 33

2.2 CARACTERIZAÇÃO DE COMPORTAMENTO INDIVIDUAL RELATIVO A VIAGENS

2.3 MODELOS DE ESCOLHA DISCRETA NA INVESTIGAÇÃO DO COMPORTAMENTO RELATIVO A VIAGENS ENCADEADAS

2.4 PESQUISAS DE PREFERÊNCIA REVELADA E EXTRAÇÃO DE DADOS DAS ALTERNATIVAS

2.5 CONCLUSÕES ASSOCIADAS À REVISÃO DA LITERATURA E LACUINAS DE PESQUISA

3 FERRAMENTAS UTILIZADAS

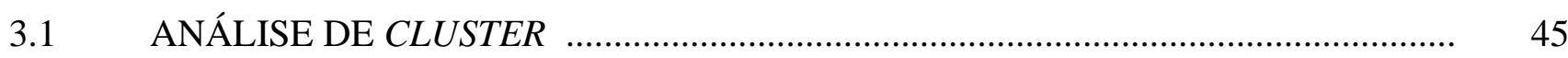

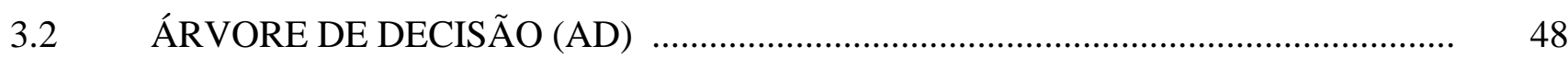

3.3 MODELOS DE ESCOLHA DISCRETA ..........................................................

4 MATERIAIS E MÉTODO

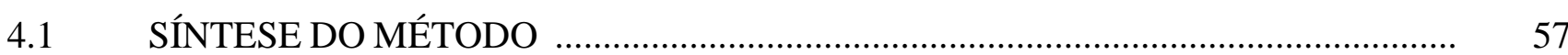

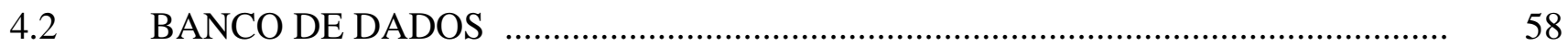

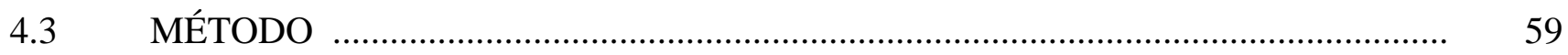

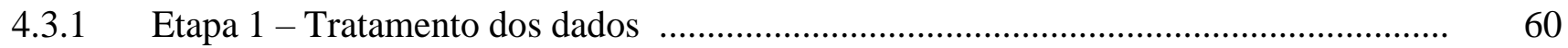

4.3.2 Etapa 2 - Determinação dos tempos de viagem agregados ........................................ 61

4.3.3 Etapa 3 - Classificação dos indivíduos e divisão da amostra ....................................... 62 
4.3.3.1 Definição dos padrões ....................................................................................................... 63

4.3.3.2 Aplicação do algoritmo TwoStep Cluster e obtenção dos clusters principais ........ 65

4.3.3.3 Divisão da amostra ........................................................................................................ 66

4.3.3.4 Determinação da nomenclatura e/ou classificação dos indivíduos ............................ 66

4.3.4 Identificação das variáveis importantes a partir da $\mathrm{AD}$................................................. 66

4.3.5 Etapa 5 - Modelagem Logit Multinomial ………………………………………….... 69

4.3.5.1 Amostra de estudantes ........................................................................................................ 70

4.3.5.2 Amostra de trabalhadores ............................................................................................. 70

4.3.6 Etapa 6 - Comparação entre os modelos a partir da amostra de validação ................... 73

$4.4 \quad$ APLICATIVOS UTILIZADOS .........................................................................

5 RESULTADOS E DISCUSSÕES - CARACTERIZAÇÃO AGREGADA DAS ALTERNATIVAS ............................................................................................................ 75

5.1 APLICAÇÃO DO ALGORITMO CART …………………………………………....

5.2 OBTENÇÃO E FILTRO DOS NÓS TERMINAIS ........................................................ 77

5.3 VALIDAÇÃO: CÁLCULO DE MÉTRICAS DE ERROS ………………………….... 80

6 RESULTADOS E DISCUSSÕES - CLASSIFICAÇÃO DOS INDIVÍDUOS SEGUNDO PADRÕES DE VIAGENS ENCADEADAS ............................................. 83

6.1 CLASSIFICAÇÃO DOS INDIVÍDUOS SEGUNDO PADRÕES DE VIAGENS ENCADEADAS SIMILARES ………………………………………………... 83

6.2 DISCUSSÕES ASSOCIADAS À LITERATURA VIGENTE ...................................... 88

7 RESULTADOS E DISCUSSÕES - ANÁLISE DO COMPORTAMENTO ASSOCIADO A VIAGENS ENCADEADAS ............................................................ 95

7.1 IDENTIFICAÇÃO DAS VARIÁVEIS IMPORTANTES PARA COMPOSIÇÃO DAS FUNÇÕES UTILIDADE A PARTIR DE ALGORITMO CART ......................... 96

7.2 MODELAGEM LOGIT MULTINOMIAL ………………………………………..... 99

7.2.1 Modelagem 1 ............................................................................................. 99

7.2.1.1 Amostra de estudantes ..................................................................................................... 99

7.2.1.2 Amostra de trabalhadores .......................................................................................... 101

7.2.2 Modelagem 2 _................................................................................................ 104

7.2.2.1 Amostra de estudantes ......................................................................................................... 105 
7.2.2.2 Amostra de trabalhadores ..................................................................................................... 106

7.2.3 Comparação entre os modelos ............................................................................... 108

8 CONSIDERAÇÕES FINAIS E RECOMENDAÇÕES PARA TRABALHOS

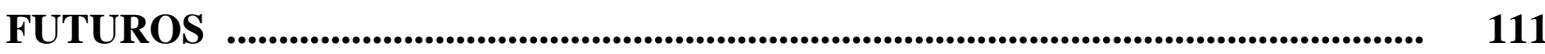

8.1 SÍNTESE DO TRABALHO: OBJETIVOS, HIPÓTESES E LACUNAS DE

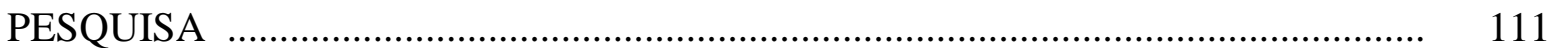

8.1.1 Objetivo específico 1 ................................................................................ 112

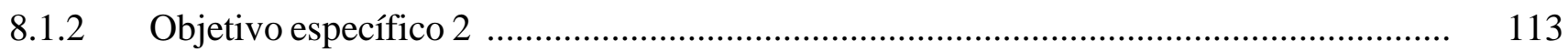

8.1.3 Objetivo específico 3 ..................................................................................... 114

8.1.4 Objetivo específico 4 .............................................................................. 115

8.2 CONCLUSÕES E CONTRIBUIÇÕES _................................................................. 117

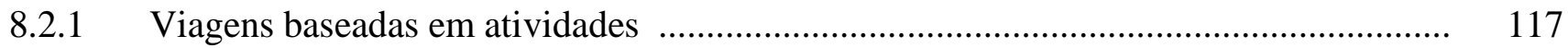

8.2.2 Caracterização agregada das alternativas ................................................................ 118

8.2.3 Redução de parâmetros a serem estimados .................................................................... 119

8.2.4 Aprimoramento do modelo …………………………………………………….... 119

8.2.5 Investigação do comportamento relativo a viagens encadeadas ................................... 120

8.3 RECOMENDAÇÕES PARA TRABALHOS FUTUROS ......................................... 120

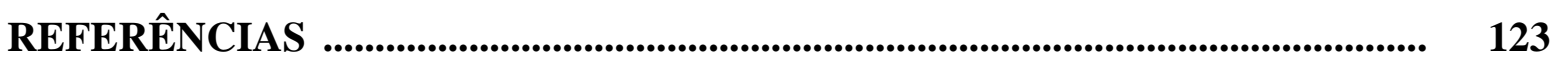

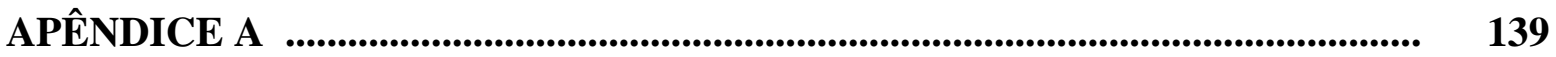




\section{Capítulo}

INTRODUÇÃO

Este capítulo introdutório traz uma breve contextualização do problema abordado, fazendo um paralelo entre os modelos baseados em viagens e a abordagem de viagens baseadas em atividades. Descreve também a ausência de dados de alternativas em pesquisas de Preferência Revelada, incluindo as pesquisas de Origem e Destino. Na sequência, apresenta os problemas de pesquisa e as hipóteses levantadas. Finalmente, relaciona os objetivos, as lacunas e contribuições deste trabalho.

\subsection{CONTEXTUALIZAÇÃO}

Compreender o comportamento da população no que se refere aos fatores que determinam a tomada de decisão individual, relacionada aos seus deslocamentos, é de fundamental importância nos estudos e análises da demanda por transportes. Esses trabalhos possibilitam, através do entendimento de como as pessoas realizam suas escolhas em termos de viagens realizadas ao longo do dia, elaborar políticas públicas mais consistentes para o planejamento urbano e dos sistemas de transportes (GARLING; SCHUITEMA, 2007; PUCHER, 1995; SCHWANEN et al., 2004).

Tradicionalmente, os estudos de demanda por transportes são baseados na modelagem da demanda em função de características socioeconômicas, das viagens e do sistema de transportes, de forma agregada ou desagregada. A modelagem mais tradicional baseia-se nos conhecidos modelos sequenciais.

O Modelo Quatro Etapas ou Modelos Sequenciais, que fazem parte da abordagem baseada em viagens, são aplicados até os dias atuais. Esses modelos buscam prever a demanda por viagens, considerando que as decisões individuais são tomadas, sequencialmente, e que todas as viagens, realizadas pelo mesmo indivíduo, ao longo de um dia, são independentes entre si (MCNALLY, 2008; ORTÚZAR; WILLUMSEM, 2011; PAPACOSTAS; PREVEDOUROS, 1993).

Nos modelos de quatro etapas, as viagens são consideradas de forma independente, sendo estas as unidades de análise. Entretanto, as viagens realizadas pelo mesmo indivíduo, 
bem como familiares, muitas vezes são interligadas e interdependentes. As características da pessoa, do domicílio e o seu estilo de vida determinam suas atividades diárias, suas escolhas, a forma e a sequência com que as viagens são programadas e realizadas. O estudo do comportamento relativo às viagens encadeadas inclui-se na abordagem da demanda por viagens baseadas em atividades (BOWMAN e BEN-AKIVA, 1997).

A partir da década de 1970, iniciaram-se estudos com base na abordagem de demanda por viagens, baseada nas atividades, a partir do pressuposto de que a demanda por viagens é derivada das atividades a serem realizada (BEN-AKIVA; BOWMAN, 1998; BRADLEY et al., 2010; ETTEMA, 1996; HAO et al., 2010; JONES, 1983; JONES et al., 1990; LU; PAS; 1999; PINJARI; BHAT, 2011; TIMMERMANS; ARENTZE, 2011).

Davidson et al. (2007) apontam três importantes características dos modelos de viagens baseadas em atividades, sendo elas: (1) são baseados em um padrão de viagens e não mais uma única viagem; (2) relacionam as viagens às atividades que as motivaram e (3) são utilizadas, em geral, abordagens desagregadas por indivíduos.

As atividades desenvolvidas por uma pessoa ao logo do dia pode ser programada a fim de que consiga realizar o maior número de viagens no menor tempo. A forma sequencial (encadeada) com que as atividades são realizadas fora do domicílio determinam um padrão de viagens daquele indivíduo. Os trabalhos que aplicam modelos de viagens baseadas em atividades buscam investigar as variáveis que determinam essas escolhas individuais e consequentemente a sequência das viagens realizadas, levando-se em conta características socioeconômicas, do sistema de transporte e da estrutura urbana (JOHANSSON et al., 2006; JONES et al., 1990).

O processo de decisão do indivíduo é complexo e baseia-se em escolhas, as quais podem ser caracterizadas através de funções utilidade, nos modelos de escolha discreta, partindo das características dos indivíduos e das alternativas disponíveis (BEN-AKIVA; LERMAN, 1985; MACFADDEN, 1973). Ortúzar e Willumsen (2011) apontam alguns fatores que podem interferir nessas escolhas, tais como: (1) as características do indivíduo (posse do carro, renda, idade, etc.), (2) as características da viagem (motivo de viagem, período do dia, etc.), e (3) as características do modo de viagem (tempo de viagem, custos monetários, conforto, conveniência, etc.). Esses modelos proporcionam uma boa previsibilidade do comportamento individual, o que leva a sua ampla utilização na modelagem da demanda por transportes. 
Para formulação do modelo comportamental, com base nos modelos de escolha discreta, pode-se utilizar dados coletados através de pesquisas de Preferência Revelada (PR) e/ou pesquisas de Preferência Declarada (PD). A pesquisa Origem-Destino (OD), é importante fonte de dados PR, sendo instrumento para inúmeros estudos na área de planejamento de transportes, pois descreve as escolhas reais dos indivíduos, permitindo assim fazer projeções futuras.

Entretanto, as informações, obtidas na Pesquisa OD, referem-se apenas aos dados sobre as viagens realizadas, não caracterizando as demais alternativas disponíveis ao indivíduo. A incorporação de variáveis que caracterizem as alternativas possíveis, dentro da área de estudo, proporcionaria um aprimoramento do modelo e uma melhoria das estimativas realizadas (FEZZI et al., 2014; SOUZA et al., 2017). É possível estimar um modelo apenas considerando variáveis relativas aos indivíduos, variando-se os valores dos parâmetros associados aos indivíduos em cada função utilidade. No entanto, essa não seria a condição mais adequada para estimativa das probabilidades das escolhas (BEN-AKIVA e LERMAN, 1985).

Além disso, o uso de modelos como o Logit Multinomial em problemas relativos à abordagem de viagens baseadas em atividades está vinculado a algumas restrições, tais como: grande quantidade de alternativas a serem analisadas, possibilidade de violação da propriedade Independência das Alternativas Irrelevantes (IIA) e heterogeneidade não observada (BORDLEY, 2013; BOWMAN e BEN-AKIVA, 2001). A principal restrição associada ao presente trabalho é o grande conjunto de alternativas. Tais problemas geralmente acarretam extensas coletas de informações relacionadas ao decisor e ao conjunto de alternativas e restrições computacionais relativas à calibração de tais modelos.

\subsection{PROBLEMAS DE PESQUISA E HIPÓTESES}

- Abordagem de viagens baseadas em atividades

É conhecida, na literatura vigente, a necessidade de representação realística do comportamento individual relativo a viagens. Ao longo dos anos, algumas abordagens têm contribuído para a melhor representação comportamental relativa aos deslocamentos individuais, havendo duas principais: (1) a abordagem baseada em viagens e (2) a abordagem de viagens baseada em atividades (BHAT; KOPPELMAN, 2003). 
A primeira abordagem considera as viagens individuais como unidades de análise, não representando a dependência entre todas as viagens, realizadas pelo mesmo indivíduo, ao longo de um dia, além de desconsiderar a programação (espacial e temporal) da sequência de viagens realizadas. Desta forma, surgiu a segunda abordagem, baseada no pressuposto de que a demanda por viagens é derivada da atividade a ser realizada (BRADLEY et al., 2010; ETTEMA, 1996; HAO et al., 2010; JONES, 1983; JONES et al., 1990; PINJARI; BHAT, 2011), trazendo melhor representação comportamental, relativa aos deslocamentos.

- Uso de modelos de escolha discreta na abordagem de viagens baseadas em atividades

Para a análise do comportamento individual relativo a viagens, há uma ampla utilização da família de modelos de escolha discretas, sendo as escolhas baseadas em características dos indivíduos e das alternativas. Desta forma, a ausência de informações relativas às alternativas torna o processo de modelagem menos preciso (DOMECICH e MCFADDEN, 1975; MCFADDEN, 1978).

Adicionalmente, tais modelos envolvem, originalmente, problemas associados a um número pequeno de alternativas. Assim, considerando a necessidade de representação de vários aspectos dos padrões de atividades/viagens e, consequentemente, aumento do número de alternativas e funções utilidade, há um problema de pesquisa associado ao uso de um grande conjunto de alternativas (CHEN e DUANN, 2005; KEANE e WASI, 2012).

Dessa forma, o presente trabalho está contextualizado com os seguintes problemas de pesquisa: (1) Necessidade de melhor representação do comportamento individual relativo a viagens com o uso da abordagem de viagens baseadas em atividades e (2) Restrições da aplicação de modelo Logit Multinomial associadas tanto aos dados disponíveis quanto à abordagem. Assim, o segundo problema trata da restrição voltada ao uso de dados de Pesquisa Revelada e à análise de diferentes aspectos de viagens encadeadas, através de funções utilidade, acarretando a ausência de dados relativos às alternativas e grande conjunto de alternativas. Assim, a Figura 1.1 sintetiza e ilustra os problemas de pesquisa envolvidos para melhor caracterização posterior das lacunas e contribuições. 
Figura 1.1 - Síntese dos problemas de pesquisa envolvidos.

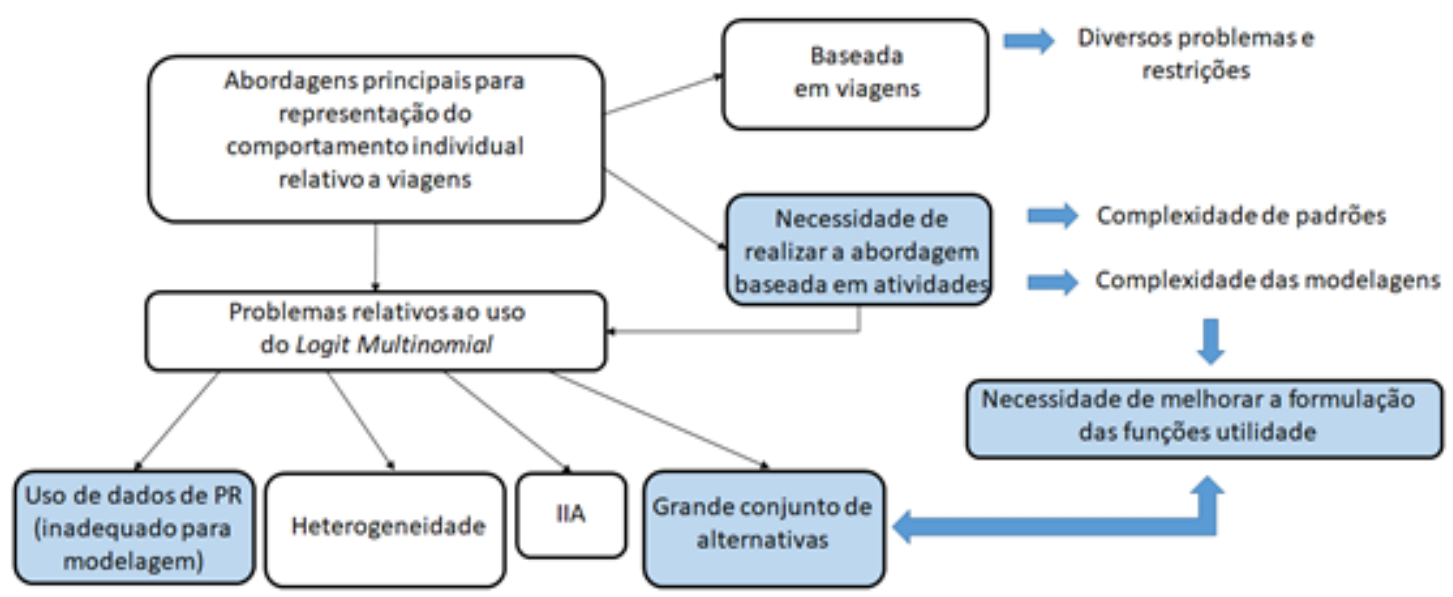

- Lacunas de pesquisa

Considerando os problemas mencionados anteriormente, este trabalho trata das seguintes lacunas de pesquisa:

1. Necessidade de melhor representação comportamental, associada aos deslocamentos, através de análise de viagens baseadas em atividades;

2. Ausência de dados relativos às alternativas não escolhidas pelo indivíduo em pesquisas de Preferência Revelada (PR);

3. Inadequação de modelos de escolha discreta, baseados apenas em característica dos indivíduos;

4. Ausência de critério para formulação das funções utilidade em caso de um alto número de alternativas e parâmetros a serem estimados.

- Hipóteses de pesquisa

Isso posto, são hipóteses desse trabalho:

1. A análise de viagens baseadas em atividades permite um entendimento mais preciso do comportamento; 
2. A utilização de algoritmos de Árvore de Decisão (AD) é adequada para obtenção de características agregadas das alternativas, com uso de dados de pesquisa de Preferência Revelada;

3. Algoritmos de AD podem ser adequados no auxílio à formulação de funções utilidade para o conjunto vasto de alternativas;

4. A modelagem do comportamento individual associado a viagens encadeadas, pode ser aprimorada, a partir da inclusão de características agregadas de alternativas modais, estimadas a partir de dados de PR.

\subsection{OBJETIVOS}

\subsubsection{Objetivo geral}

Analisar o comportamento individual relativo a viagens encadeadas a partir de características socioeconômicas, participação em atividades e características agregadas das alternativas modais, provenientes de dados de Preferência Revelada.

\subsubsection{Objetivos específicos}

Especificamente, este trabalho se propõe a

(1) Classificar os indivíduos em grupos que apresentem similares padrões de viagem, utilizando-se as sequências de motivos e modos de viagem (Variável dependente);

(2) Caracterizar, de forma agregada, as alternativas modais a partir de dados de PR;

(3) Propor um critério para formulação do Modelo Logit Multinomial e redução de parâmetros a serem estimados;

(4) Incorporar as variáveis agregadas, obtidas em (2), e mensurar o aprimoramento nas estimativas através de Modelo Logit Multinomial.

\subsection{ESTRUTURA DO TRABALHO}

Esta tese é composta por oito capítulos, além desta introdução. O Capítulo 2 apresenta o referencial teórico acerca dos temas centrais abordados neste trabalho. O Capítulo 3 descreve e conceitua as ferramentas que são utilizadas. O Capítulo 4 é destinado à apresentação dos dados e à descrição do método. Os resultados são apresentados nos capítulos seguintes. O 
Capítulo 5 apresenta os resultados e as principais discussões da etapa de caracterização agregadas das alternativas, o Capítulo 6, apresenta os resultados e discussões sobre a etapa de classificação dos indivíduos de acordo com os padrões de viagens encadeadas e o Capítulo 7 , os resultados e discussões sobre a investigação do comportamento associado a viagens encadeadas. E por último, no Capítulo 8 são feitas as considerações finais e recomendações para trabalhos futuros. 


\section{Capítulo}

REVISÃO DA LITERATURA

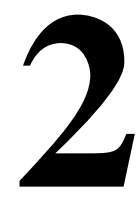

Esse capitulo, inicialmente, traz uma breve contextualização histórica associada à abordagem de demanda por viagens baseadas em atividades. Na sequência, trata sobre a caracterização do comportamento individual relativo a viagens, viagens encadeadas, sobre os modelos de escolha discreta na investigação do comportamento relativo a viagens encadeadas. Também é abordada a temática relacionada a dados provenientes de pesquisas de Preferência Revelada e sobre a extração de dados das alternativas. Finalmente, é realizada uma reflexão acerca dos resultados encontrados ao longo da literatura e as lacunas de pesquisa deste trabalho de doutorado.

\subsection{ABORDAGEM DA DEMANDA POR VIAGENS BASEADAS EM ATIVIDADES}

Já está bem consolidada na literatura a importância da concepção de modelos de demanda condizentes com a realidade. O que se verifica é que é crescente a substituição dos modelos tradicionais, baseados em viagens, por modelos mais orientados para o comportamento (BHAT et al., 2004; BHAT; KOPPELMAN, 1999; KADDOURA et al., 2015; ZELLNER et al., 2016).

Os modelos de demanda por viagens baseadas em atividades surgiram como uma necessidade de rever as bases das previsões de viagens dos modelos convencionais, baseados em viagens, chamados modelos quatro etapas. A base conceitual para esta abordagem começou a ser desenvolvida a partir da década de 1970. Os estudos de Chapin (1971), Cullen e Godson (1975) e Hägerstrand (1970), formam a base dos primeiros estudos focados no pressuposto de demanda por viagens, derivada de atividades, distribuídas no espaço.

Jones (1983) aponta que os primeiros modelos formulados (os modelos quatro etapas) se baseiam na análise das viagens como vetores de movimento entre dois pontos, usando um determinado modo para um motivo específico e é formulado a partir de quatro etapas sequenciais: (1) Geração de viagens; (2) Distribuição de viagens; (3) Divisão modal e (4) Alocação das viagens. 
Bhat e Koppelman (1999) relacionam algumas questões conceituais da abordagem baseada em viagens que limitam sua aplicação. Nestes modelos, a viagem é a unidade de análise e os modelos são desenvolvidos para viagens isoladas, sem levar em conta uma organização das viagens, ou seja, nestes modelos não se considera uma interligação entre as diversas viagens realizadas pelo mesmo indivíduo, ao longo de um dia. Outra questão apontada é o fato de que a parada, em um determinado local (para algum fim), entre várias outras paradas, é afetada pela localização das diversas atividades desenvolvidas ao longo do dia e que o modo de viagem escolhido depende, entre outras coisas, das características de todas as viagens, e não de uma única viagem. Estas questões acabam por limitar a aplicação dos modelos baseados em viagens, trazendo restrições à sua aplicação para o estudo do comportamento individual relativo a viagens.

Alguns dos primeiros trabalhos, desenvolvidos da abordagem de demanda por viagens baseadas em atividades, concentraram-se em estudar a participação de indivíduos em uma única atividade (BHAT, 1997; DAMM, 1980; HIRSH et al., 1986; VAN DER HOORN, 1983). Outros autores direcionaram seus estudos para analisar os padrões de atividades através da análise das programações de viagens (ADLER; BEN AKIVA, 1979; CLARKE, 1986; ETTEMA et al., 1993; KITAMURA, 1983, 1984; NISHII et al., 1988; RECKER et al., 1986).

Os modelos de demanda por viagens baseadas em atividades partem do pressuposto de que a demanda por viagens é derivada da necessidade das pessoas em realizar suas atividades diárias, que são distribuídas no tempo e no espaço (JONES et al., 1990), podendo ser no âmbito domiciliar ou individual, como é o caso deste estudo. Pitombo (2007) coloca que os deslocamentos no ambiente urbano se dão em função das necessidades diárias dos indivíduos de realizarem suas atividades fora domicílio, dos atributos domiciliares, das suas características individuais e do meio urbano. Os modelos têm uma estrutura que reproduz a complexidade das interações das atividades e do comportamento individual de viagem.

Esses modelos proporcionam um maior nível de detalhamento das previsões e estimativas de viagens, sendo uma análise mais ampla e complexa. São modelos de demanda que geralmente utilizam dados desagregados e são baseados no comportamento de escolha individual ou domiciliar. As abordagens acontecem em estruturas nas quais são analisadas como padrões diários de comportamento decorrentes de diferentes estilos de vida (BHAT; KOPPELMAN, 1999; BHAT et al., 2004; BIFULCO et al., 2010; CHOW; DJAVADIAN, 2015; GUN et al., 2016; JONES et al., 1990; KADDOURA et al., 2015; KITAMURA, 1997; 
LEE; MCNALLY, 2006; LI et al., 2018; PAS EL, 1988; SIRIPIROTE et al., 2015; ZELLNER et al., 2016; ZHANG et al., 2009; ZHU et al., 2018).

A base dessa abordagem se fundamenta no entendimento de que os fatores associados à necessidade ou desejo de realizar uma atividade são mais importantes do que a própria viagem (BHAT; KOPPELMAN, 1999). Logo, esses modelos enfatizam os estudos de participação em atividades com o foco nas sequências das viagens e nos padrões de viagem individual adotados.

Bowman (1995) aponta quatro pontos como sendo os fundamentos da abordagem da demanda por viagens baseadas em atividades: (1) A demanda por viagens é derivada da demanda por atividades; (2) As atividades humanas estão restritas no tempo e no espaço; (3) O domicílio afeta, significativamente, as atividades individuais e as escolhas; e (4) As decisões, referentes às viagens, se dão de forma dinâmica.

Macnally (1996) acrescenta um outro fundamento, de que as sequências de padrões são as unidades de análise realmente importante. Heinen (2016) e Van Acker et al. (2011) estudaram as atitudes, estilos de vida e valores na tentativa de entender a escolha do modo ou escolha de destino. Jonnalagadda et al. (2001) e Miller et al. (2005) apresentaram evidências empíricas de que a escolha do modo de transporte depende de fatores relacionados à cadeia de atividades do indivíduo ao longo do dia. Kurani e Lee-Gosselin (1996) analisaram os fatores que podem determinar a escolha do modo de transporte em função das atividades que o indivíduo precisa cumprir.

A aplicação dos modelos de demanda por viagens baseadas em atividades amplia a análise dos deslocamentos considerando que não fica limitada apenas a viagens isoladas. Possibilita uma melhor compreensão do comportamento individual considerando a interdependência espaço-temporal entre as viagens. Nesta abordagem tem-se que identificar os padrões de deslocamento a partir da caracterização das atividades e viagens realizadas em um período mínimo de um dia.

\subsection{CARACTERIZAÇÃO DE COMPORTAMENTO INDIVIDUAL RELATIVO A VIAGENS}

O comportamento individual relativo a viagens é norteado pelas escolhas individuais associadas aos deslocamentos pessoais. De forma geral, nos modelos de demanda por viagens baseadas em atividades, o comportamento individual, associado às viagens, é a variável 
dependente. A relevância de sua caracterização tem como foco o entendimento dos diferentes padrões de viagem e das variáveis que influenciam as escolhas (ASSIRATI; PITOMBO, 2019).

A caracterização do comportamento individual dos viajantes, ao longo dos anos, foi tornando-se mais complexa de forma a considerar, simultaneamente, cada vez mais aspectos das escolhas. São exemplos tradicionais de variáveis que representam o comportamento individual subjacente a viagens: (1) Escolha modal; (2) Escolha de rota; (3) Distância total percorrida em um dia; (4) Escolha do horário de saída; (5) Escolha de destinos; (6) Escolhas associadas aos motivos de viagem; (7) Grau de Motorização ao longo de um dia ou múltiplos dias, etc.

Diversos estudiosos, caracterizaram o aspecto da escolha modal de cada viagem, através de variáveis categóricas, fazendo estimativas probabilísticas das escolhas através de modelos de escolha discreta, tanto para viagens urbanas (BHAT, 1995, 1998; BHAT; STEED, 2002; DING; ZHANG, 2016; KIM; ULFARSSON, 2004; LINDNER et al., 2017; MADAN; GROENHOUT, 1987; PITOMBO et al., 2015; SCHLOSSBERG et al., 2006; STEED; BHAT, 2000; VOVSHA; BRADLEY, 2004) ou intermunicipais (ANTONIOU et al., 2007; CAN, 2013; LEWE et al., 2014; PEETA et al.,2008; SOCORRO; VIENCES, 2013; YAO; MORIKAWA, 2005), considerando viagens com motivo trabalho ou atividades de “subsistência" (BHAT, 1997, 2000; CHIKARAISHI et al., 2011; DHIBI; BELKACEM, 2013; ELURU et al., 2012; HAO et al., 2010; LI et al., 2016; LU; KAWAMURA, 2010; SHUKLA et al., 2013a, 2013b, 2015; VIJ et al., 2013; XIAN-YU; JIAN-CHUAN, 2011) ou atividades de compras ou lazer (MISKEEN et al., 2014; VERPLANKEN et al., 1994).

O aspecto comportamental da escolha de rota e escolha do horário de saída, através de variável dependente categórica e modelos de escolha discreta também foi amplamente analisado ao longo dos anos (BAJWA et al.; 2008; BEKHOR et al., 2006; BEN-AKIVA; BIERLAIRE, 2003; FREJINGER; BIERLAIRE, 2007; GAO et al., 2008; HESS et al., 2015; VOVSHA; BRADLEY, 2004). As escolhas desagregadas dos destinos também foram vastamente estudadas, como escolhas discretas. Tanto no âmbito urbano (CALDAS et al., 2019; GREENWALD, 2006; KITAMURA, 1984; LEVINSON; KUMAR, 1995; MOLLOY, 2017; SHREWSBURY, 2012), como para viagens de longa distância ou intermunicipais (GAUDRY; LAPPARENT, 2015; HOLGUÍN-VERAS; THORSON, 2003; LI, 2003; NAZARI et al., 2015; PITOMBO et al., 2017; ROMA et al., 2018;). 
Com a popularização dos estudos relacionados à abordagem da demanda por viagens, baseada em atividades, vários autores (ADLER e BEN AKIVA, 1979; BEN-AKIVA e BOWMAN, 1994; ARRUDA, 2005; ICHIKAWA et al., 2002; PITOMBO et al., 2011, TACO, 2003) começaram a analisar aspectos de escolhas voltadas para programação diária de atividades, realizadas pelos indivíduos. Assim, o comportamento individual começou a ser analisado através de cadeias de viagens (trip-chaining).

A programação de atividades e, consequentemente, de viagens de uma pessoa pode se dar de uma forma sequencial (encadeada) possibilitando a realização de um maior número de atividades com melhor aproveitamento do tempo. A sequência de atividades, fora do domicílio, que a pessoa escolhe desenvolver, os modos utilizados, se faz uso do mesmo modo ou se é multimodal, entre outras escolhas, determina um padrão de viagens daquele indivíduo.

A análise de viagens baseadas em atividades busca investigar as variáveis que condicionam essa sequência de viagens do indivíduo. Estudos mostram que a pessoa ao realizar seus deslocamentos leva em conta alguns fatores como: a participação em atividades, as características socioeconômicas (individuais e domiciliares), atributos do sistema de transporte e estrutura urbana (BHAT; KOPPELMAN, 1991; JOHANSSON et al., 2006; JONES et al., 1990; KRIZEK; WADDELL, 2002; KWAM, 2000).

Bhat e Koppelman (1991) definiram viagens encadeadas como uma apropriada sequência de viagens, realizadas com a proposta de cumprir várias atividades relacionadas a um programa de atividades de cada indivíduo. Para Ichikawa et al. (2002) as viagens encadeadas podem ser definidas como a união sequencial de viagens realizadas em determinado período. A Figura 2.1 ilustra exemplos de dois padrões de viagens encadeadas, caracterizando o motivo, modo de viagem e período do dia de realização. No primeiro exemplo o indivíduo realiza durante o dia cinco viagens, sendo a primeira viagem de automóvel para o trabalho, a segunda ele faz a pé para almoçar, depois ele retorna também a pé ao trabalho, a quarta viagem do dia é para a escola utilizando o automóvel e a quinta e última viagem, o indivíduo retorna para residência de automóvel. O segundo exemplo é de um indivíduo que realiza somente duas viagens, ida e volta para escola, sendo que ele vai de ônibus e retorna para casa a pé. 
Figura 2.1 - Viagens encadeadas (adaptado de Gomes et al., 2021)
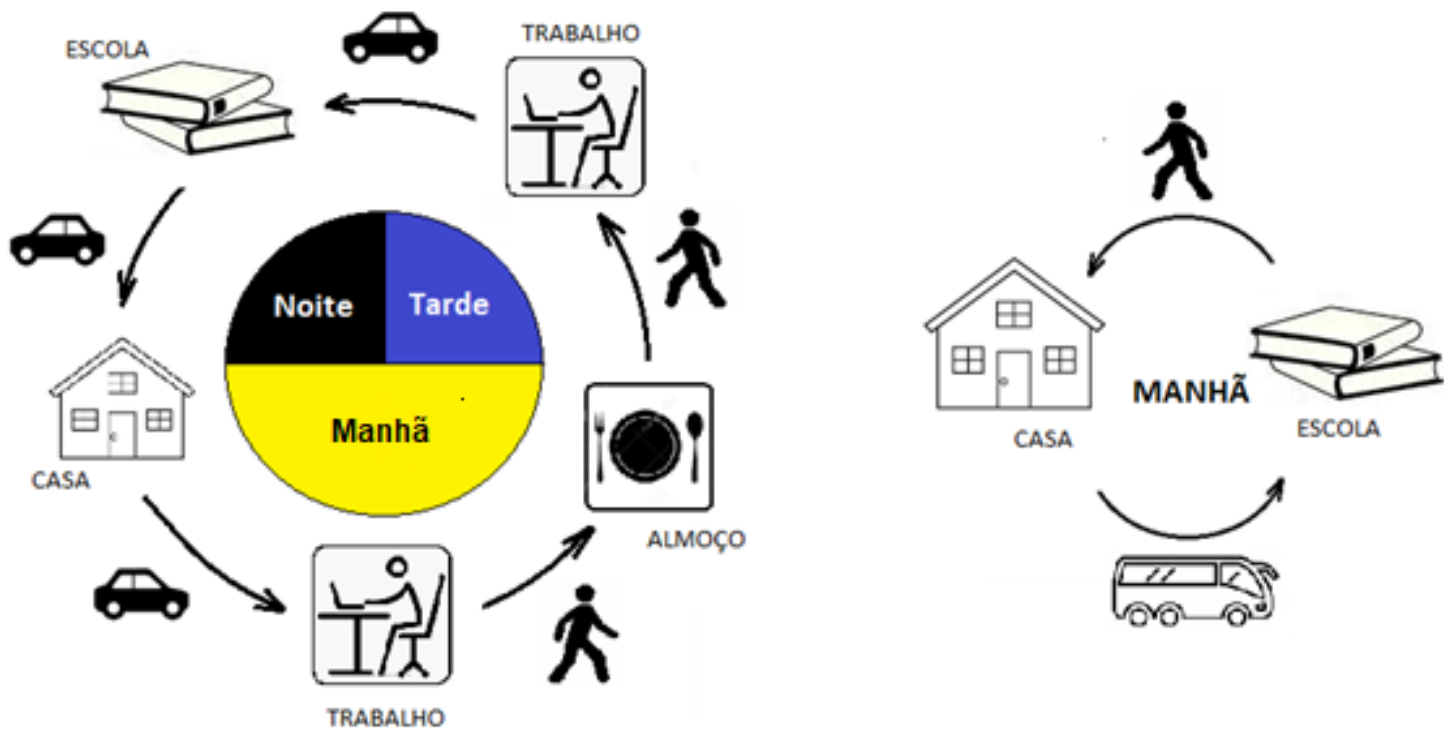

A variável dependente (comportamento individual relativo a viagens), é o padrão de encadeamento de viagens realizadas pelos indivíduos que é composta por categorias que caracterizam as sequências de viagens realizadas. Esses padrões de viagens foram estudados sob várias perspectivas.

Adler e Ben Akiva (1979) estudaram os padrões diários de viagens a partir da premissa de que a pessoa planeja de forma antecipada suas viagens diárias. Os autores trabalharam com padrões de viagens diários descritos por variáveis agregadas, como os modos usados nas viagens e o número de viagens.

Ben-Akiva e Bowman (1994) estimaram um modelo de escolha discreta que maximiza a utilidade do diário de atividades levando-se em conta o motivo, as prioridades, modo, escolha de destino das paradas e o horário de partida de casa.

Speckman et al. (1997) desenvolveram um conjunto de padrões de atividades incluindo o número e a natureza de cada atividade, tempo de duração, número de idas ao domicílio e ao trabalho/escola e horários de início e término.

Ichikawa et al. (2002) caracterizaram as cadeias de viagens considerando a sequência de motivos e modos de viagens. Caracterizadas as categorias de variável dependente (comportamento relativo a viagens encadeadas), foram encontradas relações entre o comportamento e participação em atividades e variáveis socioeconômicas. 
Bifulco et al. (2010), com o objetivo de capturar interações entre os membros da família e as cadeias de viagens, representaram a sequência de atividades através de letras: Trabalho (W), Casa (H), Lazer (L), Acompanhamento (A) e Outros (O).

Posteriormente, Pitombo et al. (2011) caracterizaram as viagens encadeadas através de padrões, que foram representados através de uma codificação alfanumérica, sendo uma primeira sequência referente às atividades (motivos), uma segunda correspondente aos modos de transporte utilizados e um terceiro conjunto de caracteres correspondente à sequência de destinos, agregados por faixas de distância. Em seguida, as relações entre os padrões de viagens, participação em atividades, uso do solo e características socioeconômicas foram investigadas através do algoritmo de Árvore de Decisão e Regressão Linear Múltipla.

Scheiner e Holz-Rau (2017) estudaram a complexidade dos padrões de atividade e padrões de encadeamento de viagens através de uma perspectiva específica de gênero. As variáveis de interesse foram "entropia de padrão de atividade" e "complexidade do passeio (ou tour)". A complexidade do passeio refere-se ao número de viagens por tour (origem e destino em casa) e a entropia de padrão de atividade à necessidade de conciliar várias atividades em termos de tempo, sendo que um nível de entropia baixo indica que a pessoa dedica-se a somente uma atividade.

Assirati e Pitombo (2019) utilizaram dados de viagens realizados em três dias consecutivos, e classificaram os indivíduos, considerando o grau de motorização, distâncias de viagens em três dias consecutivos e a sequência de atividades (recorrentes ou não). Os grupos de viajantes foram determinados considerando tais aspectos, através de Análise de Cluster e dados coletados por smartphones.

Daisy et al. (2018b) buscaram prever o encadeamento de viagens de grupos de não trabalhadores através da investigação das características de viagem aplicando Análise de Cluster. Foram identificados cinco grupos de não trabalhadores, com base nos padrões diários de atividades e no uso do tempo. Os autores aplicaram o algoritmo CART (Classification And Regression Tree) a dados sociodemográficos e de viagens dos indivíduos para fazer o reconhecimento dos padrões. Aqueles com padrões de atividade semelhantes foram agrupados usando um k-médias e um conjunto de padrões de atividades foram identificados. Os padrões de atividades foram categorizadas em nove tipos: tarefas domésticas $(\mathrm{H})$, lazer (L), sono 
noturno em casa $(\mathrm{N})$, trabalho fora de casa $(\mathrm{W})$, compras $(\mathrm{P})$, serviços $(\mathrm{S})$, organização/hobbies fora de casa $(G)$, entretenimento fora de casa $(E)$ e esportes fora de casa $(T)$.

\subsection{MODELOS DE ESCOLHA DISCRETA NA INVESTIGAÇÃO DO COMPORTAMENTO RELATIVO A VIAGENS ENCADEADAS}

Há décadas, modelos de escolha discreta têm sido aplicados. Suas primeiras aplicações se deram em estudos de estimação de demanda e comportamento do consumidor (CARDELL; DUNBAR, 1980; MCFADDEN, 1974) e hoje são utilizados em diferentes áreas do conhecimento, como Marketing (CHAKRAVATI et al., 2005); redes sociais (BROCK; DURLAUF, 2001; WALKER et al., 2010), escolha de localização residencial (GUEVARA; BEN-AKIVA, 2006, 2012); entre outras.

Em planejamento de transportes, são vários os trabalhos desenvolvidos, como na identificação de fatores que interferem na decisão de uma rota (ABDEL-ATY et al., 1997; BEN-AKIVA; BIERLAIRE, 2003; DE LAPPARENT, 2010; HESS, 2010; JÁNOŠÍKOVÁ et al., 2014; JARA-DÍAZ et al., 2000; LABBÉ et al., 1998; PALMA; PICARD, 2006; TINGUELY et al., 2015), na escolha do modo de transporte (ALEX et al., 2016; FOSGERAU; RANJAN, 2017; GOETZKE; ANDRADE, 2009; HESS et al., 2003; JARA-DÍAZ; ORTÚZAR， 1989; JARA-DÍAZ; VIDELA， 1989; KOPPELMAN; SETHI， 2000; MCFADDEN, 1978; MONZÓN; RODRÍGUEZ, 2006; MURO-RODRÍGUEZ et al., 2017; ORTÚZAR; GONZÁLEZ， 2002; RANJAN; FOSGERAU， 2017; SARKAR; MALLIKARJUNA, 2018; SWAIT, 2001; TENG et al., 2017; VITON, 1985; WALKER et al., 2010) e em diversos outros trabalhos relativos à demanda por viagens (ANTONINI et al., 2006; ASSIRATI, 2018; BEN-AKIVA; MORIKAWA, 1990b; FREJINGER, 2008; HENSHER, et al., 1999; MORIKAWA, 1989; MORIKAWA et al., 1991; SILVA, 2015).

Entender como as pessoas fazem as suas escolhas, em cada uma das diferentes situações do dia a dia, é de grande interesse para uma sociedade (LOUVIERE et al., 2000). Os modelos de escolha discreta, utilizados na abordagem de viagens baseadas em atividades, visam a análise do comportamento individual e procuram identificar as variáveis que influenciam nesse processo de escolha (MCFADDEN, 1973). A variável de análise (variável dependente), em geral, é representada pelos padrões de atividades/viagens definidos através de um processo individual de escolha. 
Os modelos de escolha discreta são fundamentados na teoria econômica clássica do comportamento do consumidor e da utilidade. Essa teoria propõe um modelo que caracterize as preferências do consumidor, representadas através de funções utilidade. No âmbito da demanda por transportes, de acordo com Ben-Akiva e Lerman (1985), a escolha individual resulta da análise do usuário que, a partir de uma necessidade em se deslocar, analisa o conjunto de alternativas e escolhe aquela de maior utilidade.

Nestes modelos, a utilidade é tratada como uma variável aleatória, formada por uma componente chamada determinística ou sistemática, e outra aleatória, que reflete a influência de fatores não-observados da escolha individual (BEN-AKIVA; BIERLAIRE, 2003). Na função utilidade, aplicada empiricamente, as diferentes observações são utilizadas para estimar os parâmetros desconhecidos da função e identificar como as escolhas variam. Segundo BenAkiva e Lerman (1985), essa é a razão pela qual se considera as características socioeconômicas na função utilidade e pela qual a estimação é realizada para grupos socioeconômicos diferentes (segmentação).

Adler e Ben-Akiva (1979) propuseram um modelo de comportamento individual relativo a viagens, baseado na utilidade, para selecionar um padrão de viagem entre os padrões disponíveis. Os autores aplicaram o modelo Logit Multinomial e a utilidade foi modelada em função da sequência de atividades, tempos e custos de viagem, dados de destino e características socioeconômicas dos domicílios. Strathman et al. (1994) estimaram a escolha entre cadeias de viagens alternativas utilizando o modelo Logit Binomial. Cadeias de viagem de trabalho e nãotrabalho foram modeladas separadamente e os resultados mostraram que a estrutura da família interfere no tipo de encadeamento da viagem. Bhat (2000) utilizou o Modelo Logit Multinomial para modelar o padrão de atividades de pessoas que trabalham à noite.

O Modelo Logit Multinominal tem sido amplamente utilizado para modelar escolhas discretas na investigação do comportamento relativo a viagens (ANTONIOU et al., 2007; BHAT; GOSSEN, 2004; FORINASH; KOPPELMAN, 1993; KATO et al., 2011; MCCAFFERTY; HALL, 1982; MISHRA et al., 2013; PAULSSEN et al., 2014; TIMMERMANS et al., 2002; WANG et al., 2017; YE X et al., 2017) e mais especificamente no estudo de viagens encadeadas (LEE et al., 2017; RUAN et al., 2012; BUEHLER e HAMRE, 2015; LEE et al., 2007) 
Conforme descrito anteriormente, os modelos Logit são os mais comumente usados para modelar escolhas discretas de viagens baseadas em atividades. Com relação ao modelo Logit Multinomial, há importantes premissas que o caracterizam, como a independência dos termos aleatórios das utilidades, a homogeneidade de resposta entre indivíduos e a homogeneidade da variância dos erros (BHAT; KOPPELMAN, 1999). Essas suposições conferiram a esse modelo a propriedade Independência das Alternativas Irrelevantes (IIA), a qual desconsidera possíveis correlações entre as alternativas (LUCE; SUPPES, 1965).

Nesse sentido, algumas variantes de modelos Logit foram desenvolvidas e aplicadas para a análise de viagens baseadas em atividades, como os modelos Probit, Logit Aninhado e de duração baseados em riscos (BHAT; KOPPELMAN, 1999).

Além disso, para um grande conjunto de alternativas, muitas vezes, as ferramentas computacionais à disposição não conseguem calibrar a grande quantidade de parâmetros necessários em análises desagregadas que possuem muitas alternativas e/ou muitas variáveis explicativas, ou, quando o fazem, demandam longo intervalo de tempo e configurações computacionais robustas (Gomes et al., 2021).

\subsection{PESQUISAS DE PREFERÊNCIA REVELADA E EXTRAÇÃO DE DADOS DAS}

\section{ALTERNATIVAS}

Os modelos de escolha discreta permitem um bom grau de previsibilidade do comportamento das pessoas e, por conta disso, têm sido há anos aplicados na área de demanda por transportes (ANTONINI et al., 2006; ASSIRATI, 2018, ASSIRATI; PITOMBO, 2019; BEN-AKIVA; MORIKAWA, 1990a). Os dados utilizados nesses modelos têm como fonte Pesquisas de Preferência Revelada (PR) e Preferência Declarada (PD). Os dados de PR representam as escolhas reais feitas pelos indivíduos e os dados de PD referem-se às possíveis escolhas diante de um cenário hipotético (BEN-AKIVA; LERMAN, 1985).

As pesquisas Origem e Destino (OD), são importantes fontes de dados de Preferência Revelada (ORTÚZAR; WILLUMSEN, 2011). Descrevem as escolhas e comportamentos reais dos indivíduos e possibilitam fazer projeções futuras das necessidades de viagens.

A pesquisa OD corresponde à base de dados primária para modelos com dados desagregados. Entretanto, elas não retratam as outras alternativas disponíveis, apresentando, por isso, um fator limitante para utilização de seus dados na modelagem de escolha discreta 
(CERVEIRA et al., 2018; SOUZA et al., 2017). Para que haja um aprimoramento da modelagem, é importante a inclusão de variáveis que retratem as alternativas disponíveis na área estudada.

Alguns estudos propuseram a caracterização agregada das alternativas a partir de critérios empíricos, decorrentes da escolha de variáveis e valores de corte (FEZZI et al., 2014; KATO et al., 2013; SOUZA et al., 2017). Observa-se que, comumente, utiliza-se as variáveis de duração e custo da viagem, e os critérios de agrupamento nesses estudos foram definidos, muitas vezes, de forma subjetiva.

\subsection{CONCLUSÕES ASSOCIADAS À REVISÃO DA LITERATURA E LACUNAS} DE PESQUISA

Esta seção traz uma breve síntese relacionada às lacunas de pesquisa, abordadas neste trabalho. A primeira delas seria a necessidade de melhor representação comportamental, associada aos deslocamentos, através de análise de viagens baseadas em atividades. Ao longo de décadas, os diversos autores vêm desenvolvendo diferentes trabalhos no intuito de melhor capturar as decisões associadas aos deslocamentos. Desta forma, esta tese aborda a encadeamento de viagens, representada aqui através de sequências, tratando aspectos da interdependência entre as viagens realizadas, caracterizando os motivos de viagem e modos de transporte. Embora os modelos 4 Etapas ainda sejam amplamente utilizados, especialmente para o caso de aplicações práticas para previsão de matriz Origem-Destino, críticas à sua concepção vêm sendo realizadas ao longo dos anos.

A segunda e terceira lacunas de pesquisa estão associadas à ausência de dados relativos às alternativas em pesquisas de Preferência Revelada (PR) e inadequação de modelos de escolha discreta, unicamente baseados em característica dos indivíduos. Diversos autores (SOUZA et al., 2017; FEZZI et al., 2014; KATO et al., 2013) realizaram trabalhos, no intuito de estimar características agregadas das alternativas (como tempo e custo de viagem, por exemplo), agrupando as viagens por grupos similares de distâncias, por exemplo. No entanto, há problemas na delimitação de faixas de valores para divisão dos grupos de viagens. Através de algoritmos de Árvore de Decisão, esse trabalho sugere uma automatização no processo de agrupamento de viagens, considerando, como variáveis independentes, características relativas às viagens, tais como distâncias, períodos do dia, zona de origem, zona de destino, etc. 
Finalmente, a última lacuna de pesquisa - Ausência de critério para formulação das funções utilidade em caso de um alto número de alternativas, sem a diminuição do conjunto de alternativas e sim das variáveis explicativas relativas aos indivíduos (BORDLEY, 2013; CHEN e DUANN, 2005) - está associada à complexidade de calibração do modelo Logit Multinomial para o caso de viagens encadeadas, considerando-se a combinação de aspectos dos deslocamentos representados e também a diversidade da amostra, que é composta por diversos indivíduos, com características socioeconômicas diferentes e, portanto heterogêneos comportamentos. Assim, os padrões de viagens encadeadas delimitam as funções utilidade. Dessa forma, os modelos a serem calibrados possuem problemas relativos à quantidade de alternativas (e funções utilidade), além de quantidade de parâmetros a serem estimados, associados às variáveis independentes. Desta forma, esta tese de doutorado propõe um procedimento simplificado para auxiliar na formulação de funções utilidade, através de algoritmo CART (Classification And Regression Tree), no intuito de excluir algumas variáveis independentes, associadas aos indivíduos, que não influenciaram determinados comportamentos associados a algumas funções utilidade. 


\section{Capítulo}

FERRAMENTAS UTILIZADAS

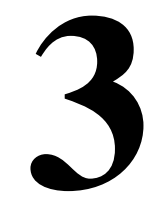

Este capitulo apresenta, de forma sucinta, uma base teórica e conceitual associada às ferramentas utilizadas no presente trabalho.

\subsection{ANÁLISE DE CLUSTER}

A Análise de Cluster (AC) é um conjunto de técnicas estatísticas, utilizadas para classificar e reunir objetos, de acordo com suas peculiaridades, de tal forma que objetos pertencentes ao mesmo cluster apresentem características semelhantes, e sejam distintos dos objetos pertencentes aos outros clusters. Hair et al. (2009) ressaltam que o objetivo da técnica é maximizar a homogeneidade dentro de cada cluster e maximizar a heterogeneidade entre clusters. Os algoritmos podem ser classificados em hierárquicos e não-hierárquicos.

O algoritmo hierárquico utiliza uma matriz de medidas de similaridades para identificar a semelhança entre os elementos. Reúne conjuntos de elementos, em estágios distintos, configurando uma hierarquia em forma de árvore (dendrograma). A árvore apresenta uma organização hierárquica entre os grupos. Os grupos pertencentes a níveis inferiores possuem maior homogeneidade entre si e valores maiores de medidas de similaridades (ou valores menores de medidas de dissimilaridade). Aumentando-se o nível do dendograma, os grupos anteriores são reagrupados (método aglomerativo), diminuindo-se assim tanto o número total de grupos quanto a homogeneidade interna de cada um (Figura 3.1). A determinação do melhor nível de agrupamento, portanto, o número de clusters, depende de cada aplicação, especificamente (ANDERBERG, 1973; KAUFMAN; ROUSSEEUW, 1990; MATHWORKS, 2002; TAN et al., 2006). 
Figura 3.1 - Ilustração de um dendrograma (Método de agrupamento hierárquico).

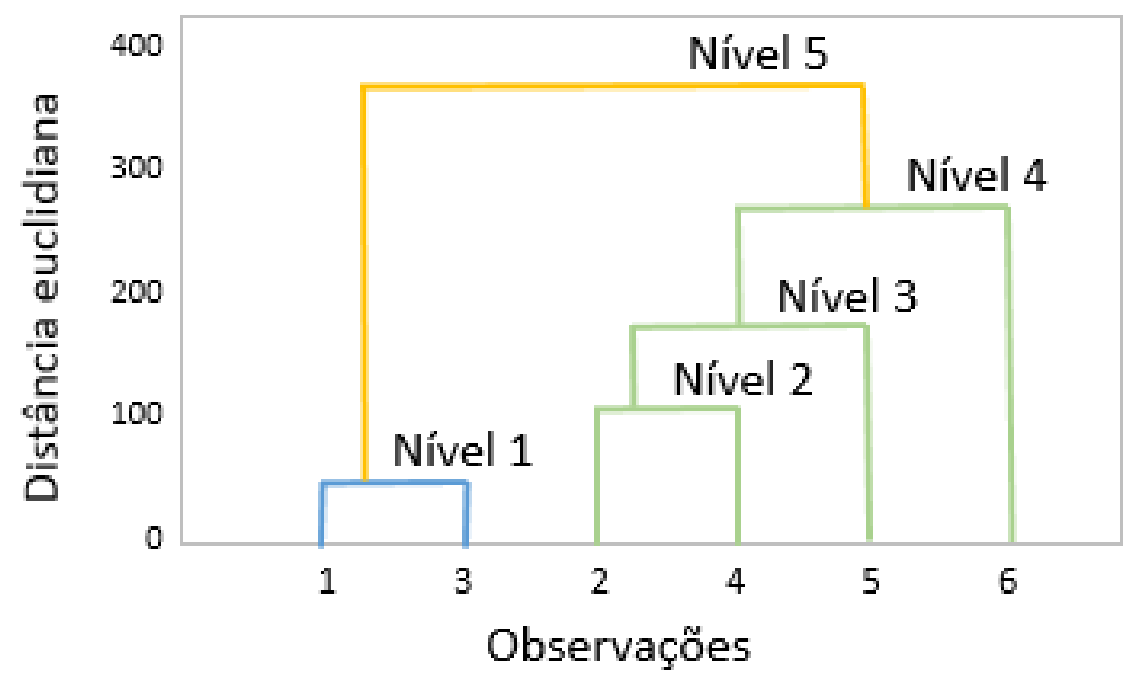

Observando-se a Figura 3.1, verifica-se, no exemplo, que a medida de similaridade utilizada foi a distância euclidiana entre observações, assim, quanto menor a distância entre observações, maiores similaridades são observadas. No mencionado exemplo, são utilizadas 6 observações no total e o agrupamento é feito em cinco níveis. No nível zero, cada observação corresponde a um único grupo, havendo, dessa forma, seis grupos no total. No nível 1, são agrupadas as observações 1 e 3, que possuem a menor distância euclidiana observada. No nível 2, são agrupadas as observações 2 e 4. Desta forma, no nível 2 são observados quatro clusters distintos (1-3; 2-4; 5 e 6). Em seguida, no nível 3, a observação 5 é agrupada ao grupo formado anteriormente pelas observações 2 e 4 . O nível 4 forma um único grupo compondo as observações 2, 4, 5 e 6. Finalmente, o nível 5 forma um único grupo, unindo o grupo 1 (observações 1 e 3) ao grupo 2 (observações 2, 4, 5 e 6). Como algoritmos hierárquicos têm-se os métodos: aglomerativos e divisivos. O método aglomerativo foi aquele demonstrado através do exemplo do dendograma da Figura 3.1. No método divisivo se dá o inverso, ou seja, todos os componentes se iniciam em um único grupo, que vai se dividindo em cada iteração em grupos de elementos com a maior diferença. O processo se repete até que cada componente seja um grupo (ANDERBERG, 1973; KAUFMAN; ROUSSEEUW, 1990; TAN et al., 2006).

Quanto aos algoritmos não-hierárquicos (também conhecidos por "quick cluster groups"), estes geram apenas um resultado de agrupamento para uma determinada amostra. $\mathrm{O}$ método mais aplicado é o K-médias. Conhecido o número adequado de clusters $(\mathrm{k})$ para uma amostra de (n) observações, o algoritmo objetiva definir k centroides, associados aos k grupos. Inicialmente, as coordenadas dos centroides iniciais, de cada grupo, são definidas 
aleatoriamente. Em seguida, cada uma das $n$ observações é associada ao centroide do grupo mais próximo. Na próxima etapa, é necessário recalcular os $k$ novos centroides dos grupos, resultantes da etapa anterior. Depois de se ter esses $k$ novos centroides, um novo reagrupamento é proposto no intuito de minimizar a distância entre cada uma das n observações e um dos k grupos. Tais etapas são repetidas, de forma iterativa, até os centroides não mais variarem (HARTIGAN, 1975).

Neste trabalho de doutorado, optou-se por aplicar o algoritmo Two-step Cluster, disponível no pacote IBM SPSS 24, que é um algoritmo de análise de agrupamentos escalável, projetado para lidar com grandes conjuntos de dados. O algoritmo permite lidar com variáveis ou atributos contínuos, numéricos discretos e categóricos. O seu processamento é realizado em dois estágios: (1) Pré-agrupamento: consiste no pré-agrupamento de observações em muitos subgrupos pequenos; e (2) Agrupamento: nesta etapa os subgrupos anteriores são agrupados, considerando-se um número desejável de grupos. Pode-se também selecionar, automaticamente, o número de clusters (IBM SPSS, 2012).

Inicialmente, o algoritmo forma os subgrupos, que são aglomerados formados a partir dos dados originais, com o objetivo de reduzir o tamanho da matriz que contém distâncias entre todos os casos possíveis. Nesta etapa, o algoritmo verifica os dados um a um, em uma abordagem de agrupamento sequencial, e identifica se o registro atual deve ser inserido em algum subgrupo já formado ou formar um novo subgrupo com base no critério de menor distância. Se o número de subgrupos aumentar além do número máximo, os subgrupos são redefinidos aumentando o critério da distância limite. Esse processo continua até que uma passagem de dados completa seja concluída (CHIU et al., 2001; IBM SPSS, 2012; ZHANG et al., 1996).

Após a primeira etapa (Pré-agrupamento), todos os elementos, em um mesmo subgrupo são tratados como um único elemento, baseado em uma técnica de hierarquização. Nesta fase, o tamanho da matriz de distâncias não dependente mais do número de elementos da amostra, mas do número de subgrupos.

No segundo estágio, o algoritmo utiliza os subgrupos resultantes da etapa de préagrupamento como entrada e, posteriormente, agrupa-os no número desejado de grupos.

Tem-se que quanto maior o número de subgrupos, produzidos na etapa de préagrupamento, mais preciso é o resultado final. Entretanto, muitos subgrupos deixam o segundo 
estágio mais complexo. O número de subgrupos deve ser cuidadosamente escolhido para que seja grande o suficiente para produzir resultados precisos e pequeno o suficiente para não desacelerar o Agrupamento da segunda etapa (IBM SPSS, 2012).

Por ser uma técnica exploratória, são previstas várias tentativas a partir da variação de número de grupos obtidos. Neste trabalho, várias tentativas foram realizadas para identificar os melhores agrupamentos segundo padrões de viagens encadeadas. Após análise dos diferentes grupos, obtidos nas diversas tentativas, escolheu-se o agrupamento capaz de identificar similaridades intrínsecas a cada grupo. Vale ressaltar que uma das medidas de similaridades, utilizadas neste algoritmo, é a distância do logaritmo da Verossimilhança, além da distância euclidiana, sendo permitindo, assim, o uso de variáveis categóricas. Como no atual trabalho, foram utilizadas variáveis categóricas nesta etapa, a escolha do algoritmo é facilmente justificada. Para geração automática do número de clusters, sugere-se o uso do método do cotovelo - elbow method (THORNDIKE, 1953).

\section{2. ÁRVORE DE DECISÃO (AD)}

Essa técnica foi utilizada como ferramenta principal para se atingir dois objetivos específicos: (Objetivo específico 2) Caracterizar, de forma agregada, as alternativas modais a partir de dados de Preferência Revelada e (Objetivo específico 3) Propor um critério simplificado para formulação do Modelo Logit Multinomial e redução de parâmetros a serem estimados. Para o objetivo específico 2, a aplicação do algoritmo de AD se deu com variável dependente numérica (sendo um problema de estimação), enquanto que, para o caso do objetivo específico 3, a variável dependente foi categórica, caracterizando um problema de classificação.

Consiste em um conjunto de algoritmos que servem para classificar, estimar e representar as relações existentes em um conjunto de dados. Os modelos são ajustados por sucessivas divisões dos dados, a partir de declarações do tipo "Se... então..." com o intuito de se obter subconjuntos cada vez mais homogêneos em relação à variável dependente (BREIMAN et al., 1984).

São algoritmos não-paramétricos e têm uma estrutura que se assemelha a uma árvore. O conjunto total de dados (nó raiz) é separado por sequenciais divisões (nós filhos) e essas divisões se dão de forma sequencial até os nós terminais (ou folhas), quando não é possível mais a formação de nenhum subgrupo. A Figura 3.2 exemplifica, de forma geral, a estrutura de 
um algoritmo de $\mathrm{AD}$, representando nó raiz, nós filhos e nós terminais, para um caso de variável dependente categórica (escolha do modo) e duas variáveis independentes: uma binária (sexo) e duas numéricas (Idade e Renda).

Figura 3.2 - Exemplo da estrutura de uma Árvore de Decisão.

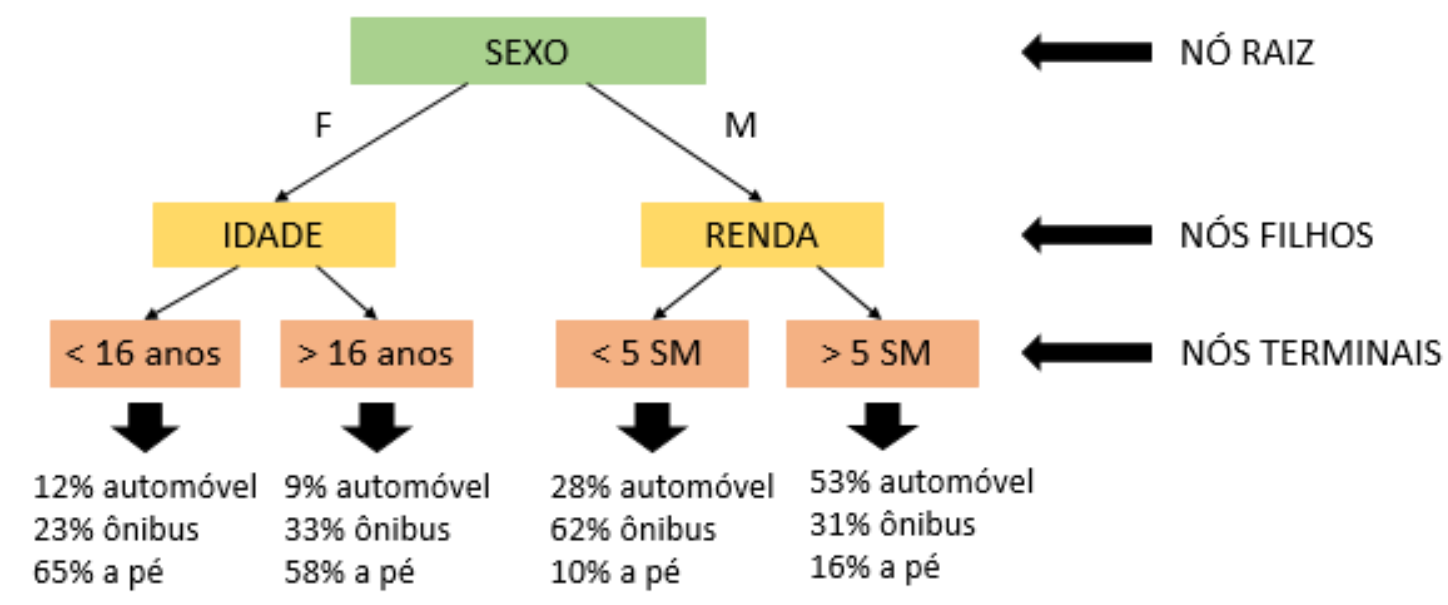

Um algoritmo de AD, em geral, tem as seguintes propriedades (BREIMAN et al., 1984; KASS, 1980; PITOMBO et al., 2015; QUILAN, 1983):

- A hierarquia resultante é chamada de árvore e cada segmento é conhecido como um nó;

- Tem um nó, denominado raiz, que contém o banco de dados completo;

- O nó raiz é dividido sequencialmente criando nós filhos;

- Quando não é possível mais subdivisão de dados, os subgrupos finais são chamados nós terminais ou folhas.

Para a segmentação dos dados, são definidos três elementos principais para executar a Árvore de Decisão: um conjunto de questões delimitando a divisão dos dados, um critério para estabelecer a melhor divisão para produzir os nós filhos e uma regra para determinar o término das subdivisões (BREIMAN et al., 1984).

Os principais algoritmos de Árvore de Decisão são: C4.5 (QUINLAN, 1983), CHAID (KASS, 1980) e CART (BREIMAN et al., 1984). Neste trabalho foi aplicado o algoritmo CART (Classification and Regression Tree) para estimar o tempo de viagem dos modos de 
transporte disponíveis na área de estudo e, posteriormente, para propor um critério para formulação do Modelo Logit Multinomial e redução de parâmetros a serem estimados.

O algoritmo CART (Classification And Regression Tree), desenvolvido por Breiman et al. (1984), se dá basicamente, através de divisões binárias dos dados buscando reduzir as impurezas dos nós filhos e maximizar a homogeneidade nos nós terminais, segundo variável dependente.

Para as Árvores de Classificação do algoritmo CART (variável dependente categórica), o critério de partição ou medidas de impureza mais conhecido é o índice Gini. Em um determinado nó, a melhor divisão é adotada para maximizar homogeneidade interna do nó, segundo categorias da variável dependente.

Considerando a Figura 3.3, tem-se que $t$ é um nó, $x_{j}$ é uma variável explicativa; $x_{j}^{R}$ é o melhor valor da divisão de variável $x_{j}$ e $P$ é a probabilidade de determinada categoria da variável dependente em cada nó.

Figura 3.3 - Algoritmo CART

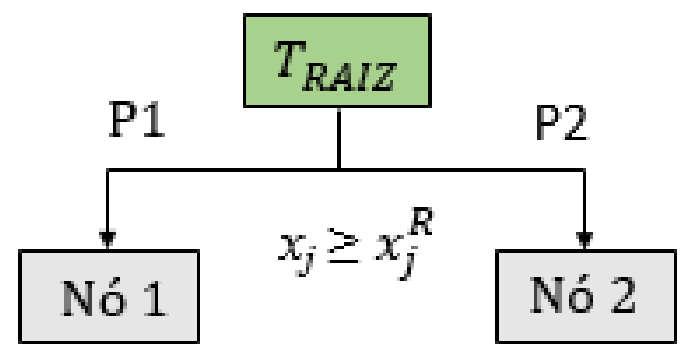

Fonte - Adaptado de Breiman et al. (1984) e Pitombo et al. (2017).

Para o caso da árvore de classificação, a impureza, que deve ser minimizada, é representada pelo índice Gini, descrito na Equação 3.1.

$$
G(t)=1-\sum_{i=1}^{n} p\left(\frac{i}{t}\right)
$$

$\mathrm{n}$ : quantidade de categorias da variável dependente $(\mathrm{y}=1,2,3, \mathrm{i}, \ldots . \mathrm{n}) ; \mathrm{p}(\mathrm{i} / \mathrm{t})$ : probabilidade da categoria i se formar no nó t. 
Para determinar o melhor critério de divisão, calcula-se, a partir dos valores do índice Gini para cada nó, o valor do aprimoramento para cada possível divisão. Para uma divisão ser considerada a mais adequada, seu valor de aprimoramento deve ser o maior dentre os de todas as divisões possíveis da mesma variável. O aprimoramento, a partir do nó raiz, é calculado a partir da Equação 3.2. O mesmo cálculo é replicado para todos os demais nós pais e respectivos nós filhos.

$$
\text { Aprimoramento }=G\left(t_{\text {raiz }}\right)-p_{1} \cdot G\left(t_{1}\right)-p_{2} \cdot G\left(t_{2}\right)
$$

p : proporção de casos no nó filho da esquerda; p2: proporção de casos no nó filho da direita; $\mathrm{t}_{1}$ : nó filho da esquerda; $\mathrm{t}_{2}$ : nó filho da direita.

Já para as Árvores de Regressão do CART (variável dependente quantitativa), a medida de impureza é chamada de redução da variância a qual representa a redução da variância da variável dependente em cada nó. A redução da variância, que representa a função de impureza, é apresentada na Equação 3.3.

$$
I_{V}(t)=\frac{1}{|S|^{2}} \sum_{i \in s} \sum_{j \in s} \frac{1}{2}\left(x_{i}-x_{j}\right)^{2}-\left(\frac{1}{\left|S_{t}\right|^{2}} \sum_{i \in s_{t}} \sum_{j \in s_{t}} \frac{1}{2}\left(x_{i}-x_{j}\right)^{2}+\frac{1}{\left|S_{f}\right|^{2}} \sum_{i \in s_{j}} \sum_{j \in s_{f}} \frac{1}{2}\left(x_{i}-x_{j}\right)^{2}\right)
$$

Sendo:

$I v(t)=$ redução da variância no nó $t ; S=$ conjunto da amostra de teste; $S_{t}=$ conjunto da amostra teste do qual o valor da variável explicativa é verdadeiro; $S_{f}=$ conjunto da amostra teste do qual o valor da variável explicativa é falso; $x_{i}=$ valor da variável dependente da amostra teste; $x_{j}=$ valor da variável dependente da amostra que compõe o nó $t$.

\subsection{MODELOS DE ESCOLHA DISCRETA}

Os modelos de escolha discreta têm como fundamento a teoria microeconômica do consumidor, que fornece uma base para a identificação das preferências individuais (BENAKIVA; LERMAN, 1985). Estimam a probabilidade de uma pessoa escolher um bem ou serviço entre um conjunto de alternativas discretas. Ben-Akiva et al. (1985) descrevem que os modelos de escolha discreta relacionam a escolha (variável dependente) às características do indivíduo e das alternativas possíveis. 
O princípio dos modelos de escolha discreta é a estimação dos parâmetros que compõem as funções utilidade. Tais funções mensuram a preferência por alternativas e são baseadas numa combinação de parâmetros e variáveis, as quais caracterizam as alternativas e os indivíduos (BEN-AKIVA; BIERLAIRE, 2003). Neste trabalho, utilizou-se o Modelo Logit Multinomial para análise do comportamento relativo a viagens encadeadas, com base na participação em atividades, variáveis socioeconômicas e características agregadas das alternativas (Objetivo geral).

O Modelo Logit é um modelo de escolha discreta que tem como resultado a probabilidade de escolha de uma pessoa tomando como base as características socioeconômicas e a atratividade das alternativas, ou seja, a utilidade das alternativas (DOMECICH; MCFADDEN, 1975). A utilidade é medida através de uma função que resulta da associação de variáveis explicativas que a maximize e os coeficientes, em geral, estimados pelo método da máxima verossimilhança.

No modelo Logit Multinomial, a utilidade é tratada como uma variável aleatória, formada por uma componente chamada determinística ou sistemática, e outra aleatória, que reflete as "irracionalidades" da escolha individual (BEN-AKIVA; BIERLAIRE, 2003). Desse modo, a utilidade da alternativa $i$ para um indivíduo $n\left(U_{i n}\right)$ pode ser expressa através da Equação 3.4 .

$$
U_{\text {in }}=V_{\text {in }}+\varepsilon_{\text {in }}
$$

Sendo, $U_{\text {in }}$ a utilidade global de uma alternativa $i$ para um indivíduo $n, V_{\text {in }}$ é a componente sistemática da utilidade de uma alternativa $i$ para um indivíduo $n$ e $\varepsilon_{i n}$ a componente aleatória (que pode ser uma função), representa uma parcela desconhecida da função utilidade que captura a dispersão das escolhas e os fatores não controláveis ou desconhecidos do pesquisador, tais como atributos relevantes não considerados, erros de medição dos atributos, erros de percepção do entrevistado e diferenças não observáveis na avaliação. A forma mais comum de representar as componentes sistemáticas é a linear (Equação $3.5)$.

$$
V_{i n}=\beta_{0}+\beta_{1} x_{i n 1}+\beta_{2} x_{i n 2}+\beta_{3} x_{i n 3}+\cdots+\beta_{k} x_{i n k}
$$

Sendo que: atributo $k$ da alternativa $i$ para o indivíduo $n$; 
$\beta_{0}:$ constante específica da alternativa;

$\beta_{k}$ : peso relativo do atributo $x_{i n k}$ na composição da função utilidade.

A probabilidade de escolha de uma alternativa sobre outra pode ser calculada pela Equação 3.6:

$$
\operatorname{Pr}\left(i / C_{n}\right)=\operatorname{Pr}\left\{V_{i n} \geq V_{j n} \forall j \in C_{n}\right\}=\operatorname{Pr}\left\{V_{i n}=\max _{j \in C_{n}} V_{j n}\right\}
$$

Em que $C n$ é o conjunto de escolhas de $\mathrm{n}$ indivíduos.

Na função utilidade, aplicada empiricamente, as observações de diferentes indivíduos são utilizadas para estimar os parâmetros desconhecidos da função e identificar como as preferências variam entre os indivíduos. Segundo Ben-Akiva e Lerman (1985), essa é a razão pela qual se considera as características socioeconômicas na função utilidade e pela qual a estimação é realizada para grupos socioeconômicos diferentes (segmentação).

O modelo Logit Multinominal é estimado por máxima verossimilhança (Equação 3.7). A maximização da função é obtida através da maximização da produtória das probabilidades das alternativas realmente escolhidas por cada indivíduo.

$$
L L=\sum_{n=1}^{N} \sum_{i \in C_{n}} P_{n i}^{\text {yin }}
$$

Para a avaliação e comparação entre modelos, foram utilizadas as medidas de rhoquadrado, rho-quadrado ajustado, o valor do critério Akaike, a taxa de acertos e logaritmo da verossimilhança para a amostra de validação.

O rho-quadrado é definido pela Equação 3.8:

$$
\rho^{2}=1-\frac{\operatorname{Ln}\left(L^{*}\right)}{\operatorname{Ln}\left(L_{0}\right)}
$$

Sendo Ln $\left(L_{0}\right)$ o valor do logaritmo da verossimilhança obtida ao assumir todos os parâmetros $\beta$ do modelo como zero e $\operatorname{Ln}\left(L^{*}\right)$ é o valor de logaritmo da máximo-verossimilhança obtida quando os parâmetros $\beta$ correspondem aos valores estimados. Sendo assim, um modelo ideal tende a unidade, pois a razão de $\operatorname{Ln}\left(L^{*}\right)$ (caso em que os parâmetros $\beta$ tem seus valores 
ótimos) por $\operatorname{Ln}\left(L_{0}\right)$ (caso em que os parâmetros $\beta$ são todos nulos), tende a zero por $\operatorname{Ln}\left(\mathrm{L}^{*}\right)$ ser muito menor que $\operatorname{Ln}\left(L_{0}\right)$.

A métrica do critério Akaike é definida pela Equação 3.9:

$$
\mathrm{A}=2 K-1_{\mathrm{n}} L^{*}
$$

O critério Akaike avalia e penaliza o acréscimo demasiado de variáveis nas equações, através da subtração entre o número $K$ de parâmetros e o logaritmo do valor de $L^{*}$ de máxima verossimilhança. Segundo essa formulação, quanto menor o valor do critério Akaike, melhor o modelo (AKAIKE, 1974).

Por fim, a validação corresponde em dividir a amostra, sendo uma parte usada para estimar os parâmetros e a outra para validação dos parâmetros estimados. Aplica-se a modelagem dos parâmetros calibrados da amostra de calibração nos elementos da amostra de validação, alcançando os valores estimados para essa amostra. Sendo os valores da amostra de validação conhecidos, é possível medir a taxa de acertos comparando os valores reais com os valores estimados. Quanto maior o valor da taxa de acertos, melhor é o modelo sendo que a qualidade deste valor pode ser mensurada pelo cálculo de verossimilhança Equação 3.10 (ASSIRATI, 2018; MYUNG, 2003).

$$
L=p^{y} \cdot(1-p)^{(n-y)}
$$

Sendo $n$ o número total de elementos considerados na amostra de teste, e $y$ a quantidade de elementos avaliados corretamente, tem-se a razão $p=y / n$ entre o número de elementos avaliados corretamente e o total de elementos considerados. Quando o valor de $p$ tende a unidade ( $100 \%$ de taxas de acertos), o valor de $L$ também tende a unidade, e consequentemente, $\log L$ tende a zero.

Finalmente, o Quadro 3.1 sintetiza o uso de cada ferramenta, associada ao objetivo geral e/ou específico do presente trabalho. 
Quadro 3.1 - Síntese do uso de cada ferramenta, associada aos objetivos.

\begin{tabular}{|c|c|c|}
\hline Ferramenta & Objetivo associado & $\begin{array}{c}\text { Descrição sucinta do seu uso } \\
\text { no trabalho }\end{array}$ \\
\hline Two-Step Cluster & $\begin{array}{l}\text { Objetivo Específico } 1 \\
\text { Reunir os indivíduos em } \\
\text { grupos que apresentem } \\
\text { similares padrões de viagens. }\end{array}$ & $\begin{array}{l}\text { Identificados os padrões de } \\
\text { viagens e após a divisão da } \\
\text { amostra (Estudantes e } \\
\text { Trabalhadores) aplicou-se o } \\
\text { algoritmo Two-Step Cluster } \\
\text { para a obtenção dos Clusters } \\
\text { principais (variável } \\
\text { dependente). }\end{array}$ \\
\hline \multirow[t]{2}{*}{ CART } & $\begin{array}{l}\text { Objetivo Específico } 2 \\
\text { Realizar a caracterização das } \\
\text { alternativas modais a partir de } \\
\text { dados de Preferência } \\
\text { Revelada. }\end{array}$ & $\begin{array}{l}\text { A partir dos dados da } \\
\text { Pesquisa O/D, aplicou-se o } \\
\text { algoritmo de Árvore de } \\
\text { Decisão (AD) para estimar os } \\
\text { tempos de viagens dos modos } \\
\text { de transporte, disponíveis na } \\
\text { área de estudo. }\end{array}$ \\
\hline & $\begin{array}{l}\text { Objetivo Específico } 3 \\
\text { Propor um critério para } \\
\text { formulação do Modelo Logit } \\
\text { Multinomial e redução de } \\
\text { parâmetros a serem } \\
\text { estimados. }\end{array}$ & $\begin{array}{l}\text { A utilização do algoritmo } \\
\text { CART teve como intuito } \\
\text { reduzir o número de } \\
\text { parâmetros a serem estimados } \\
\text { no Modelo Logit } \\
\text { Multinomial. }\end{array}$ \\
\hline Logit Multinomial & $\begin{array}{l}\text { Objetivo geral e } \\
\text { Objetivo Específico } 4 \\
\text { Avaliar o aprimoramento das } \\
\text { estimativas, através da } \\
\text { inclusão de características } \\
\text { agregadas das alternativas } \\
\text { (Tempos médios de viagens). }\end{array}$ & $\begin{array}{l}\text { Foram gerados dois modelos } \\
\text { em cada uma das amostras. O } \\
\text { primeiro modelo continha } \\
\text { apenas variáveis } \\
\text { socioeconômicas, enquanto o } \\
\text { segundo incorporava as } \\
\text { variáveis agregadas de } \\
\text { tempos de viagem. }\end{array}$ \\
\hline
\end{tabular}




\section{Capítulo}

MATERIAIS E MÉTODO

\section{4}

Este capítulo começa apresentando uma síntese do método, a área de estudo e a Pesquisa Origem e Destino de 2007 da Região Metropolitana de São Paulo. Em seguida descreve, com maiores detalhes, as etapas metodológicas realizadas.

\subsection{SÍNTESE DO MÉTODO}

Este trabalho investiga o comportamento individual, relativo a viagens encadeadas, para duas amostras distintas (trabalhadores e estudantes), através de participação em atividades, características socioeconômicas e características modais agregadas. Essas últimas obtidas através do algoritmo CART (Classification And Regression Tree) e de Pesquisa OD (Preferência Revelada).

Embora viagens encadeadas estejam sendo analisadas, não há uma modelagem para cada uma das viagens em sequência. Neste trabalho, todas as viagens encadeadas, realizadas por um indivíduo ao longo do dia, são representadas através de um único bloco. Após representação alfanumérica dos padrões de viagens encadeadas realizados pelos indivíduos, esses são agrupados com o uso do algoritmo TwoStep Cluster. Tal algoritmo identifica, através do Log da Verossimilhança, grupos de indivíduos que realizam padrões de viagens encadeadas similares, considerando número de viagens, motivos das viagens e modos de transporte.

Os grupos obtidos para as duas amostras (5 para estudantes e 15 para trabalhadores), através do algoritmo TwoStep Cluster, são os conjuntos de alternativas. Dessa forma, o modelo estima a probabilidade de um indivíduo pertencer a um grupo (dentre 15 possíveis para a amostra de trabalhadores, por exemplo) que realiza determinado tipo de viagens em cadeia. A Figura 4.1 traz a ilustração simplificada dos procedimentos metodológicos vinculados à etapa de modelagem para a amostra de trabalhadores, através do Logit Multinomial. 
Figura 4.1 - Etapas metodológicas associadas à modelagem paramétrica (exemplo para amostra formada por trabalhadores) - adaptado de Gomes et al. (2021)

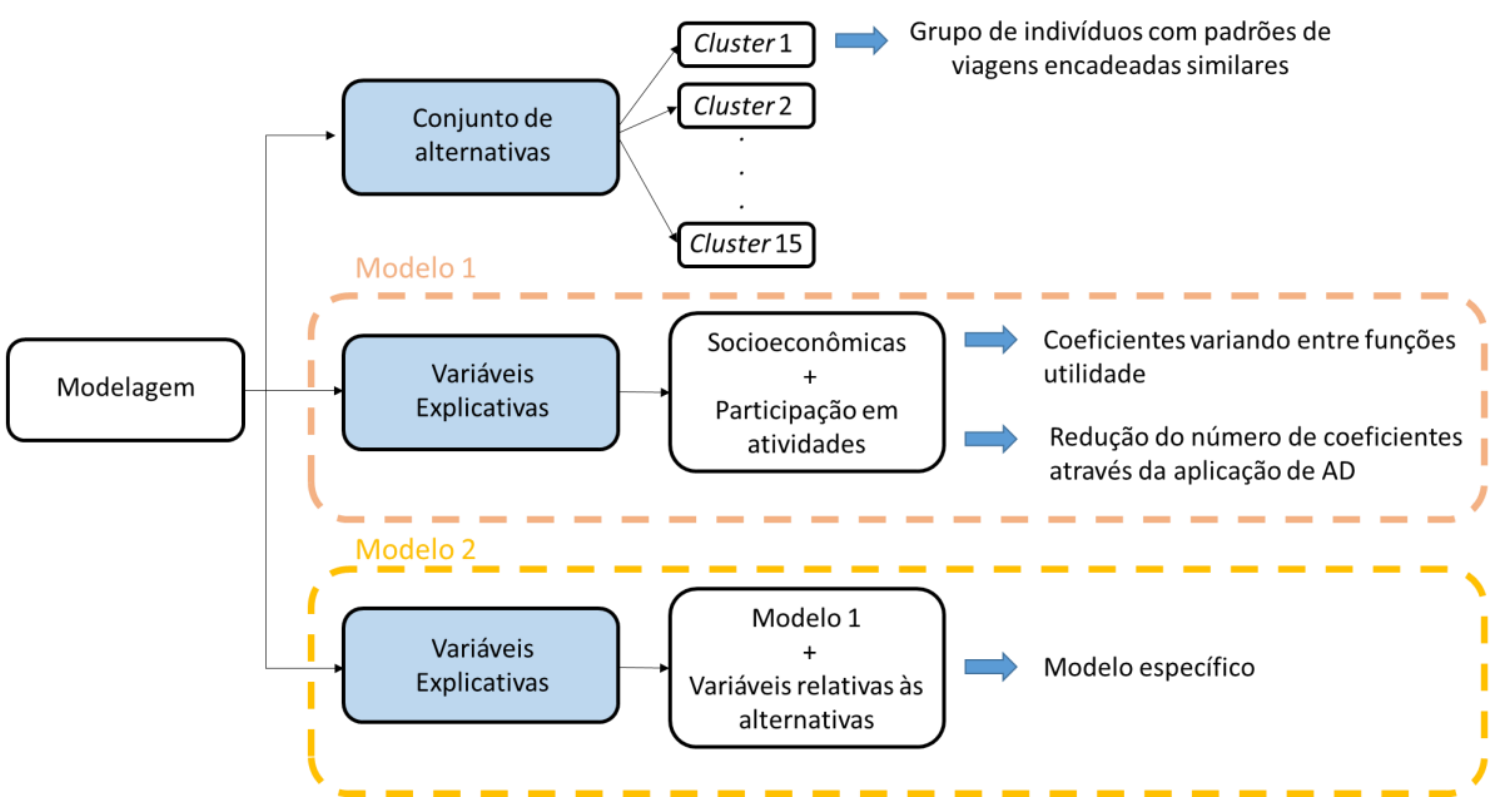

\subsection{BANCO DE DADOS}

Neste trabalho foram utilizados os dados da Pesquisa Origem-Destino (O/D), realizada na Região Metropolitana de São Paulo (RMSP) em 2007. A RMSP é composta por 39 municípios e na pesquisa foi dividida em 460 zonas de tráfego, sendo que 320 representam a cidade de São Paulo, a qual foi o foco deste estudo. A Figura 4.2 ilustra a área onde a pesquisa foi realizada.

Figura 4.2 - Pesquisa Origem Destino - RMS 2007.

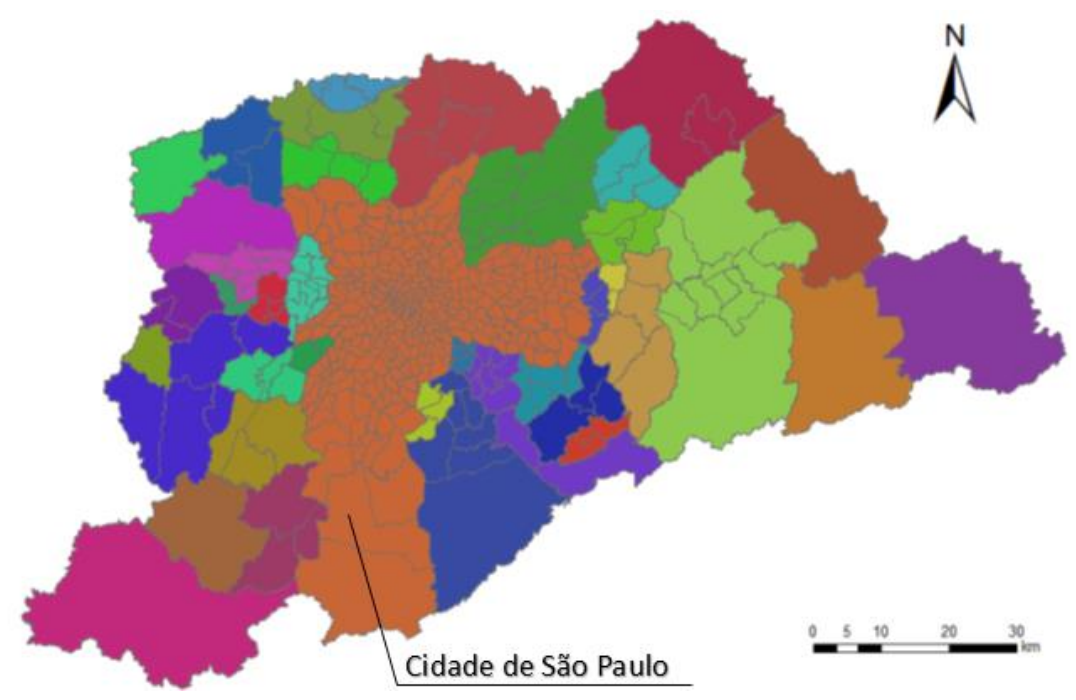

Fonte: Metrô (2008). 
Durante a Pesquisa O/D de 2007 levantou-se informações de 30 mil domicílios, escolhidos aleatoriamente onde foram entrevistadas aproximadamente 120 mil pessoas. É composta por quatro bancos de dados: agregados por zonas de tráfego, desagregados por viagens, desagregados por domicílios e desagregados por indivíduos. Para este estudo foram utilizados dados desagregados por viagens e dados desagregados relativos aos trabalhadores e estudantes, compostos por características individuais, domiciliares e de viagens.

\subsection{MÉTODO}

Para que os objetivos fossem atingidos, o método proposto compreende seis etapas expostas a seguir. A Figura 4.3 ilustra a sequência do procedimento metodológico proposto e as subseções descrevem as etapas ilustradas.

Figura 4.3 - Procedimento metodológico - adaptado de Gomes et al. (2021).

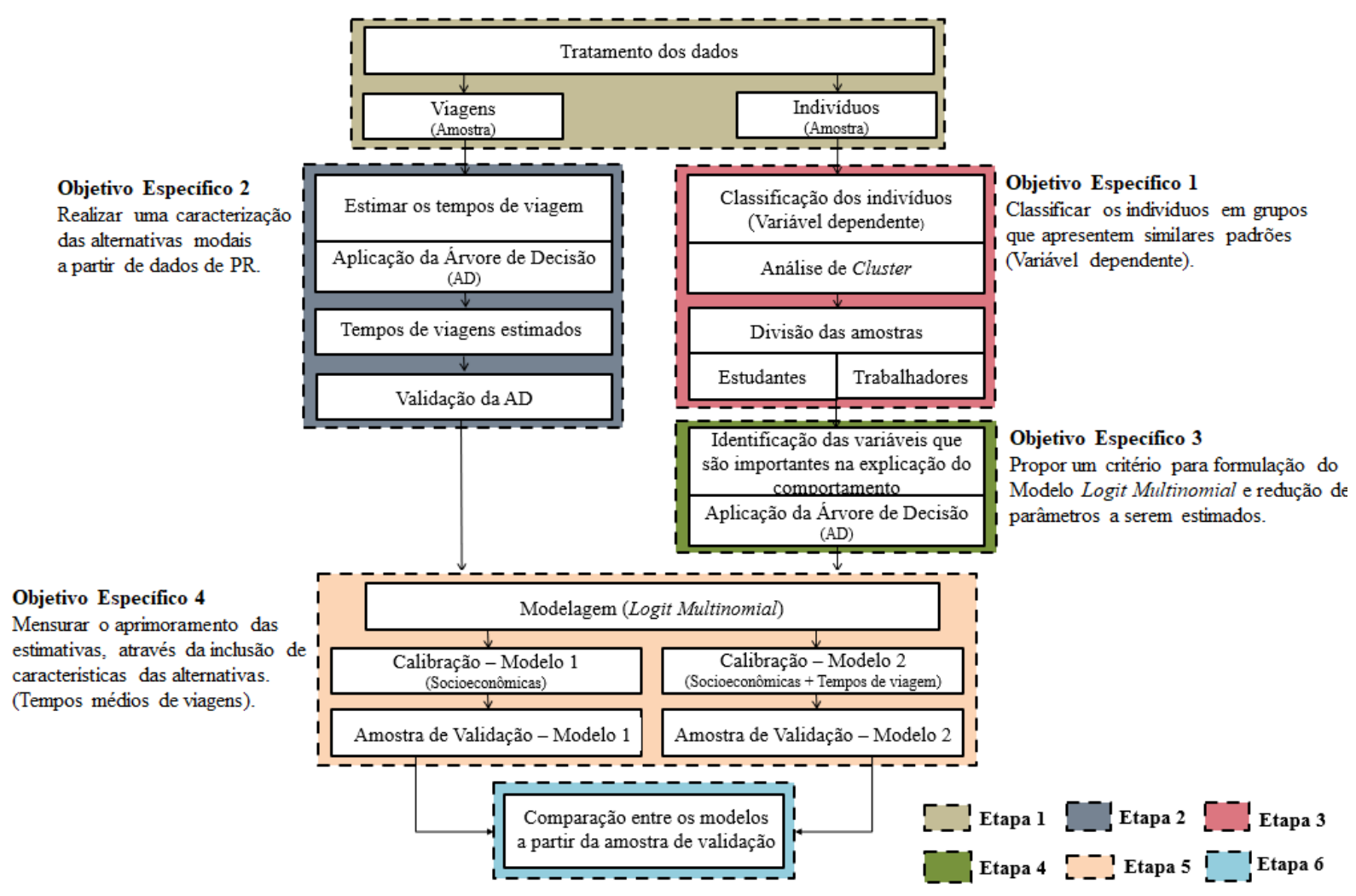




\subsubsection{Etapa 1 - Tratamento dos dados}

A pesquisa OD é composta pelos seguintes bancos de dados: (1) agregados por zona de tráfego; (2) desagregados por indivíduos; (3) desagregados por domicílios; (4) desagregados por viagens. Nesta etapa do método foi realizado o tratamento dos dados para obtenção de duas amostras finais desagregadas sendo: (A) amostra de viagens: para obtenção de tempos de viagens para todas as alternativas modais; (B) amostra de indivíduos: que é uma composição dos demais bancos de dados, sendo composto por indivíduos, associados às coordenadas geográficas dos domicílios de residências, características socioeconômicas individuais e domiciliares, tempos de viagens, características das zonas de tráfego de origem e destino, além de padrões de viagem que caracterizam o comportamento individual de viagens urbanas. Posteriormente, a amostra descrita em "B" é dividida em indivíduos classificados como Trabalhadores e Estudantes, compondo as duas sub-amostras finais utilizadas para investigação do comportamento individual relativo a viagens.

Inicialmente, foram selecionados somente os dados referentes à cidade de São Paulo e deletados aqueles registros incompletos, ou seja, sem dados de viagens. Posteriormente, foram selecionadas as variáveis que seriam utilizadas durante as análises. A Tabela 4.1 descreve as variáveis relativas ao banco de dados composto pelos indivíduos trabalhadores, associado às características das viagens e etapa metodológica que houve o uso de tais variáveis.

Tabela 4.1 - Variáveis da amostra por indivíduos trabalhadores.

\begin{tabular}{|c|c|c|c|}
\hline \multicolumn{4}{|c|}{ Amostra de trabalhadores } \\
\hline Variáveis & \multicolumn{2}{|c|}{ Natureza } & Etapa metodológica \\
\hline Motivo na origem & \multicolumn{2}{|c|}{ Qualitativa } & Etapa 2 \\
\hline Motivo no destino & \multicolumn{2}{|c|}{ Qualitativa } & Etapa 2 \\
\hline Hora de saída & \multicolumn{2}{|c|}{ Qualitativa } & Etapa 2 \\
\hline Tempo andando na origem & \multicolumn{2}{|c|}{ Quantitativa } & Etapa 2 \\
\hline Tempo andando no destino & \multicolumn{2}{|c|}{ Quantitativa } & Etapa 2 \\
\hline Duração da viagem para o modo & \multicolumn{2}{|c|}{ Quantitativa } & Etapa 2 \\
\hline Modo principal & \multicolumn{2}{|c|}{ Qualitativa } & Etapa 2 \\
\hline Distância & \multicolumn{2}{|c|}{ Quantitativa } & Etapa 2 \\
\hline Quantidade de automóveis & Quantitativa & Discreta & Etapas 2 e 4 \\
\hline Renda familiar & Quantitativa & Contínua & Etapas 2 e 4 \\
\hline Idade & \multicolumn{2}{|c|}{ Qualitativa Ordinal } & Etapas 2 e 4 \\
\hline Sexo & \multicolumn{2}{|c|}{ Qualitativo } & Etapas 2 e 4 \\
\hline Grau de instrução & \multicolumn{2}{|c|}{ Qualitativa Ordinal } & Etapas 2 e 4 \\
\hline Situação na família & \multicolumn{2}{|c|}{ Qualitativo } & Etapa 4 \\
\hline Estuda & \multicolumn{2}{|c|}{ Qualitativa Ordinal } & Etapa 4 \\
\hline Número de moradores no domicílio & Quantitativa & Discreta & Etapa 4 \\
\hline
\end{tabular}




\begin{tabular}{|c|c|c|c|}
\hline Quantidade de motos & Quantitativa & Discreta & Etapa 4 \\
\hline Quantidade de bicicletas & Quantitativa & Discreta & Etapa 4 \\
\hline Assalariado com carteira & \multicolumn{2}{|c|}{ Qualitativo } & Etapa 4 \\
\hline Assalariado sem carteira & \multicolumn{2}{|c|}{ Qualitativo } & Etapa 4 \\
\hline Funcionário público & \multicolumn{2}{|c|}{ Qualitativo } & Etapa 4 \\
\hline Autônomo & \multicolumn{2}{|c|}{ Qualitativo } & Etapa 4 \\
\hline Empregador & \multicolumn{2}{|c|}{ Qualitativo } & Etapa 4 \\
\hline Profissional liberal & \multicolumn{2}{|c|}{ Qualitativo } & Etapa 4 \\
\hline Dono de negócio familiar & \multicolumn{2}{|c|}{ Qualitativo } & Etapa 4 \\
\hline Trabalhador familiar & \multicolumn{2}{|c|}{ Qualitativo } & Etapa 4 \\
\hline Tem outro trabalho & \multicolumn{2}{|c|}{ Qualitativo } & Etapa 4 \\
\hline Motivo da viagem 1 & \multicolumn{2}{|c|}{ Qualitativa } & Etapa 3 \\
\hline Motivo da viagem 2 & \multicolumn{2}{|c|}{ Qualitativa } & Etapa 3 \\
\hline Motivo da viagem 3 & \multicolumn{2}{|c|}{ Qualitativa } & Etapa 3 \\
\hline Motivo da viagem 4 & \multicolumn{2}{|c|}{ Qualitativa } & Etapa 3 \\
\hline Modo principal da viagem 1 & \multicolumn{2}{|c|}{ Qualitativa } & Etapa 3 \\
\hline Modo principal da viagem 2 & \multicolumn{2}{|c|}{ Qualitativa } & Etapa 3 \\
\hline Modo principal da viagem 3 & \multicolumn{2}{|c|}{ Qualitativa } & Etapa 3 \\
\hline Modo principal da viagem 4 & \multicolumn{2}{|c|}{ Qualitativa } & Etapa 3 \\
\hline
\end{tabular}

Fonte: Metrô (2008).

\subsubsection{Etapa 2 - Determinação dos tempos de viagem agregados}

O objetivo desta etapa é estimar os tempos de viagens para todas as alternativas modais disponíveis na área estudada e fazer a caracterização agregada dos tempos de viagens dos modos não utilizados (objetivo específico 2). Para isso utilizou-se do algoritmo CART de Árvore de Decisão (AD). Utilizando os dados da Pesquisa O/D, essa etapa testa uma técnica de mineração de dados na proposta de estimação do tempo de viagem dos demais modos de transporte, disponíveis na área de estudo.

Aplicou-se o algoritmo CART e as variáveis independentes utilizadas foram: distância, clusters da hora de saída, motivo na origem, motivo no destino. Os modos principais foram agrupados em cinco categorias: modo motorizado privado (1), ônibus (2), metrô ou trem (3), bicicleta (4) e a pé (5). Este procedimento foi proposto anteriormente no trabalho de Cerveira et al. (2018) e, através de filtros nos nós terminais do algoritmo CART, é possível obter tempos médios, por modos de transporte, para diferentes grupos de viagens. A Figura 4.4 ilustra um exemplo do procedimento realizado. Desta forma, com o banco de dados desagregado de viagens, aplica-se o algoritmo CART, sendo a "duração de viagens" a variável dependente. Os dados são sequencialmente divididos até os nós terminais (Nó 4, Nó 5, Nó 6 e Nó 7). Observase no Nó terminal 4, por exemplo, o filtro das 500 viagens por modo de transporte. Finalmente, são calculados os tempos médios das viagens por cada opção modal para as viagens que 
compreendem o Nó terminal 4. O mesmo procedimento é repetido para os demais nós terminais obtidos.

Figura 4.4 - Ilustração do procedimento adotado para obtenção dos tempos de viagens médios por modo de transporte - adaptado de Gomes et al. (2021).

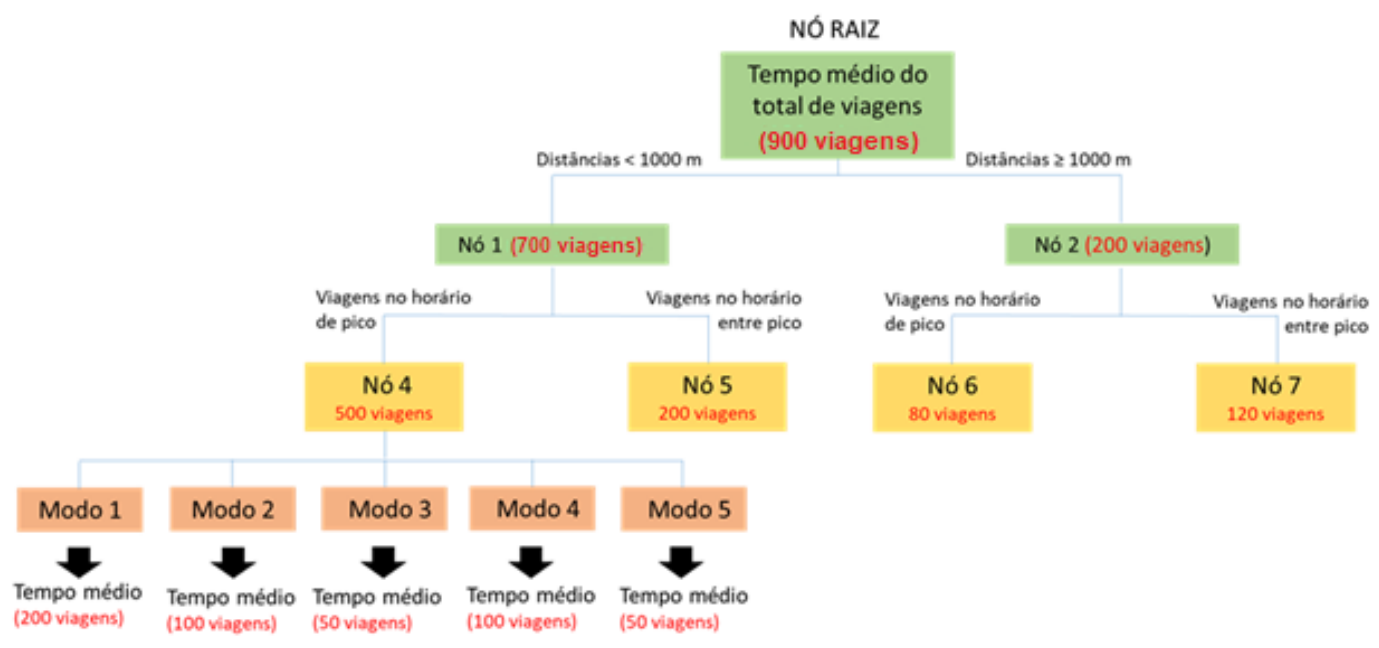

Vale ressaltar que o dado de tempos de viagens estimados, para os cinco modos de transporte, é representado por indivíduo no banco de dados. Indivíduos que realizam viagens similares, identificadas através do algoritmo CART (Contidas no Nó terminal 4, por exemplo), terão os mesmos tempos de viagens médios estimados. O termo "agregado", neste caso, referese à agregação das viagens contidas no mesmo nó terminal e não significa agregação dos indivíduos.

A validação dessa etapa do método foi realizada considerando-se apenas os tempos das viagens realizados pelos modos efetivamente escolhidos pelos indivíduos. Assim, foi feita a comparação dos tempos de viagem estimados com os valores das durações de viagens observadas. Ambos os tempos, utilizados para fins de validação, foram dos modos de transportes declarados na pesquisa de PR. A amostra foi dividida aleatoriamente em treinamento (70\%) e teste (30\%) e, em seguida, calculou-se as medidas de erros e de correlação com a amostra de teste: Erro Médio Quadrático, Raiz do Erro Médio Quadrático, Erro Médio Absoluto e Correlação de Pearson.

\subsubsection{Etapa 3 - Classificação dos indivíduos e divisão da amostra}

Essa etapa visa reunir os indivíduos em grupos que apresentem similares padrões de viagens (objetivo específico 1). Para essa etapa utilizou-se o banco de dados de indivíduos, e o 
agrupamento foi realizado a partir da geração de clusters, através do algoritmo Two-Step Cluster, contido no software IBM SPSS 24. Os dados utilizados nessa classificação foram referentes às variáveis motivo de viagem e modo de transporte, referentes ao máximo de quatro viagens diárias, realizadas pelo mesmo indivíduo. A classificação dos indivíduos, segundo seus padrões de viagens encadeadas, foi a variável dependente, utilizada na etapa de modelagem paramétrica.

Esta etapa foi composta por quatro subetapas:

(1) Definição dos padrões de viagens;

(2) Divisão da amostra;

(3) Aplicação do algoritmo Two-Step Cluster e obtenção dos Clusters principais;

(4) Determinação de nomenclatura e/ou classificação dos indivíduos.

\subsubsection{Definição dos padrões}

A primeira etapa para a determinação da variável dependente ou classificação dos indivíduos foi a definição dos padrões de viagens. Neste trabalho, os padrões de viagens, que caracterizam o comportamento individual relativo a viagens urbanas, foram definidos por uma sequência alfanumérica, que representa os motivos das viagens e os modos de transporte, conforme procedimento similar ao proposto por Ichikawa et al. (2003), Taco (2003) e Pitombo et al. (2011).

As características das viagens, consideradas para composição dos padrões de viagens, foram adaptadas e agrupadas a partir dos dados originais, provenientes da Pesquisa OrigemDestino de 2007. A Tabela 4.2, em seguida, apresenta a nomenclatura adotada neste trabalho, a partir dos dados da Pesquisa O/D. 
Tabela 4.2 - Relação dos motivos e dos modos de viagem na Pesquisa O/D (2007) e classificados neste trabalho.

\begin{tabular}{|c|c|}
\hline Motivo (pesquisa O/D) & Motivo (neste trabalho) \\
\hline $\begin{array}{ll}\text { 1. } & \text { trabalho/indústria } \\
\text { 2. } & \text { trabalho/comércio } \\
\text { 3. } & \text { trabalho/serviço } \\
\text { 4. } & \text { escola/educação } \\
\text { 5. } & \text { compras } \\
\text { 6. } & \text { médico/dentista/saúde } \\
\text { 7. } & \text { recreação/visitas/lazer } \\
\text { 8. } & \text { residência } \\
\text { 9. } & \text { procurar emprego } \\
\text { 10. } & \text { assuntos pessoais }\end{array}$ & $\begin{array}{l}\text { W - Trabalho }(1,2,3) \\
S \text { - Estudo (4) } \\
\text { H - Residência (8) } \\
\text { A - Outras Atividades }(5,6,7,9,10)\end{array}$ \\
\hline Modo (pesquisa O/D) & Modo (neste trabalho) \\
\hline $\begin{array}{l}\text { 1. ônibus município São Paulo } \\
\text { 2. ônibus outros municípios } \\
\text { 3. ônibus metropolitano } \\
\text { 4. ônibus fretado } \\
\text { 5. escolar } \\
\text { 6. dirigindo automóvel } \\
\text { 7. passageiro de auto } \\
\text { 8. táxi } \\
\text { 9. micro-ônibus/van município São Paulo } \\
\text { 10. micro-ônibus/van outros municípios } \\
\text { 11. micro-ônibus/van metropolitano } \\
\text { 12. metro } \\
\text { 13. trem } \\
\text { 14. moto } \\
\text { 15. bicicleta } \\
\text { 16. a pé } \\
\text { 17. outros* }\end{array}$ & $\begin{array}{l}1 \text { - privado motorizado }(6,7,8,14) \\
2 \text { - público }(1,2,3,4,5,9,10,11,12,13) \\
3 \text { - não motorizado (15 e 16) }\end{array}$ \\
\hline
\end{tabular}

outros* - foram excluídos

Fonte: Metrô-SP (2008).

As letras e números indicam as características das viagens realizadas pelo indivíduo no dia que antecedeu a entrevista e representam o seu padrão de viagem. A partir da amostra de 4.952 indivíduos foram gerados 284 Padrões (combinações).

"WH33" é um exemplo de um padrão que indica que o indivíduo realizou duas viagens. Os dois primeiros dígitos representam a sequência de atividades "WH". Essa sequência indica que o indivíduo foi para o trabalho e depois voltou para casa. A segunda sequência de números indica a sequência de modos de viagens utilizados. Assim " 33 ” indica que o indivíduo fez as duas viagens (ida e volta do trabalho) utilizando o modo não motorizado (bicicleta ou a pé). 
"SHWH2211" é um exemplo de um padrão que indica que o indivíduo realizou quatro viagens. Os quatro primeiros dígitos representam a sequência de atividades "SHWH". Essa sequência indica que o indivíduo foi para a escola, depois voltou para casa, em seguida foi para o trabalho e por último, voltou para casa. A segunda sequência numérica indica a sequência de modos de viagens utilizados. Assim "2211" indica que as duas primeiras viagens foram realizadas pelo modo público e as duas últimas pelo modo privado motorizado. A Figura 4.5 ilustra os dois padrões exemplificados anteriormente. Vale ressaltar que, neste trabalho, a primeira e última viagem foram baseadas no domicílio.

Figura 4.5 - Exemplos de padrões de viagens.
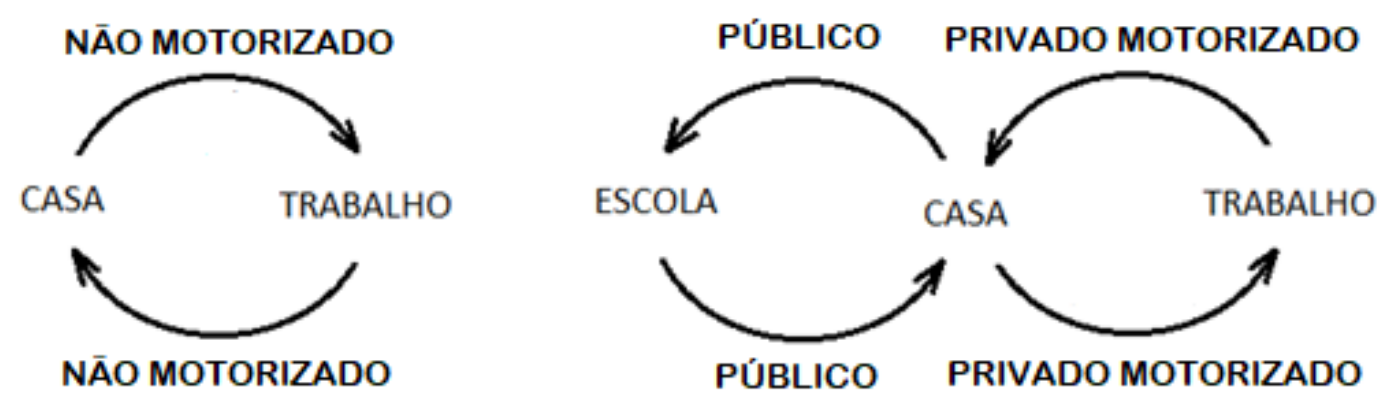

\subsubsection{Aplicação do algoritmo TwoStep Cluster e obtenção dos clusters principais}

A partir da determinação dos padrões de viagens, codificados na etapa anterior, foram gerados clusters, a partir de 2 variáveis categóricas: (1) Sequência de atividades (Exemplo SH - primeira viagem à escola e segunda viagem de retorno ao domicílio); (2) Sequência de modos de viagem (Exemplo 33 - duas viagens realizadas pelo modo não motorizado). A ideia desta subetapa metodológica é explorar as similaridades de padrões de viagens a partir de uma técnica de agrupamentos.

O algoritmo Two-step Cluster, é um algoritmo de análise de cluster escalável, projetado para lidar com grandes conjuntos de dados. Neste trabalho, optou-se por aplicar esse método de agrupamento por ele possibilitar agrupar variáveis categóricas, utilizando como medida de similaridade o Logaritmo da Verossimilhança (IBM SPSS, 2012). 


\subsubsection{Divisão da amostra}

Antes da obtenção dos diferentes grupos possíveis, optou-se por dividir a amostra criando uma amostra de Estudantes e outra amostra de Trabalhadores de forma a capturar uma homogeneidade adequada do comportamento.

Após a segmentação e obtenção das duas amostras (Estudantes: 163 indivíduos; Trabalhadores: 4.952 indivíduos), diversas tentativas de agrupamentos, a partir da variação de número de grupos obtidos, foram realizadas em ambas amostras. A ideia é identificar os melhores agrupamentos segundo padrões de viagens encadeadas. Após análise dos diferentes grupos, obtidos nas diversas tentativas, escolheu-se o agrupamento capaz de identificar similaridades intrínsecas a cada grupo. Finalmente, optou-se por 15 clusters na amostra de Trabalhadores e 5 clusters na amostra de Estudantes.

Considerando a grande diversidade de comportamentos contidos na amostra, esta etapa foi essencial para identificação de similaridades de padrões.

\subsubsection{Determinação da nomenclatura e/ou classificação dos indivíduos}

A partir dos clusters, foi possível extrair informações importantes relativas ao comportamento dos trabalhadores e estudantes, associado a viagens e, finalmente, classificar indivíduos segundo características similares inerentes a cada cluster.

\subsubsection{Etapa 4 - Identificação das variáveis importantes a partir da AD}

Determinada a variável dependente (15 clusters para trabalhadores e 5 clusters para estudantes, obtidos na etapa prévia), realizou-se a formulação do modelo Logit Multinomial, considerando 15 e 5 funções utilidade, respectivamente. O número alto de funções utilidade, especialmente para o caso de amostra de trabalhadores, e de parâmetros a serem estimados pode ser uma restrição computacional na etapa de calibração do modelo de escolha discreta. Por essa razão, neste trabalho é proposta uma análise e seleção das variáveis, associadas ao indivíduo, potencialmente não relevantes a serem excluídas em cada função utilidade (objetivo específico 3). O intuito é reduzir o número de parâmetros a serem estimados posteriormente. Essa etapa compreende o terceiro objetivo específico do presente trabalho, no qual se propõe a aplicação 
de um critério simplificado para formulação do Modelo Logit Multinomial com redução na quantidade de parâmetros a serem estimados.

Nessa etapa do método também é utilizado o algoritmo CART. Neste caso específico, onde a variável dependente corresponde aos 15 e 5 clusters, obtidos previamente (variável dependente categórica), o problema é de classificação e os dados são segmentados no intuito de tornar os nós filhos homogêneos segundo as categorias de variável dependente. Isso posto, este estudo propôs o procedimento metodológico composto das seguintes etapas:

- Inicialmente, determina-se a variável dependente e as variáveis independentes. Neste trabalho, para a amostra de trabalhadores, a variável dependente foi o agrupamento dos indivíduos segundo padrões de viagens (15 grupos de indivíduos) e as variáveis independentes iniciais foram as características socioeconômicas e de participação em atividades dos trabalhadores (19 variáveis - Tabela 4.3).

Tabela 4.3 - Descrição das variáveis.

\begin{tabular}{|c|c|c|}
\hline Variáveis & Amostra de Estudantes & Amostra de Trabalhadores \\
\hline Situação na família & \multicolumn{2}{|c|}{1 - Responsável pela família } \\
\hline Tipo de escola & 1-Pública 2 - Particular & ---- \\
\hline Número de moradores & De 1 a 11 & De 1 a 14 \\
\hline Quantidade de moto & De 0 a 1 & De 0 a 9 \\
\hline Quantidade de automóvel & De 0 a 7 & De 0 a 6 \\
\hline Quantidade de bicicleta & De 0 a 4 & De 0 a 9 \\
\hline Renda familiar & $\begin{array}{c}1-\operatorname{Renda} \leq \mathrm{R} \$ 2.856,00 \\
2-\mathrm{R} \$ 2.856,01<\mathrm{Renda} \leq \mathrm{R} \$ 4.110,00 \\
3-\mathrm{R} \$ 4.110,01<\mathrm{Renda} \leq \mathrm{R} \$ 9.000,00 \\
4->\mathrm{R} \$ 9.000,01\end{array}$ & $\begin{array}{l}0-\text { Renda } \leq \mathrm{R} \$ 2.502,00 \\
1-\text { Renda }>\mathrm{R} \$ 2.502,00\end{array}$ \\
\hline Idade & $\begin{array}{c}1-\text { até } 11 \text { anos } \\
2-\text { de } 12 \text { a } 20 \text { anos } \\
3-\text { de } 21 \text { a } 59 \text { anos } \\
----\end{array}$ & $\begin{array}{c}\text { 2- de } 12 \text { a } 20 \text { anos } \\
3-\text { de } 21 \text { a } 59 \text { anos } \\
4-\geq 60 \text { anos }\end{array}$ \\
\hline Sexo & 0 - Masculino & \\
\hline Grau de instrução & \multicolumn{2}{|c|}{$\begin{array}{c}1 \text { - não alfabetizado -Primário incompleto } \\
2 \text { - Primário completo - Fundamental incompleto } \\
3 \text { - Fundamental completo - Ensino Médio incompleto } \\
4 \text { - Ensino Médio completo - Superior incompleto } \\
5 \text { - Superior completo }\end{array}$} \\
\hline
\end{tabular}


Conclusão

\begin{tabular}{c|c|c}
\hline Variáveis & Amostra de Estudantes & Amostra de Trabalhadores \\
\hline & ---- & Estuda \\
Variáveis associadas à & ---- & Assalariado com carteira \\
participação em atividades & ---- & Assalariado sem carteira \\
(Todas binárias com valor & ---- & Funcionário público \\
1 correspondem ao "Sim") & ---- & Autônomo \\
& ---- & Empregador \\
& ---- & Profissional liberal \\
& ---- & Dono de negócio familiar \\
& ---- & Trabalhador familiar \\
\end{tabular}

- $\quad$ Em seguida, são geradas 19 árvores bivariadas, com apenas uma divisão do conjunto total dos dados (variável dependente versus variável independente 1, variável dependente versus variável independente 2 , ..., variável dependente versus variável independente 19), conforme exemplificado na Figura 4.6;

- $\quad$ Observa-se a variação de cada uma das categorias da variável dependente entre os dois nós terminais a partir da divisão proposta, para cada árvore gerada (neste trabalho, total de 19). Utilizando-se o exemplo da Figura 4.6, percebe-se que a variável independente 1, quando assume os valores menores ou iguais a 0,5 , influencia positivamente a presença no Cluster 2 (12\% das observações do Nó 1 se referem a ele). Isso pode ser verificado ao observar que, quando a mesma variável assume valores maiores que 0,5, a presença do Cluster 2 entre as viagens classificadas no Nó 2 é bem pequena (0,5\%). Assim, há uma alta variação proporcional $(95,83 \%)$ na categoria 2 (Cluster 2), mediante divisão do nó pai a partir da variável independente 1. Para o caso do Cluster 15, no entanto, percebe-se que a presença desse grupo é semelhante entre os nós filhos 1 e 2 (1,3\% e 1,3\%, respectivamente), indicando que a variável independente 1 não exerce influência significativa sobre a caracterização do Cluster 15 (variação de 0\%), podendo, então, ser excluída da sua função utilidade;

- Identifica-se, para cada uma das variáveis independentes, as alternativas/categorias em que a sua variação proporcional entre os nós filhos difere em até 10\%. O objetivo deste método é identificar, para cada variável independente, variações relativamente altas nas categorias da variável dependente. Esses casos sinalizam uma influência e/ou relevância de determinada variável explicativa na utilidade de uma alternativa específica. 
Vale ressaltar que o procedimento proposto é simplificado e que é necessária uma validação futura, de forma a aferir se as variáveis retiradas de determinadas funções utilidade seriam realmente associadas à estimação de parâmetros não significativos, para um nível de confiança de $95 \%$.

Figura 4.6 - Exemplo do procedimento adotado com a AD para redução do número de parâmetros - adaptado de Gomes et al. (2021).

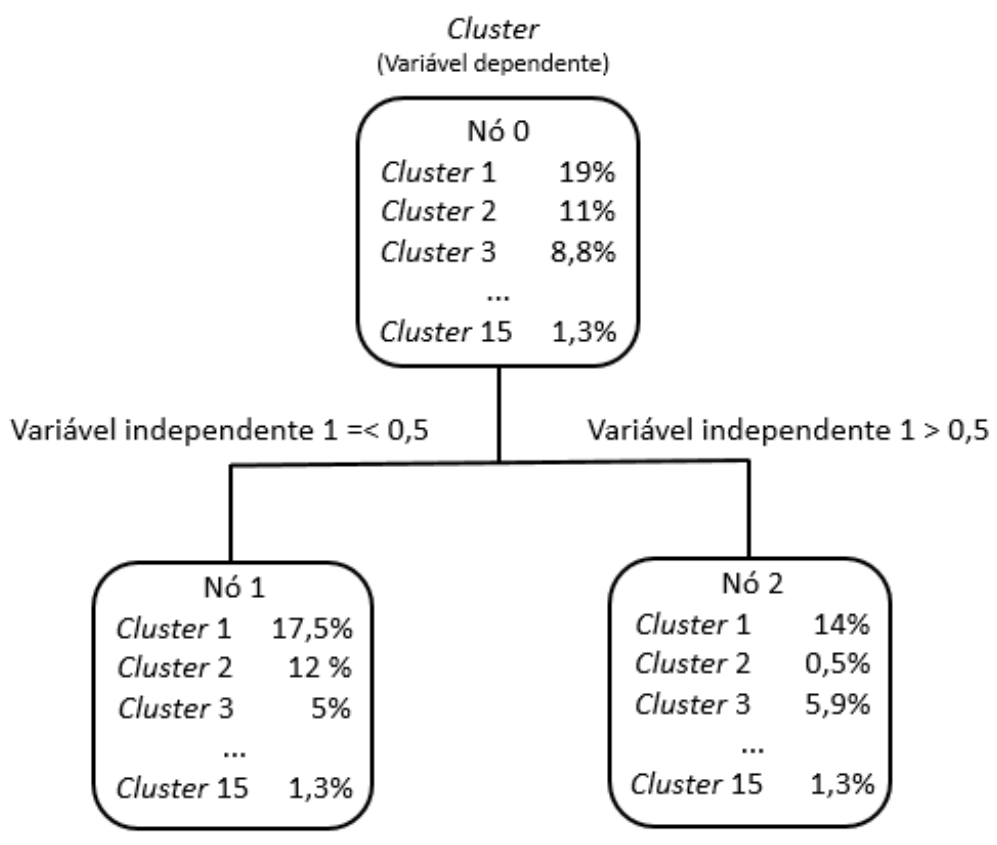

\subsubsection{Etapa 5 - Modelagem Logit Multinomial}

Nesta etapa, referente ao objetivo específico 4, utilizou-se o software Biogeme (Bierlaire, 2020) e foram definidas as funções utilidade dos modelos Logit Multinomial, com base nas variáveis socioeconômicas e de participação em atividades do banco de dados e também do critério proposto anteriormente, que definia as variáveis importantes, a serem consideradas em cada função utilidade. As amostras de Estudantes e de Trabalhadores foram divididas aleatoriamente para calibração (70\%) e validação (30\%). Dois modelos foram gerados em cada uma das amostras. O primeiro modelo (Modelagem 1) continha apenas variáveis socioeconômicas e participação em atividades, enquanto o segundo modelo (Modelagem 2) incorporava as variáveis agregadas de tempos de viagem. A descrição dos modelos é apresentada a partir das duas amostras. Vale ressaltar que na Modelagem 2 foram usados, para ambas as amostras, parâmetros específicos de cada alternativa. 


\subsubsection{Amostra de estudantes}

Modelo 1: No Modelo 1 foram inseridas como variáveis independentes as características socioeconômicas dos indivíduos: "situação na família", "tipo de escola", "número de moradores na residência", "quantidade de moto na residência", "quantidade de automóveis na residência", "quantidade de bicicleta na residência", "grau de instrução", "idade", "sexo" e "renda familiar", apresentadas anteriormente na Tabela 4.3.

A variável dependente foi a classificação dos indivíduos, gerada a partir da Etapa 2 do método. As Equações 4.1, 4.2, 4.3, 4.4 e 4.5 correspondem às funções utilidade desta modelagem. Com intuito de reduzir o número de parâmetros a serem estimados, optou-se por anular uma das funções utilidade (referência).

$$
\begin{aligned}
& \mathrm{V}_{1}=0 \\
& \mathrm{~V} 2=\text { ASC2 + B2_GRAU_INS*grau_ins } \\
& \mathrm{V}_{3}=\text { ASC3 + B3_SIT_FAM*sit_fam } \\
& \mathrm{V}_{4}=\text { ASC4 + B4_QT_AUTO*qt_auto } \\
& \text { V5 }=\text { ASC5 + B5_TIPO_ESC *tipo_esc }
\end{aligned}
$$

QT_AUTO (quantidade de automóvel no domicílio); GRAU_INS (grau de instrução); SIT_FAM (situação na família); TIPO_ESC (tipo de escola); ASC2 = Constante associada à Função Utilidade 2; ASC3 = Constante associada à Função Utilidade 3; ASC4 = Constante associada à Função Utilidade 4; ASC5 = Constante associada à Função Utilidade 5; B2 = Parâmetro associado à variável GRAU_INS e função utilidade 2; B3 = Parâmetro associado à variável SIT_FAM e função utilidade 3; B4 = Parâmetro associado à variável QT_AUTO e função utilidade 4; B5 = Parâmetro associado à variável TIPO_ESC e função utilidade 5.

Modelo 2: No Modelo 2, além das variáveis relacionadas no Modelo 1, foram inseridas como variáveis independentes, os tempos de viagens estimados na etapa 2.

\subsubsection{Amostra de trabalhadores}

Modelo 1: No Modelo 1, da amostra de trabalhadores, foram inseridas como variáveis independentes, as características socioeconômicas dos indivíduos: "situação na família", "número de moradores na residência", "quantidade de moto na residência", "quantidade de automóveis na residência", "quantidade de bicicleta na residência", "se estuda", "grau de instrução", "idade", "sexo", "renda familiar" e as variáveis que descrevem participação em atividades obrigatórias: "assalariado com carteira", "assalariado sem carteira", "funcionário 
público", "autônomo", “empregador", "profissional liberal”, “dono de negócio familiar” e "trabalhador familiar", conforme ilustrado na Tabela 4.3. Nesse modelo, a variável dependente foi a classificação dos indivíduos, gerada a partir da Etapa 2 do método. As Equações de 4.6 a 4.20, correspondem às funções utilidade desta modelagem. Neste modelo a função utilidade 15 foi anulada (referência).

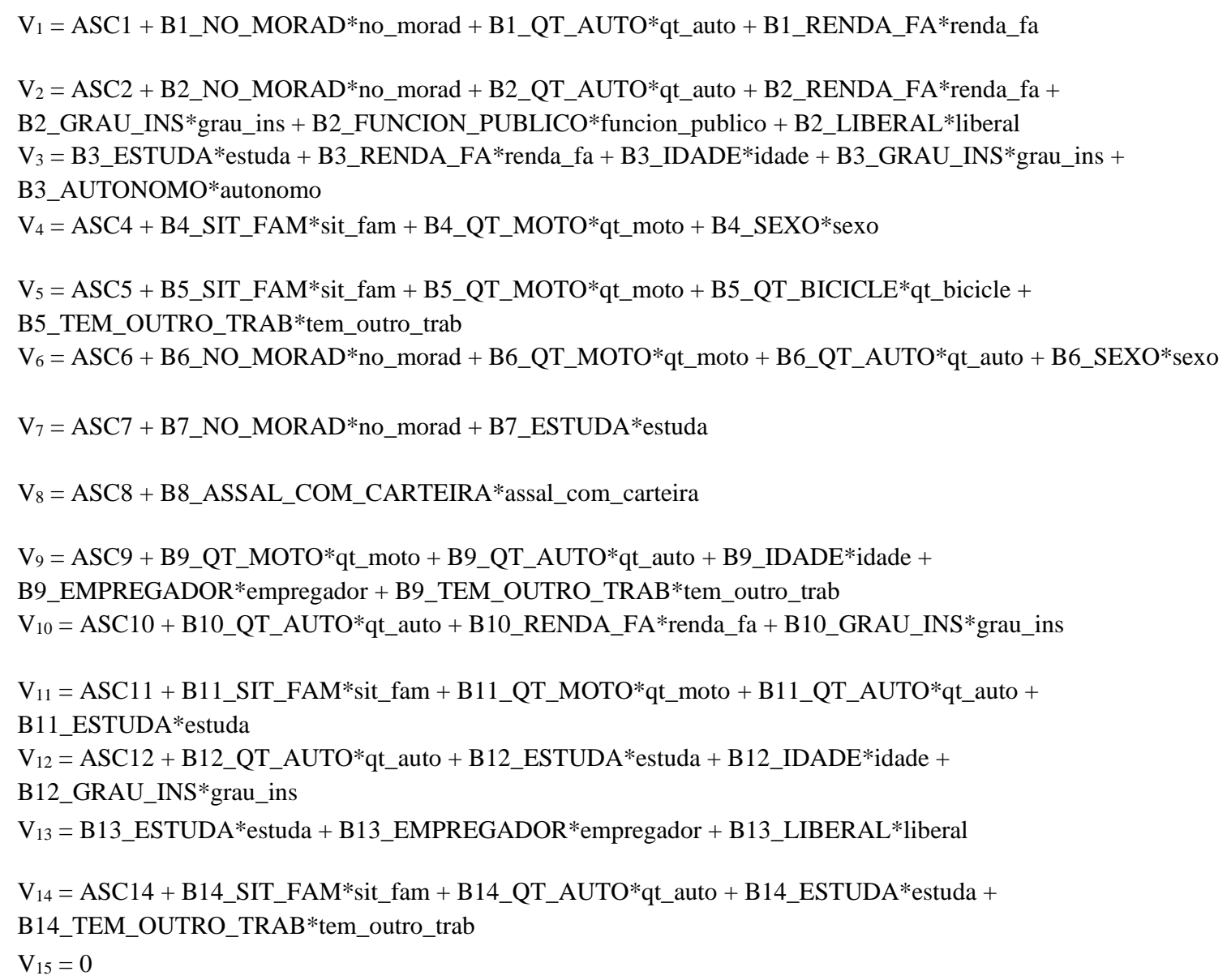

NO_MORAD (número de moradores no domicílio); QT_AUTO (quantidade de automóvel no domicílio); RENDA_FA (renda familiar); GRAU_INS (grau de instrução); FUNCION_PUBLICO (funcionário público); LIBERAL (profissional liberal); ESTUDA (se estuda); IDADE (idade); AUTONOMO (autônomo); SIT_FAM (situação na família); QT_MOTO (quantidade de moto no domicílio); SEXO (sexo); QT_BICICLE (quantidade de bicicleta no domicílio); TEM_OUTRO_TRAB (tem outro trabalho); ASSAL_COM_CARTEIRA (assalariado com carteira); EMPREGADOR (empregador).

Sendo:

ASC1, ASC2, ASC3,... ASC15: constante das funções utilidades;

Bx_NO_MORAD: parâmetro a ser estimado para variável "número de moradores no domicílio", da função utilidade $\mathrm{x}$, sendo que x pode variar de 1 a 14 ; 
Bx_QT_AUTO: parâmetro a ser estimado para variável "quantidade de automóvel no domicílio", da função utilidade $\mathrm{x}$, sendo que x pode variar de 1 a 14 ;

Bx_RENDA_FA: parâmetro a ser estimado para variável "renda familiar", da função utilidade $x$, sendo que $\mathrm{x}$ pode variar de 1 a 14 ;

Bx_GRAU_INS: parâmetro a ser estimado para variável "grau de instrução", da função utilidade x, sendo que $\mathrm{x}$ pode variar de 1 a 14 ;

Bx_FUNCION_PUBLICO: parâmetro a ser estimado para variável "funcionário público", da função utilidade $\mathrm{x}$, sendo que $\mathrm{x}$ pode variar de 1 a 14 ;

Bx_LIBERAL: parâmetro a ser estimado para variável "profissional liberal", da função utilidade $\mathrm{x}$, sendo que x pode variar de 1 a 14 ;

Bx_ESTUDA: parâmetro a ser estimado para variável "estuda", da função utilidade x, sendo que x pode variar de 1 a 14;

Bx_IDADE: parâmetro a ser estimado para variável "idade", da função utilidade $\mathrm{x}$, sendo que x pode variar de 1 a 14 ;

Bx_AUTONOMO: parâmetro a ser estimado para variável "autônomo", da função utilidade x, sendo que $\mathrm{x}$ pode variar de 1 a 14 ;

Bx_SIT_FAM: parâmetro a ser estimado para variável "situação na família", da função utilidade x, sendo que $\mathrm{x}$ pode variar de 1 a 14 ;

Bx_QT_MOTO: parâmetro a ser estimado para variável "quantidade de moto no domicílio", da função utilidade $\mathrm{x}$, sendo que x pode variar de 1 a 14 ;

Bx_ SEXO: parâmetro a ser estimado para variável "sexo", da função utilidade x, sendo que x pode variar de 1 a 14 ;

Bx_QT_BICICLE: parâmetro a ser estimado para variável "quantidade de bicicleta no domicílio", da função utilidade $\mathrm{x}$, sendo que x pode variar de 1 a 14 ;

Bx_TEM_OUTRO_TRAB: parâmetro a ser estimado para variável "tem outro trabalho", da função utilidade $\mathrm{x}$, sendo que $\mathrm{x}$ pode variar de 1 a 14 ;

Bx_ASSAL_COM_CARTEIRA: parâmetro a ser estimado para variável "assalariado com carteira", da função utilidade $\mathrm{x}$, sendo que x pode variar de 1 a 14 ;

Bx_EMPREGADOR: parâmetro a ser estimado para variável "empregador", da função utilidade x, sendo que $\mathrm{x}$ pode variar de 1 a 14 ;

Modelo 2: Na modelagem 2, além das variáveis socioeconômicas e participação em atividades, relacionadas acima, foram inseridos os tempos de viagens agregados estimados.

Ressalta-se que os modelos estimam a probabilidade de um indivíduo pertencer a um grupo que realiza determinado tipo de cadeia de viagens. Logo, as probabilidades calculadas 
não se referem a escolhas, e sim ao pertencimento do indivíduo a determinado grupo homogêneo segundo padrões de viagem. Assim, as alternativas são independentes entre si, e não se comportam de maneira hierárquica.

4.3.6. Etapa 6 - Comparação entre os modelos a partir da amostra de validação

Para a comparação entre os modelos, utilizou-se parte da amostra (30\%), selecionada aleatoriamente, e mensurou-se a qualidade do ajuste dos modelos 1 e 2 através do Rho-quadrado ajustado, do valor de Verossimilhança, do Log-verossimilhança e do Critério de informação Akaike. O procedimento foi realizado em ambas as amostras (Trabalhadores e Estudantes).

\subsection{APLICATIVOS UTILIZADOS}

Foram dois os aplicativos utilizados como ferramentas computacionais para se realizar as análises neste trabalho. Nas fases iniciais de tratamento dos dados e classificação dos indivíduos utilizou-se o software IBM SPSS 24, que também foi usado na etapa de identificação das variáveis importantes para a modelagem. Na etapa de Modelagem Logit Multinomial utilizou-se do software Biogeme (Bierlaire, 2020), desenvolvido pela École Polytechnique Fédérale de Lausanne. 


\section{Capítulo}

\section{RESULTADOS E DISCUSSÕES:}

\section{CARACTERIZAÇÃO AGREGADA \\ DAS ALTERNATIVAS}

Este capitulo apresenta os resultados associados à caracterização agregada das alternativas disponíveis da área de estudo (Objetivo específico 2), através da aplicação do algoritmo de Árvore de Decisão CART.

Neste trabalho, a caracterização das alternativas é dada de forma agregada (por viagens) pela variável "Tempo Médio de Viagem" (em minutos). Para obtenção dos tempos médios de viagens por modo de transporte (1: motorizado privado; 2: ônibus; 3: metrô e trem; 4: bicicleta; 5: a pé), seguiu-se o procedimento ilustrado na Figura 5.1.

Figura 5.1 - Esquema ilustrativo para obtenção dos tempos de viagens por modo de transporte.

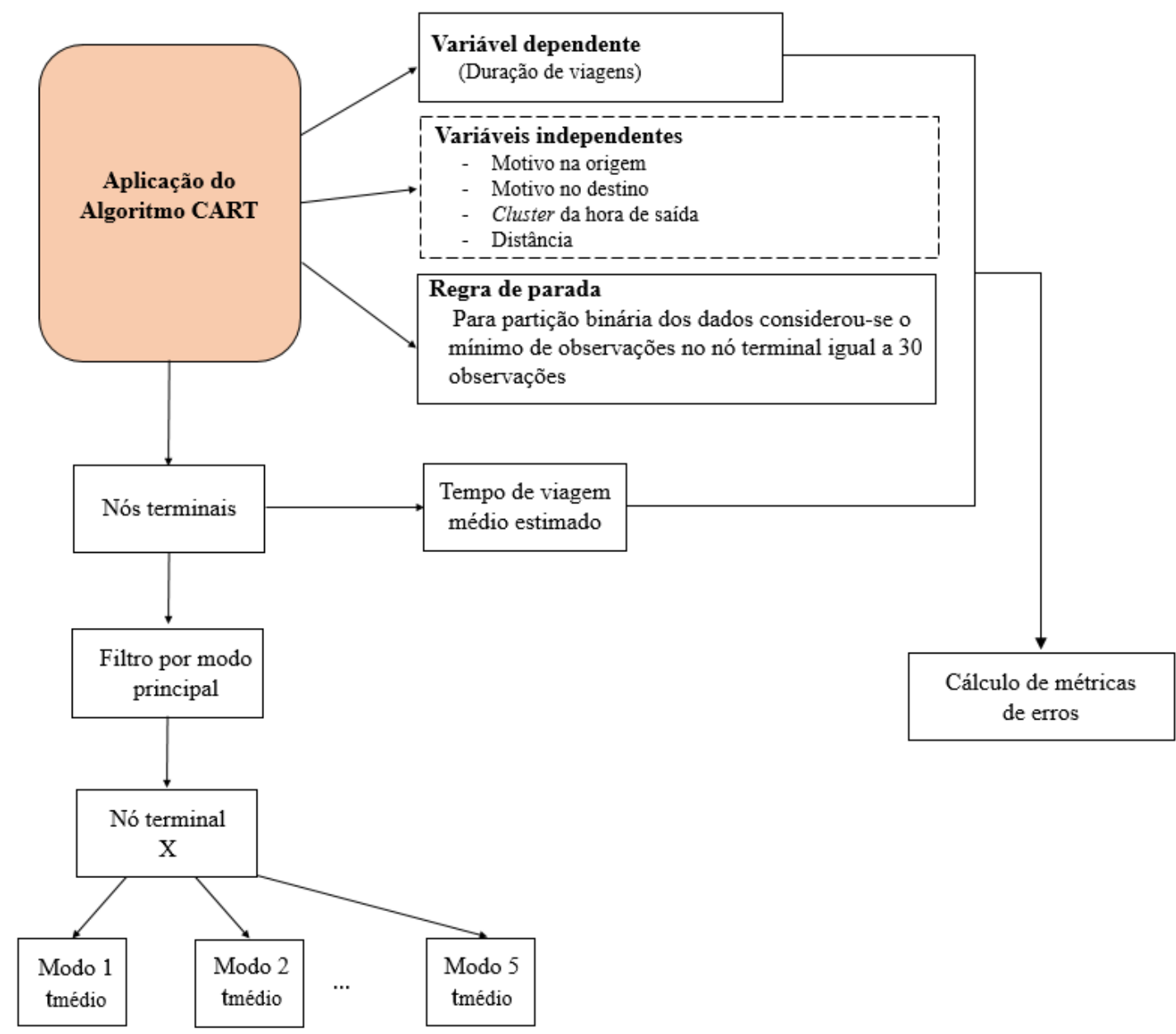




\subsection{APLICAÇÃO DO ALGORITMO CART}

Nesta etapa do trabalho, foram utilizados dados desagregados por viagens. Cada viagem está associada ao identificador do indivíduo, identificador do domicílio de residência, características individuais, domiciliares e de viagens. A Tabela 5.1 descreve as variáveis utilizadas nesta etapa. A variável "hora de saída" foi agrupada em seis categorias, em função dos períodos pico e entre pico. A Tabela 5.2, em seguida, traz a caracterização das variáveis numéricas através das medidas descritivas. Já a Tabela 5.3 apresenta as frequências das categorias das variáveis nominais. A amostra final foi composta de 54.895 viagens. Vale ressaltar que a amostra foi dividida, de forma aleatória em treinamento (70\%) e teste (30\%). As regras induzidas do algoritmo, geradas na amostra de treinamento, foram aplicadas na amostra teste para fins de validação - cálculo de métricas de erros.

A variável dependente corresponde à duração das viagens (em minutos). As variáveis independentes estão caracterizadas nas tabelas seguintes. Para a estimação dos tempos de viagem utilizou-se os algoritmos CART (Classification And Regression Tree), disponível no pacote IBM SPSS 24.

Tabela 5.1 - Variáveis da Amostra.

\begin{tabular}{|c|c|c|}
\hline Variáveis & \multicolumn{2}{|c|}{ Natureza } \\
\hline Zona de origem & \multicolumn{2}{|c|}{ Qualitativa } \\
\hline Zona de destino & \multicolumn{2}{|c|}{ Qualitativa } \\
\hline Motivo na origem & \multicolumn{2}{|c|}{ Qualitativa } \\
\hline Motivo no destino & \multicolumn{2}{|c|}{ Qualitativa } \\
\hline Hora de saída & Qualitativa & Ordinal \\
\hline Duração da viagem (em minutos) & Quantitativa & Contínua \\
\hline Modo principal & \multicolumn{2}{|c|}{ Qualitativa } \\
\hline Distância & Quantitativa & Contínua \\
\hline
\end{tabular}

Fonte: Cerveira et al. (2018) e Metrô (2008).

Tabela 5.2 - Medidas descritivas das variáveis numéricas.

\begin{tabular}{lcccc}
\hline $\begin{array}{c}\text { Dados por } \\
\text { domicílio }\end{array}$ & Mínimo & Máximo & Média & $\begin{array}{c}\text { Desvio } \\
\text { Padrão }\end{array}$ \\
\hline Duração (min.) & 1 & 240 & 29,70 & 25,27 \\
Distância (m) & 1,28 & $45.876,38$ & $3.600,11$ & $4.192,08$ \\
\hline \multicolumn{5}{c}{ Fonte - Cerveira et al. (2018). }
\end{tabular}


Tabela 5.3 - Frequência das categorias das variáveis categóricas.

\begin{tabular}{|c|c|c|c|}
\hline Variáveis & Variáveis categóricas & $\begin{array}{l}\text { Quantidade na } \\
\text { amostra }\end{array}$ & $\begin{array}{c}\text { Percentual } \\
(\%)\end{array}$ \\
\hline \multirow{10}{*}{ Motivo na origem } & 1 - Trabalho/indústria & 761 & 1,4 \\
\hline & 2 - Trabalho/comercio & 2.306 & 4,2 \\
\hline & 3 - Trabalho/serviço & 9.645 & 17,5 \\
\hline & 4 - Escola & 7.669 & 13,9 \\
\hline & 5 - Compras & 2.015 & 3,6 \\
\hline & 6 - Médico/dentista/saúde & 1.459 & 2,6 \\
\hline & 7 - Recreação/visitas/lazer & 2.455 & 4,4 \\
\hline & 8 - Residência & 23.920 & 43,3 \\
\hline & 9 - Procurar emprego & 73 & 0,1 \\
\hline & 10 - Assuntos pessoais & 4.592 & 8,3 \\
\hline \multirow{10}{*}{ Motivo no destino } & 1 - Trabalho/indústria & 746 & 1,4 \\
\hline & 2 - Trabalho/comercio & 2.393 & 4,3 \\
\hline & 3 - Trabalho/serviço & 9.656 & 17,5 \\
\hline & 4 - Escola & 7.702 & 13,9 \\
\hline & 5 - Compras & 2.021 & 3,7 \\
\hline & 6 - Médico/dentista/saúde & 1.475 & 2,7 \\
\hline & 7 - Recreação/visitas/lazer & 2.521 & 4,6 \\
\hline & 8 - Residência & 23.612 & 42,8 \\
\hline & 9 - Procurar emprego & 77 & 0,1 \\
\hline & 10 - Assuntos pessoais & 4.692 & 8,5 \\
\hline \multirow{5}{*}{ Modo principal } & $1-$ motorizado privado & 25.497 & 46,4 \\
\hline & 2 - ônibus & 8.800 & 15,9 \\
\hline & 3 - metrô ou trem & 5.005 & 9,4 \\
\hline & 4 - bicicleta & 292 & 0,5 \\
\hline & $5-$ a pé & 15.307 & 27,8 \\
\hline
\end{tabular}

A árvore foi gerada a partir das variáveis mencionadas e os critérios adotados para parada das divisões foram: mínimo de observações no nó terminal igual a 30 observações.

\subsection{OBTENÇÃO E FILTRO DOS NÓS TERMINAIS}

A AD gerada continha 57 nós, sendo 29 nós terminais e profundidade igual a 5 . O algoritmo identificou as seguintes variáveis como sendo importantes para segmentação da base de dados relativa às viagens: "D: distância", "Ch_s: clusters da hora de saída", "Mo: motivo na origem" e "Md: motivo no destino". A Figura 5.2 ilustra o mapa da árvore gerada para amostra de treinamento onde estão representados os 57 nós, bem como os 29 nós terminais. A Figura 
5.2 (a) representa o ramo esquerdo da árvore, enquanto a Figura 5.2 (b) indica o ramo direito da árvore.

Figura 5.2 - Mapa do Algoritmo CART - Ramo 1 e Ramo 2

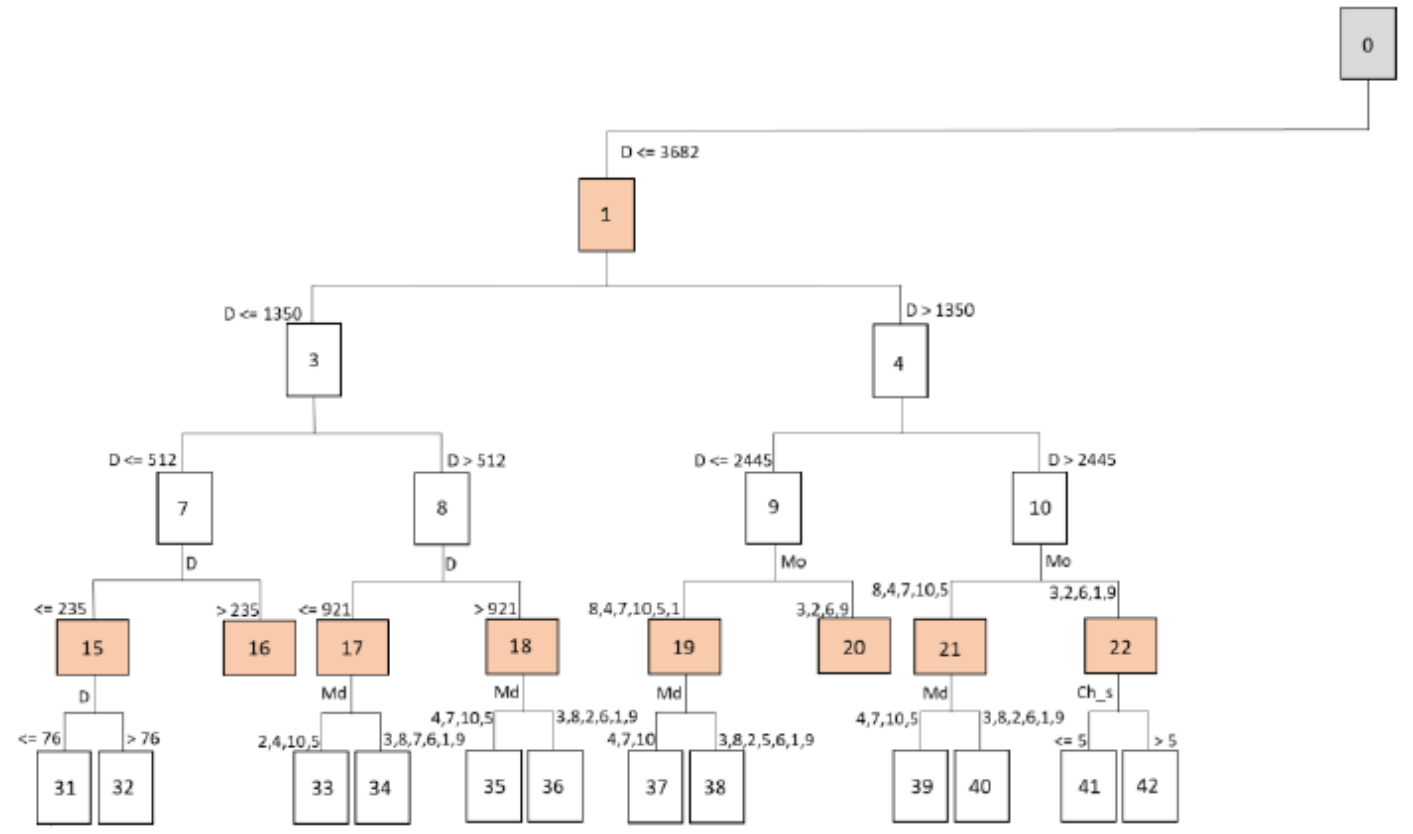

(a) Ramo esquerdo da AD gerada para estimação de tempos de viagens agregados.

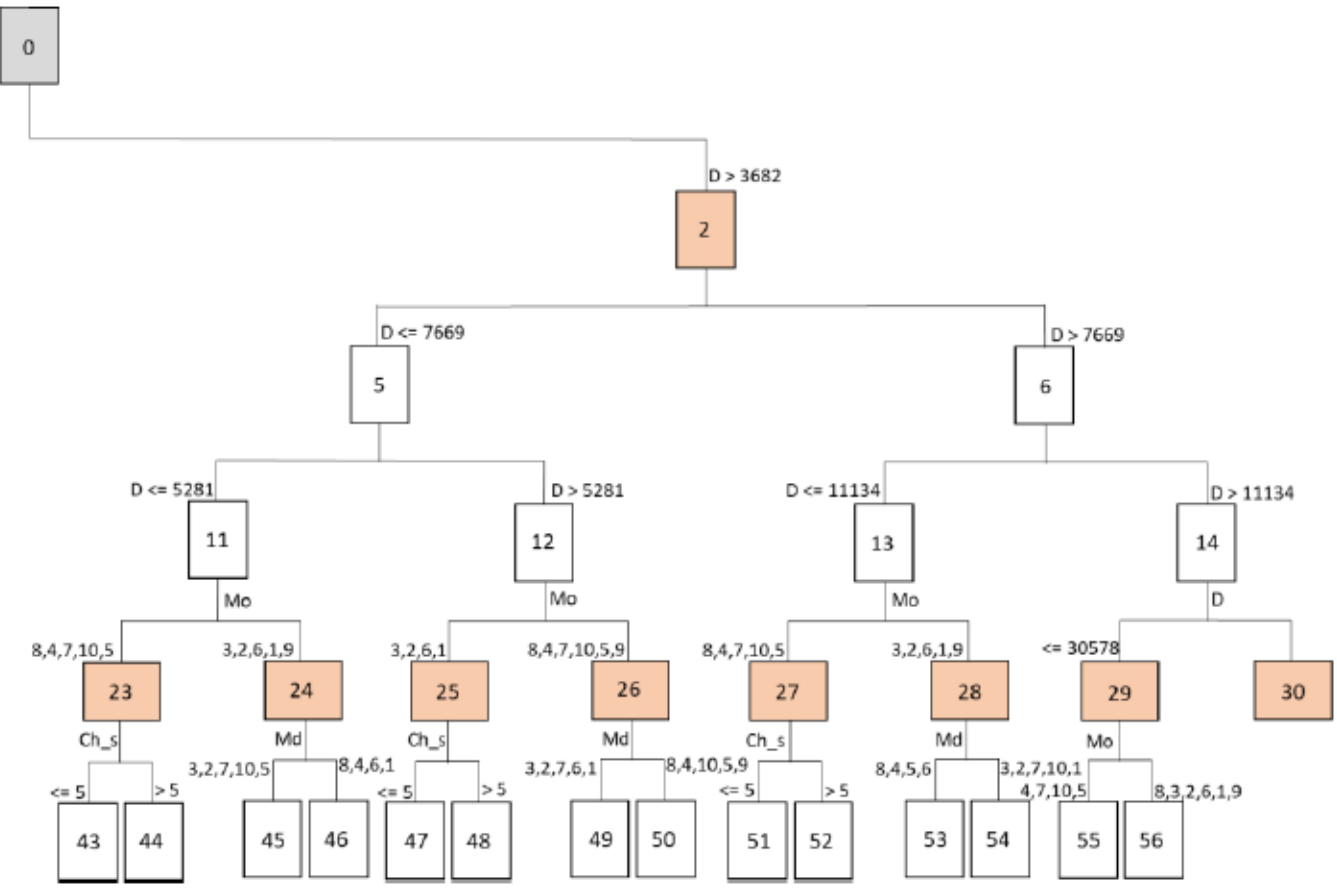

(b) Ramo direito da AD gerada para estimação de tempos de viagens agregados Fonte - Adaptado de Cerveira et al. (2018). 
$\mathrm{D}=$ Distância $(\mathrm{km}) ; \mathrm{Mo}=$ Motivo da viagem na origem; $\mathrm{Md}=$ Motivo da viagem no destino; Ch_s: cluster da hora de saída.

Assim, levando-se em conta os nós terminais obtidos, o banco de dados de viagens foi agrupado em 29 grupos de viagens similares, segundo duração (em minutos). Os tempos estimados correspondem às durações médias das viagens em cada um dos 29 nós terminais obtidos a partir do algoritmo CART. Aos nós terminais estão associados as condições de corte das variáveis independentes (Tabela 5.4).

Os tempos de viagens estimados foram associados aos nós terminais, presentes no quarto e quinto níveis da árvore. A partir dos dados gerados pela árvore, foram feitos filtros (a partir da variável "Modo Principal”) e identificados, em cada nó terminal, os tempos de viagem médios para os 5 modos de viagem (1: Privado Motorizado; 2: Ônibus; 3: Metrô e Trem; 4: Bicicleta; 5: A pé). A Tabela 5.4 também mostra o tempo médio associado a cada modo de transporte, por nó terminal. Vale ressaltar que diferentes validações dos tempos médios de viagens estimados foram propostas em Cerveira et al. (2018). Através deste trabalho, observase que o método alcançou resultados satisfatórios para distâncias de até 12.000 metros. Portanto, para distâncias maiores que este valor de corte, ressalta-se que poderá haver possíveis falhas, sobretudo para o caso dos modos ativos. Verifica-se nos Nós terminais 30, 50, 51, 52, 53, 54, 55 e 56 ressalvas em relação aos tempos estimados para os modos ativos (em vermelho - Modo 4 e Modo 5). Esses tempos, portanto, devem ser desconsiderados na análise posterior (modelagem paramétrica).

Tabela 5.4 - Condições de corte nos nós terminais e tempos de viagens para os 5 modos de transporte.

\begin{tabular}{l|lcccccc}
\hline \multirow{2}{*}{ Nó } & Condições de corte & \multicolumn{5}{c}{ TVM (min.) } \\
\cline { 3 - 7 } & & Modo & Modo & Modo & Modo & Modo \\
& & $\mathbf{1}$ & $\mathbf{2}$ & $\mathbf{3}$ & $\mathbf{4}$ & $\mathbf{5}$ \\
\hline 16 & $235<\mathrm{D}<=512$ & 10,75 & 26,2 & 30,45 & 10,43 & 12,11 \\
\hline 20 & $1350<\mathrm{D}<=2445$ e Mo $=3,2,6,9$ & 23,2 & 40,66 & 35,21 & 20,71 & 30,25 \\
\hline 30 & $\mathrm{D}>30578$ & 22,19 & 47,42 & 48,33 & 22,5 & 21,7 \\
\hline 31 & $\mathrm{D}<=76$ & 16,95 & 36,67 & - & - & 5,67 \\
\hline 32 & $76<\mathrm{D}<=235$ & 10,25 & 24,67 & 10 & 10,5 & 9,1 \\
\hline 33 & $512<\mathrm{D}<=921$ e $\mathrm{Md}=2,4,10,5$ & 11,26 & 21,3 & 32,52 & 14,73 & 15,38 \\
\hline 34 & $512<\mathrm{D}<=921$ e $\mathrm{Md}=3,8,7,6,1,9$ & 13,82 & 26,67 & 32,14 & 11,8 & 17,48 \\
\hline 35 & $\mathrm{D}>921$ e $\mathrm{Md}=4,7,10,5$ & 12,88 & 24,69 & 24,32 & 17,78 & 20,95 \\
\hline 36 & $\mathrm{D}>921$ e $\mathrm{Md}=3,8,2,6,1,9$ & 16,46 & 29,48 & 27,72 & 18,7 & 22,5 \\
\hline 37 & $1350<\mathrm{D}<=2445 ; \quad \mathrm{Mo}=8,4,7,10,5,1 \mathrm{e} \mathrm{Md}=4,7,10$ & 16,94 & 30,28 & 28,77 & 18,47 & 23,87 \\
\hline & & & & & & Continua \\
\hline
\end{tabular}




\begin{tabular}{|c|c|c|c|c|c|c|}
\hline \multicolumn{7}{|c|}{ Conclusão } \\
\hline 38 & $\begin{array}{l}1350<\mathrm{D}<=2445 ; \quad \mathrm{Mo}=8,4,7,10,5,1 \text { e } \mathrm{Md}= \\
3,8,2,5,6,1,9\end{array}$ & 19,2 & 33,11 & 31,66 & 22,62 & 26,84 \\
\hline 39 & $2445<\mathrm{D}<=3682 ; \quad \mathrm{Mo}=8,4,7,10,5$ e $\mathrm{Md}=4,7,10,5$ & 21,98 & 34,89 & 29,93 & 27,86 & 25,01 \\
\hline 40 & $\begin{array}{l}2445<\mathrm{D}<=3682 ; \quad \mathrm{Mo}=8,4,7,10,5 \text { e } \mathrm{Md}= \\
3,8,2,6,1,9\end{array}$ & 24,81 & 39,07 & 34,12 & 29,77 & 25,55 \\
\hline 41 & $2445<\mathrm{D}<=3682 ; \quad$ Mo $=3,2,6,1,9$ e Ch_s $<=5$ & 29,74 & 47,13 & 40,19 & 32 & 34,68 \\
\hline 42 & $2445<\mathrm{D}<=3682 ;$ Mo $=3,2,6,1,9$ e Ch_s $>5$ & 24,03 & 38,39 & 34,4 & 28 & 26,88 \\
\hline 43 & $3682<\mathrm{D}<=5281 ;$ Mo $=8,4,7,10,5$ e Ch_s $<=5$ & 31,81 & 46,18 & 40,2 & 24,75 & 31,16 \\
\hline 44 & $3682<\mathrm{D}<=5281 ;$ Mo $=8,4,7,10,5$ e Ch_s $>5$ & 25,69 & 39,87 & 36,32 & 30 & 30 \\
\hline 45 & $3682<\mathrm{D}<=5281 ; \quad \mathrm{Mo}=3,2,6,1,9$ e $\mathrm{Md}=3,2,7,10,5$ & 33,22 & 45,73 & 40,21 & 30 & 20 \\
\hline 46 & $3682<\mathrm{D}<=5281 ; \quad \mathrm{Mo}=3,2,6,1,9$ e $\mathrm{Md}=8,4,6,1$ & 38,15 & 55,86 & 48,16 & 28 & 44,55 \\
\hline 47 & $5281<\mathrm{D}<=7669 ; \quad$ Mo $=3,2,6,1$ e Ch_s $<=5$ & 46,04 & 69,95 & 56,5 & 41,25 & 17,73 \\
\hline 48 & $5281<\mathrm{D}<=7669 ; \quad$ Mo $=3,2,6,1$ e Ch_s $>5$ & 33,99 & 54 & 44,76 & - & 20 \\
\hline 49 & $\begin{array}{l}5281<\mathrm{D}<=7669 ; \quad \mathrm{Mo}=8,4,7,10,5,9 \text { e } \mathrm{Md}= \\
3,2,7,6,1\end{array}$ & 38,14 & 61,36 & 49,24 & 39 & 12,45 \\
\hline 50 & $\begin{array}{l}5281<\mathrm{D}<=7669 ; \quad \mathrm{Mo}=8,4,7,10,5,9 \text { e } \mathrm{Md}= \\
8,4,10,5,9\end{array}$ & 34,81 & 53,05 & 47,14 & 60 & 13,28 \\
\hline 51 & $7669<\mathrm{D}<=11134 ;$ Mo $=8,4,7,10,5$ e Ch_s $<=5$ & 45,36 & 68,49 & 58,19 & - & 21 \\
\hline 52 & $7669<\mathrm{D}<=11134 ;$ Mo $=8,4,7,10,5$ e Ch_s $>5$ & 33,53 & 65,4 & 57,07 & 30 & 15 \\
\hline 53 & $7669<\mathrm{D}<=11134 ; \quad$ Mo $=3,2,6,1,9$ e $\mathrm{Md}=8,4,5,6$ & 53,71 & 80,66 & 67,77 & 45 & 29,55 \\
\hline 54 & $7669<\mathrm{D}<=11134 ; \quad \mathrm{Mo}=3,2,6,1,9$ e $\mathrm{Md}=3,2,7,10,1$ & 46,01 & 69,4 & 57,93 & - & 10,5 \\
\hline 55 & $11134<\mathrm{D}<=30578$ e $\mathrm{Mo}=4,7,10,5$ & 44,75 & 77,16 & 77,21 & - & 23,73 \\
\hline 56 & $11134<\mathrm{D}<=30578$ e $\mathrm{Mo}=8,3,2,6,1,9$ & 56,03 & 93,03 & 82,22 & - & 19,59 \\
\hline
\end{tabular}

TVM: Tempo de Viagem Médio; D: distância (metros); Mo: motivo na origem (1, 2, 3 - Trabalho na indústria, comércio e serviço, respectivamente; 4 - Escola; 5 - Compras; 6 - Saúde, 7 - Lazer; 8 Residência; 9 - Procurar emprego; 10 - Assuntos pessoais); Md: motivo no destino; Ch_s: cluster hora de saída (1: 6 às 9h; 2: 9 às 12h; 3: 12 às 14h; 4: 14 às 16h; 5: 16 às 20h; 6: 20 às 6h); Modo 1; Modo 2; Modo 3; Modo 4; Modo 5.

Fonte - Adaptado de Cerveira et al. (2018).

\subsection{VALIDAÇÃO: CÁLCULO DE MÉTRICAS DE ERROS}

Foi realizada uma validação do método comparando os tempos de viagem estimados (pelo modo realmente utilizado) com os valores das durações de viagens efetivamente realizadas pelo entrevistado. Como mencionado no Capítulo 4, para efeitos de validação, foram utilizados dados (estimados e observados) referentes aos tempos de viagens dos modos associados às viagens efetivamente realizadas. A amostra foi dividia aleatoriamente e foram obtidas as amostras de treinamento (70\%) e teste (30\%). Foram então calculadas as medidas de erros com a amostra de teste: erro médio quadrático (Equação 5.1), raiz do erro médio 
quadrático (Equação 5.2), erro médio absoluto (Equação 5.3) e correlação de Pearson (Equação $5.4)$.

$$
\begin{aligned}
& \frac{1}{N} \sum\left(x_{i}-y_{i}\right)^{2} \\
& \sqrt{\frac{1 \sum\left(x_{i}-y_{i}\right)^{2}}{N}}
\end{aligned}
$$$$
\frac{1}{N-1} \cdot \sum \frac{\left(x_{i}-\bar{x}\right)\left(y_{i}-\bar{y}\right)}{\sigma_{x} \sigma_{y}}
$$

$$
\frac{\sum\left(x_{i}-\bar{x}\right)\left(y_{i}-\bar{y}\right)}{\sqrt{\left(\sum\left(x_{i}-\bar{x}\right)^{2}\right)\left(\sum\left(y_{i}-\bar{y}\right)^{2}\right)}}
$$

Sendo que, $x_{i}$ é a medida estimada; $y_{i}$ é a medida observada; $N$ é o número de medidas, $\overline{\mathrm{x}}$ e $\overline{\mathrm{y}}$ são as médias das amostras; $\sigma_{x}$ e $\sigma_{y}$ são os desvios-padrão da amostra.

Chegou-se aos seguintes valores: 378,677 para o Erro Médio Quadrático, 19,46 para a Raiz do Erro Médio Quadrático, -0,065 para Erro Médio Absoluto e o Correlação de Pearson foi 0,638 . O procedimento para caracterização agregada das alternativas foi testado com base na abordagem proposta por Souza et al. (2017). 


\title{
Capítulo
}

\section{RESULTADOS E DISCUSSÕES:}

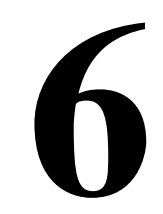

\author{
CLASSIFICAÇÃO DOS INDIVÍDUOS \\ SEGUNDO PADRÕES DE VIAGENS \\ ENCADEADAS
}

Este capítulo apresenta os resultados dos agrupamentos dos indivíduos segundo padrões de viagens encadeadas similares. Os resultados, aqui apresentados, estão associados ao objetivo específico 1 e representam as variáveis dependentes (conjunto de alternativas) a serem utilizadas na análise paramétrica, realizada posteriormente, tanto para a amostra composta por estudantes quanto para aquela composta por trabalhadores.

\subsection{CLASSIFICAÇÃO DOS INDIVÍDUOS SEGUNDO PADRÕES DE VIAGENS ENCADEADAS SIMILARES}

A classificação dos indivíduos corresponde à identificação e agrupamento dos indivíduos que apresentam comportamentos semelhantes relativos aos deslocamentos (padrões de viagens encadeadas semelhantes).

Os agrupamentos foram obtidos com a utilização da variável categórica "padrão de viagens" definida a partir das variáveis categóricas: (1) sequência de motivos de viagem e (2) sequência de modos de transporte. Para isso utilizou-se o algoritmo Two-step Cluster, com medida de similaridade correspondente ao Logaritmo da Verossimilhança.

A amostra foi dividida entre trabalhadores (4.952) e estudantes (163). Em seguida, várias tentativas de agrupamento foram consideradas, segundo padrões de viagens encadeadas, representados pela sequência de motivos e modos de transporte. Em cada tentativa, foram testados diferentes números finais de grupos para ambas as amostras. O Apêndice A apresenta exemplos de agrupamentos realizados, para amostra de trabalhadores, para o número final de clusters equivalentes a 20 e 30 grupos.

Utilizando o algoritmo, foram definidos 7 clusters na amostra de estudantes e 15 clusters na amostra de trabalhadores. Após análise dos clusters da amostra de estudantes, optou-se por unir os clusters compostos por padrões que representavam 3 e 4 viagens. Desta forma, ao final das análises, a amostra de estudante foi representada por 5 clusters. No caso da amostra de trabalhadores, também foi feito uma redistribuição dos clusters com 3 e 4 viagens a fim de garantir uma maior uniformidade dos grupos. 
Do total de indivíduos da amostra de estudantes $83 \%$ realizam apenas duas viagens por dia típico e os outros $17 \%$ realizam três e quatro viagens. Na amostra de trabalhadores observase que $68 \%$ dos indivíduos realizam duas viagens, $11 \%$ realizam três viagens e $21 \%$ dos entrevistados realizam 4 viagens. A Figura 6.1 ilustra sucintamente o procedimento utilizado para classificação dos indivíduos.

Figura 6.1 - Esquema ilustrativo do procedimento para classificação dos indivíduos.

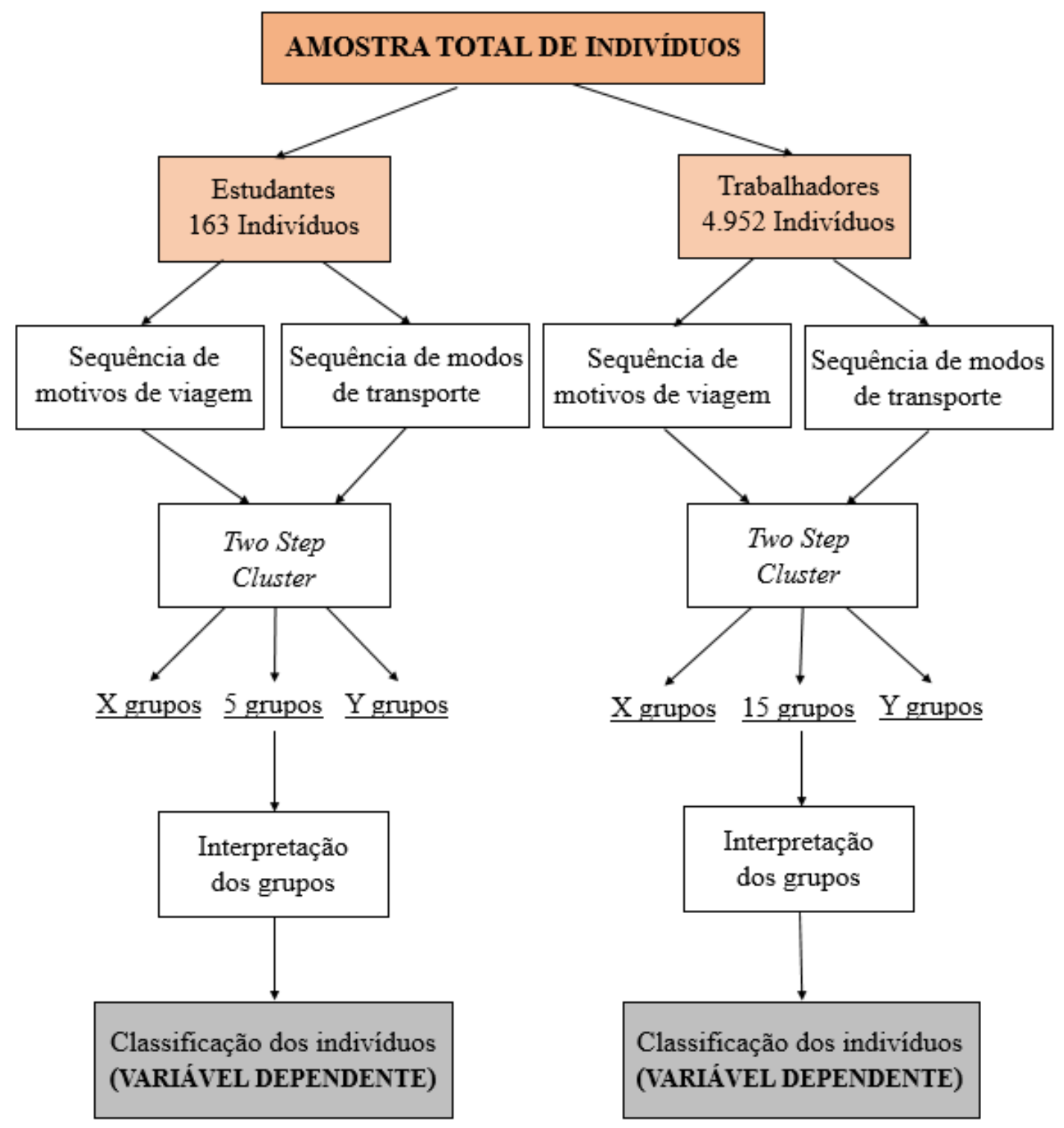

A Tabela 6.1 apresenta os clusters da amostra de estudantes, descrevendo os padrões de viagem predominantes em cada um dos grupos. 
Tabela 6.1 - Descrição dos clusters dos estudantes com padrões de viagens encadeadas similares.

\begin{tabular}{|c|c|c|c|c|c|}
\hline Cluster & Descrição & $\begin{array}{c}\mathrm{N}^{\mathbf{o}} \mathrm{de} \\
\text { viagens }\end{array}$ & Padrão & $\begin{array}{c}\mathrm{N}^{\circ} \text { de } \\
\text { registros }\end{array}$ & $\%$ \\
\hline 1 & $\begin{array}{l}\text { Vai para a escola e volta para casa. Usa o modo } \\
\text { público. }\end{array}$ & 2 & $\mathrm{SH} 22 *$ & 54 & $33 \%$ \\
\hline 2 & $\begin{array}{l}\text { Outras atividades. Usa o mesmo modo para fazer as } \\
\text { viagens }\end{array}$ & 2 & $\begin{array}{l}\text { AH11 } \\
\text { AH22 } \\
\text { AH33 }\end{array}$ & 9 & $6 \%$ \\
\hline 3 & $\begin{array}{l}\text { Viagem à escola encadeada com outras atividades. } \\
\text { Usa várias combinações dos modos }\end{array}$ & 3 e 4 & $\begin{array}{c}\text { SHAH1221 } \\
\text { ASH223 } \\
\text { SHSH3333 }\end{array}$ & 28 & $17 \%$ \\
\hline 4 & $\begin{array}{l}\text { Vai para a escola e volta para casa. Usa o modo } \\
\text { privado motorizado. }\end{array}$ & 2 & SH11* & 18 & $11 \%$ \\
\hline 5 & $\begin{array}{l}\text { Vai para a escola e volta para casa. Usa o modo não } \\
\text { motorizado. }\end{array}$ & 2 & SH33* & 54 & $33 \%$ \\
\hline & & & & 163 & $100 \%$ \\
\hline
\end{tabular}

*somente um padrão de viagem

$\mathrm{Na}$ amostra de estudantes, entre aqueles que realizam duas viagens (ida e volta da escola) que são os clusters 1, 4 e 5 existe uma distribuição entre os modos utilizados, sendo que $33 \%$ dos estudantes utilizam o modo público, $11 \%$ o modo motorizado privado e $33 \%$ o modo não motorizado (bicicleta e a pé) para realizarem as duas viagens. No cluster 3 estão agrupados os indivíduos que realizam três e quatro viagens, e que podem ser classificados como multimodais considerando que nesse grupo existem várias combinações dos modos disponíveis na área de estudo (na Tabela 6.1 estão indicados 3 exemplos dessas combinações). Em seguida, a Tabela 6.2 descreve os clusters da amostra de trabalhadores. 
Tabela 6.2 - Descrição dos clusters dos trabalhadores com padrões de viagens encadeadas similares.

\begin{tabular}{|c|c|c|c|c|c|}
\hline Cluster & Descrição & $\begin{array}{l}\mathrm{N}^{0} \text { de } \\
\text { viagens }\end{array}$ & Padrão & $\begin{array}{c}\mathrm{N}^{\circ} \text { de } \\
\text { registros }\end{array}$ & $\%$ \\
\hline 1 & Vai para o trabalho e volta para casa. Usa o modo público. & 2 & WH22* & 939 & $19 \%$ \\
\hline 2 & $\begin{array}{l}\text { Vai para o trabalho e volta para casa. Predominantemente } \\
\text { utilizam o modo não motorizado }\end{array}$ & 2 & $\begin{array}{l}\text { WH23 } \\
\text { WH13 } \\
\text { WH33 }\end{array}$ & 706 & $14 \%$ \\
\hline 3 & $\begin{array}{l}\text { Outras atividades ou escola. Predominantemente utiliza o } \\
\text { mesmo modo para fazer as duas viagens }\end{array}$ & 2 & $\begin{array}{l}\text { AH11 } \\
\text { AH33 } \\
\text { SH22 }\end{array}$ & 437 & $9 \%$ \\
\hline 4 & $\begin{array}{l}\text { Outras atividades encadeadas com trabalho. } \\
\text { Predominantemente utiliza o mesmo modo para fazer todas } \\
\text { as viagens }\end{array}$ & 3 & $\begin{array}{l}\text { WAH111 } \\
\text { AWH222 } \\
\text { AWH333 }\end{array}$ & 203 & $4 \%$ \\
\hline 5 & $\begin{array}{l}\text { Tem dois trabalhos. Predominantemente utiliza o modo } \\
\text { motorizado para fazer as viagens. }\end{array}$ & 3 & $\begin{array}{l}\text { WWH222 } \\
\text { WWH111 } \\
\text { WWH221 }\end{array}$ & 127 & $3 \%$ \\
\hline 6 & $\begin{array}{l}\text { Vai para o trabalho e volta para casa. Usa o modo privado } \\
\text { motorizado. }\end{array}$ & 2 & $\mathrm{WH} 11^{*}$ & 1.297 & $26 \%$ \\
\hline 7 & $\begin{array}{l}\text { Outras atividades, trabalho e escola encadeadas. } \\
\text { Predominantemente utiliza o mesmo modo para fazer todas } \\
\text { as viagens. }\end{array}$ & 3 & $\begin{array}{l}\text { SWH111 } \\
\text { WSH222 } \\
\text { SAH111 }\end{array}$ & 172 & $3 \%$ \\
\hline 8 & $\begin{array}{l}\text { Outras atividades. Predominantemente utiliza o modo } \\
\text { motorizado }\end{array}$ & 3 & $\begin{array}{l}\text { AAH111 } \\
\text { AAH222 } \\
\text { AAH333 }\end{array}$ & 62 & $1 \%$ \\
\hline 9 & $\begin{array}{l}\text { Trabalho intercalado com residência. Utiliza o modo } \\
\text { privado motorizado para realizar as quatro viagens. }\end{array}$ & 4 & WHWH1111* & 83 & $2 \%$ \\
\hline 10 & $\begin{array}{l}\text { Trabalho intercalado com residência. Utiliza o modo não } \\
\text { motorizado para realizar as quatro viagens. }\end{array}$ & 4 & WHWH3333* & 89 & $2 \%$ \\
\hline 11 & $\begin{array}{l}\text { Outras atividades, escola e trabalho sempre intercaladas } \\
\text { com residência. Utiliza o mesmo modo motorizado para } \\
\text { realizar as quatro viagens. }\end{array}$ & 4 & $\begin{array}{l}\text { WHAH1111 } \\
\text { AHWH2222 } \\
\text { WHSH1111 }\end{array}$ & 211 & $4 \%$ \\
\hline 12 & $\begin{array}{l}\text { Outras atividades, escola e trabalho sempre intercaladas } \\
\text { com residência. Utiliza o modo não motorizado para realizar } \\
\text { as quatro viagens. }\end{array}$ & 4 & $\begin{array}{l}\text { SHSH3333 } \\
\text { SHWH3333 } \\
\text { WHAH3333 }\end{array}$ & 65 & $1 \%$ \\
\hline 13 & $\begin{array}{l}\text { Outras atividades, escola e trabalho sempre intercaladas } \\
\text { com residência. Predominantemente utiliza o modo } \\
\text { motorizado para realizar as quatro viagens. }\end{array}$ & 4 & $\begin{array}{l}\text { WHAH2211 } \\
\text { WHWH1122 } \\
\text { WHAH3111 }\end{array}$ & 198 & $4 \%$ \\
\hline
\end{tabular}




\begin{tabular}{|c|c|c|c|c|c|}
\hline \multicolumn{6}{|c|}{ Conclusão } \\
\hline Cluster & Descrição & $\begin{array}{l}\mathbf{N}^{\mathbf{0}} \text { de } \\
\text { viagens }\end{array}$ & Padrão & $\begin{array}{l}\mathrm{N}^{\circ} \text { de } \\
\text { registros }\end{array}$ & $\%$ \\
\hline 14 & $\begin{array}{l}\text { Outras atividades, escola e trabalho encadeadas. Utiliza o } \\
\text { mesmo modo para realizar as quatro viagens. }\end{array}$ & 4 & $\begin{array}{l}\text { WAWH3333 } \\
\text { WWAH1111 } \\
\text { WAWH2222 }\end{array}$ & 203 & $5 \%$ \\
\hline 15 & $\begin{array}{l}\text { Outras atividades, escola e trabalho encadeadas. } \\
\text { Predominantemente utiliza o modo não motorizado. }\end{array}$ & 4 & $\begin{array}{l}\text { WAWH1331 } \\
\text { AAAH3331 } \\
\text { WAAH2333 }\end{array}$ & 160 & $3 \%$ \\
\hline & & & & 4.952 & $100 \%$ \\
\hline
\end{tabular}

*somente um padrão de viagem

Entre os indivíduos que realizam duas viagens diárias (clusters 1, 2, 3 e 6), é possível observar predominância do padrão Residência - Trabalho - Residência -WH (clusters 1, 2, e 6), existindo uma variação entre os modos utilizados, sendo o modo privado motorizado o mais frequente (26\% dos indivíduos realizam o Padrão "WH11"). Apesar de se tratar de uma amostra de trabalhadores, o cluster 3 apresenta os indivíduos com motivo de viagem associado à escola ou outras atividades (AH ou SH), com predominância do uso do modo privado motorizado para realização de tais viagens.

Já entre os indivíduos que realizam três viagens (clusters 4, 5, 7 e 8), identificou-se aqueles que encadeiam viagens com motivo trabalho e outras atividades (WA ou AW) e não trocam o modo de transporte (cluster 4). O cluster 5 caracteriza indivíduos que fazem duas viagens consecutivas ao trabalho, sendo que $27 \%$ dos indivíduos deste grupo possuem dois trabalhos diferentes. O cluster 7 provavelmente representa os trabalhadores que também exercem atividades de estudo, já que é formado por indivíduos que encadeiam viagens do trabalho à escola (SWH ou WSH). Finalmente, o cluster 8, apesar de ser composto por trabalhadores, representa indivíduos que encadeiam viagens consecutivas para realização de atividades diferentes do trabalho (AAH). Este grupo é formado por $40 \%$ de autônomos.

Os clusters $9,10,11,12,13,14$ e 15 são compostos por pessoas que realizam 4 viagens. Os clusters 9 e 10 representam os indivíduos que realizam o padrão de viagens associados ao trabalho e à residência, intercalando ambas as atividades (WHWH). Possivelmente, esses indivíduos retornam à residência para almoço. Há apenas variação entre o modo de transporte utilizado entre esses dois grupos. O cluster 10 é formado pelos que utilizam os modos não motorizados e devem residir próximo ao local de trabalho. Os clusters 11, 12 e 13 são 
compostos por indivíduos que fazem as atividades escola e trabalho intercalados com o motivo residência (WHAH, SHWH, AHWH, por exemplo). A variação maior entre os três grupos mencionados está na sequência dos modos de transporte. Nestes clusters, 17\% dos indivíduos estudam e 39\% são assalariados com carteira de trabalho. Finalmente, os clusters 14 e 15, são formados por pessoas que fazem 4 viagens diárias com motivos "outras atividades" e "escola", com retorno final à residência. O cluster 14 é formado por indivíduos que utilizam o mesmo modo para realizar as 4 viagens. Já os indivíduos que caracterizam o cluster 15, utilizam, em diferentes combinações, predominantemente o modo não motorizado.

\subsection{DISCUSSÕES ASSOCIADAS À LITERATURA VIGENTE}

Muitos trabalhos têm sido realizados na tentativa de agrupar viagens encadeadas similares, considerando comportamentos associados a trabalhadores e não trabalhadores. Daisy et al. (2018a) exploraram uma amostra composta por trabalhadores, com homogêneos padrões de atividades, no intuito de explorar diferenças e similaridades em relação à frequência do tour, encadeamento de viagens e a sequência de escolhas modais. Os padrões de atividades foram definidos, neste trabalho, como a quantidade de horas dedicadas a atividades associadas ao trabalho, fora do domicílio. Os autores utilizaram o fuzzy c-means clustering algoritmo para realização dos agrupamentos e algoritmo CART (Classification And Regression Tree), de forma complementar, para caracterização dos grupos e suas características sociodemográficas. Foram encontrados cinco grupos de trabalhadores: (1) Trabalhadores "prolongados" (trabalham até 10 horas por dia -8 às 20h); (2) Trabalhadores "menos prolongados" (trabalham até 6 horas por dia - 8 às 16h); (3) Trabalhadores "períodos alternativos e curtos" (trabalham menos do que 5 horas por dia); (4) Trabalhadores em períodos mais cedo (trabalham no período das 7 às 15h) e (5) Realizam as viagens ao trabalho nos períodos de pico (trabalham no período das 9 às 17h). A associação dos grupos e o comportamento relativo a viagens é feita, posteriormente, através de regressão de Poisson (para estimar o número de tours diários, baseados no domicílio). O encadeamento de viagens é modelado através do modelo Probit, enquanto a sequência de modos de transporte é estimada por modelo Logit Multinomial. Destaca-se como principal diferença, associada ao presente trabalho, o tipo de variável considerada para clusterização. No trabalho atual, foram agrupados os encadeamentos segundo sequência de modos e motivos de viagem, ou seja, o agrupamento caracterizava padrões de viagens similares enquanto que no trabalho de Daisy et al. (2018a) foram agrupados trabalhadores homogêneos segundo atividades de trabalho (e sua duração), realizadas fora do domicílio. Assim, o 
agrupamento aqui proposto torna-se mais complexo, considerando a diversidade de viagens encadeadas a serem agrupadas na amostra.

Em seguida, Daisy et al. (2018b) propuseram uma abordagem baseada em agrupamentos para modelar a complexidade do encadeamento de viagens e sequência de escolhas modais para uma amostra composta por não trabalhadores. Cinco grupos foram formados com base nos padrões de atividades diárias (dentro e fora do domicílio) e no uso do tempo, a partir do uso do fuzzy cmeans clustering algoritmo: (1) Cluster 1 é o grupo com atividades no meio-dia. Os indivíduos pertencentes a esse cluster participam de atividades predominantemente no meio-dia; (2) Cluster 2 é o grupo de atividades noturnas. Esses não trabalhadores que participam de atividades fora de casa, principalmente à noite; (3) Cluster 3 são indivíduos com um padrão de atividades realizadas no domicílio; (4) Cluster 4 é o grupo composto por indivíduos com atividades matinais e (5) Cluster 5 compreende indivíduos que realizam atividades de compras e serviços à tarde. Fazendo um paralelo com o presente trabalho, a amostra de não trabalhadores, aqui estudada, corresponde à amostra de estudantes. Além disso, o agrupamento proposto, na presente pesquisa, relaciona-se aos encadeamentos com base na sequência de motivos (a maior parte voltados para estudo) e modos de transporte. Além disso, o presente trabalho não considera as atividades realizadas no domicílio, principalmente porque a base de dados é proveniente de uma pesquisa OD e não de um diário de atividades.

Millward et al. (2019) agruparam indivíduos com similares perfis de uso do tempo diário, considerando dois dias e incluindo atividades, realizadas no domicílio e fora do domicílio. Assim como os autores mencionados anteriormente, este trabalho também utilizou o fuzzy cmeans clustering algoritmo. Foram obtidos 12 clusters, homogêneos segundo padrões de atividades (uso do tempo diário). Seis grupos foram caracterizados por atividades fora do domicílio, associadas ao trabalho. Cinco grupos associados a não trabalhadores e um grupo associado a estudantes. O diário de atividades mostrou variações importantes, relativas à sequência de motivos e complexidade dos "tours". De forma geral, indivíduos não trabalhadores, realizam um maior número de tours, no entanto, menos complexos. Em relação ao presente trabalho, houve diferenças relativas à variável e algoritmo utilizados para agrupamento. Também se destaca a diferença associada à base de dados, já que não havia um diário de atividades disponível para a região de estudo (Região Metropolitana de São Paulo).

Manoj e Verma (2015) apresentaram uma análise exploratória do padrão de atividades/viagens de uma amostra de não trabalhadores na cidade de Bangalore (Índia). Os autores caracterizaram 
fatores sociodemográficos, associados aos comportamentos de atividades/viagens com base em um diário de atividades. Os comportamentos relativos a viagens foram separados conforme a renda familiar (variável utilizada para agrupamento). Assim, foram analisados os episódios de atividades (ou paradas), relacionados à frequência da atividade, divisão modal e distância da viagem, padrão de atividade diária, hora do dia da viagem e dia preferencial, com as respectivas alocações de tempo para as diferentes atividades. Fazendo comparações considerando os resultados obtidos nesta tese de doutorado, a variável utilizada para agrupamento foi muito mais complexa ("tours" segundo motivo e modos de transporte), enquanto que no mencionado trabalho, o agrupamento considerou faixas de renda dos indivíduos. Além disso, ressalta-se as restrições de realização da abordagem de viagens derivadas de atividades com base numa pesquisa OD e não em um diário de atividades, como encontrado em diversos trabalhos da literatura.

O trabalho de Bricka (2008) também baseou o agrupamento dos indivíduos, considerando características socioeconômicas. A autora identificou a ligação entre as responsabilidades domésticas e o encadeamento de viagens e optou pela formação de grupos de indivíduos trabalhadores, com e sem filhos e de indivíduos não trabalhadores, com e sem filhos.

Cirillo e Axhausen (2001) estudaram o comportamento de indivíduos trabalhadores e não trabalhadores utilizando dados obtidos através de diário de atividades de vários dias (dados em painel). Os grupos de trabalhadores foram formados a partir da atividade "trabalho" e a divisão dos grupos de não trabalhadores considerou-se a atividade principal (com maior duração).

Em relação ao presente trabalho, pode-se observar que os trabalhos mais recentes utilizaram dados coletados utilizando dispositivos de rastreamento GPS (DAISY et al., 2018a; DAISY et al., 2018b; MILLWARD et al., 2019) ou diários de atividades preenchidos (CIRILLO; AXHAUSEN, 2001). Além disso, utilizaram como fator de divisão da amostra ou variável de agrupamento, o padrão de atividades (dentro e fora do domicílio), a sua duração, ou características sociodemográficas (CIRILLO; AXHAUSEN, 2001; DAISY et al., 2018a; DAISY et al., 2018b; MILLWARD et al., 2019).

O Quadro resumo 6.1 apresenta a síntese dos estudos aqui descritos, voltada para a etapa de formação dos clusters. Também são destacadas, no quadro, similaridades e diferenças associadas ao presente estudo. 
Quadro 6.1 - Síntese de resultados da literatura, associadas ao presente estudo.

Trabalhos (citações)
Similaridades ou diferenças relativas ao presente trabalho Daisy et al. (2018a)

Daisy et al. (2018b)
Neste trabalho foram definidos 5 grupos a partir de padrões homogêneos de uso do tempo dedicado a atividades de trabalho, fora do domicílio. Sendo eles:

Cluster 1 - Trabalhadores "prolongados" (trabalham até 10 horas por dia -8 às $20 \mathrm{~h}$ );

$\underline{\text { Cluster } 2}$ - Trabalhadores "menos prolongados" (trabalham até 6 horas por dia -8 às $16 h$ );

Cluster 3 - Trabalhadores "períodos alternativos e curtos" (trabalham menos do que 5 horas por dia);

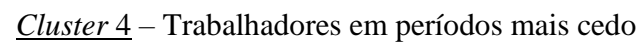
(trabalham no período das 7 às $15 \mathrm{~h}$ );

Cluster 5 - Realizam as viagens ao trabalho nos períodos de pico (trabalham no período das 9 às $17 \mathrm{~h}$ )

Com base nos padrões de atividades diárias (dentro e fora do domicílio) e no uso do tempo esse estudo identificou cinco grupos de não trabalhadores.

Cluster 1 é o grupo com atividades no meio-dia. Os indivíduos pertencentes a esse cluster participam de atividades predominantemente no meio-dia.

Cluster 2 é o grupo de atividades noturnas. Esses não trabalhadores participam de atividades fora de casa, principalmente à noite.

Cluster 3 são indivíduos com um padrão de atividades realizadas no domicílio.

Cluster 4 é o grupo composto por indivíduos com atividades matinais.

Cluster 5 compreende indivíduos que realizam atividades de compras e serviços à tarde.
1. Tipo de variável considerada para agrupamento;

2. Tipo de algoritmo de agrupamento utilizado;

3. Agrupamento do presente trabalho baseado no encadeamento de viagens e não nas atividades e sua duração;

4. Banco de dados proveniente de Pesquisa OD e não diário de atividades

1. A amostra de não trabalhadores, aqui estudada, corresponde à amostra de estudantes;

2. O agrupamento proposto, na presente pesquisa, relaciona-se aos tours com base na sequência de motivos (a maior parte voltados para estudo) e modos de transporte;

3. O algoritmo para agrupamento também é diferente do trabalho mencionado;

4. No presente trabalho não foram analisadas atividades realizadas dentro do domicílio;

5. Banco de dados proveniente de Pesquisa OD e não diário de atividades. 
Millward et al. (2019)

Foram identificados 12 grupos com padrões de atividade homogêneos, sendo 6. clusters caracterizados como trabalhadores fora de casa, 5 como não trabalhadores e um como estudantes.

Grupo 1: Trabalhadores com atividades laborais entre às 7:00 e 15:00h.

Grupo 2: Trabalhadores com atividades laborais entre às 8:00 e 16:00h.

Grupo 3: Trabalhadores que trabalham entre às $9 \mathrm{~h} 00$ e $17 \mathrm{~h} 00 \mathrm{~h}$

Grupo 4: Trabalhadores com jornada de trabalho prolongada, das 08:00 às 20:00h.

Grupo 5: Trabalhadores com jornada de trabalho mais curta, normalmente trabalham menos de 5 horas por dia, e que terminam seu trabalho no início da tarde, antes das 14:00h.

Grupo 6: Trabalhadores noturnos que têm turnos de trabalho ao final da tarde ou à noite, começando por volta 16:00h e terminando por volta da meia-noite.

Grupo 7: Este grupo é formado por alunos que frequentam a escola ou faculdade das 08:30 às 15:00h.

Grupo 8: Grupo de não trabalhadores envolvidos nas tarefas domésticas com atividades de compras entre às 09:30 e 12:00h.

Grupo 9: Não trabalhador, com atividades organizacionais ou de entretenimento no meio-dia, das 10:00 às 17:00h.

Grupo 10: Não trabalhador, com atividades de compras à tarde.

Grupo 11: Não Trabalhador, com atividades organizacionais ou de entretenimento, principalmente à noite, a partir das 18:00h até por volta das 22:00h

Grupo 12: Não trabalhador, passam o dia em casa
1. Variável utilizada para agrupamento;

2. Algoritmo considerado;

3. Banco de dados. 
presente tese que se baseou em uma pesquisa OD.

Bricka (2008)
Analisa os fatores que influenciam o encadeamento de viagens de adultos em idade produtiva trabalhadores e não trabalhadores. Os grupos foram divididos em:

Trabalhador com filhos

Trabalhador sem filhos

Não trabalhador com filhos

Não trabalhador sem filhos
1. Variável utilizada para agrupamento associada à ocupação (Trabalhador e não trabalhador) e à composição domiciliar (com filhos e sem filhos).

2. No presente trabalho o agrupamento foi realizado considerando o comportamento relativo a viagens encadeadas. (2001)

Cirillo e Axhausen
Os autores estudaram o comportamento de indivíduos trabalhadores e não trabalhadores.

Definiram 4 padrões de atividades diárias para o grupo de trabalhadores:

1. Padrão da manhã representa as atividades e viagens realizadas antes de sair de casa para trabalhar pela manhã.

2. Padrão de deslocamento (trabalho) representa as atividades e viagens realizadas durante os períodos da manhã e da noite.

3. O padrão do meio-dia inclui todas as atividades e viagens realizadas a partir do trabalho, normalmente durante o intervalo do meio-dia.

4. Finalmente, o padrão noturno compreende as atividades e viagens dos indivíduos após seu retorno do trabalho para casa

Para a divisão do grupo de Não trabalhadores considerou-se a atividade principal (com maior duração). Foram classificados em 3 grupos.

1. O padrão da manhã representa as atividades e viagens realizadas antes de sair de casa para realizar a atividade principal do dia.

2. O principal padrão de atividade representa a atividade principal do dia e as demais atividades realizadas dentro do passeio principal.

3. O padrão (tarde e noite) compreende as atividades e viagens de indivíduos após o retorno da atividade principal.
1. Variável utilizada para agrupamento;

2. Banco de dados referente a diários de atividades. 


\section{Capitulo}

RESULTADOS E DISCUSSÕES:

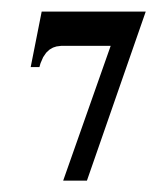

\section{ANÁLISE DO COMPORTAMENTO ASSOCIADO A VIAGENS ENCADEADAS}

Neste capítulo serão apresentados, inicialmente, os resultados associados ao objetivo específico 3 deste trabalho. Desta forma, são descritos os resultados da redução de parâmetros proposta para o modelo Logit Multinomial. Em seguida, são feitas reflexões considerando o objetivo específico 4 (investigar o aprimoramento das estimativas a partir da inclusão de variáveis agregadas de viagens).

Este capítulo apresenta os resultados da modelagem paramétrica relativa aos grupos de indivíduos com viagens encadeadas similares. A Figura 7.1 sintetiza todas as etapas importantes, incluindo aquelas relativas à redução de parâmetros a serem incluídos na modelagem. Os resultados encontrados nas etapas ilustradas são descritos nas subseções subsequentes.

Figura 7.1 - Ilustração das etapas relativas à redução de parâmetros e composição das funções utilidade e modelagem paramétrica.

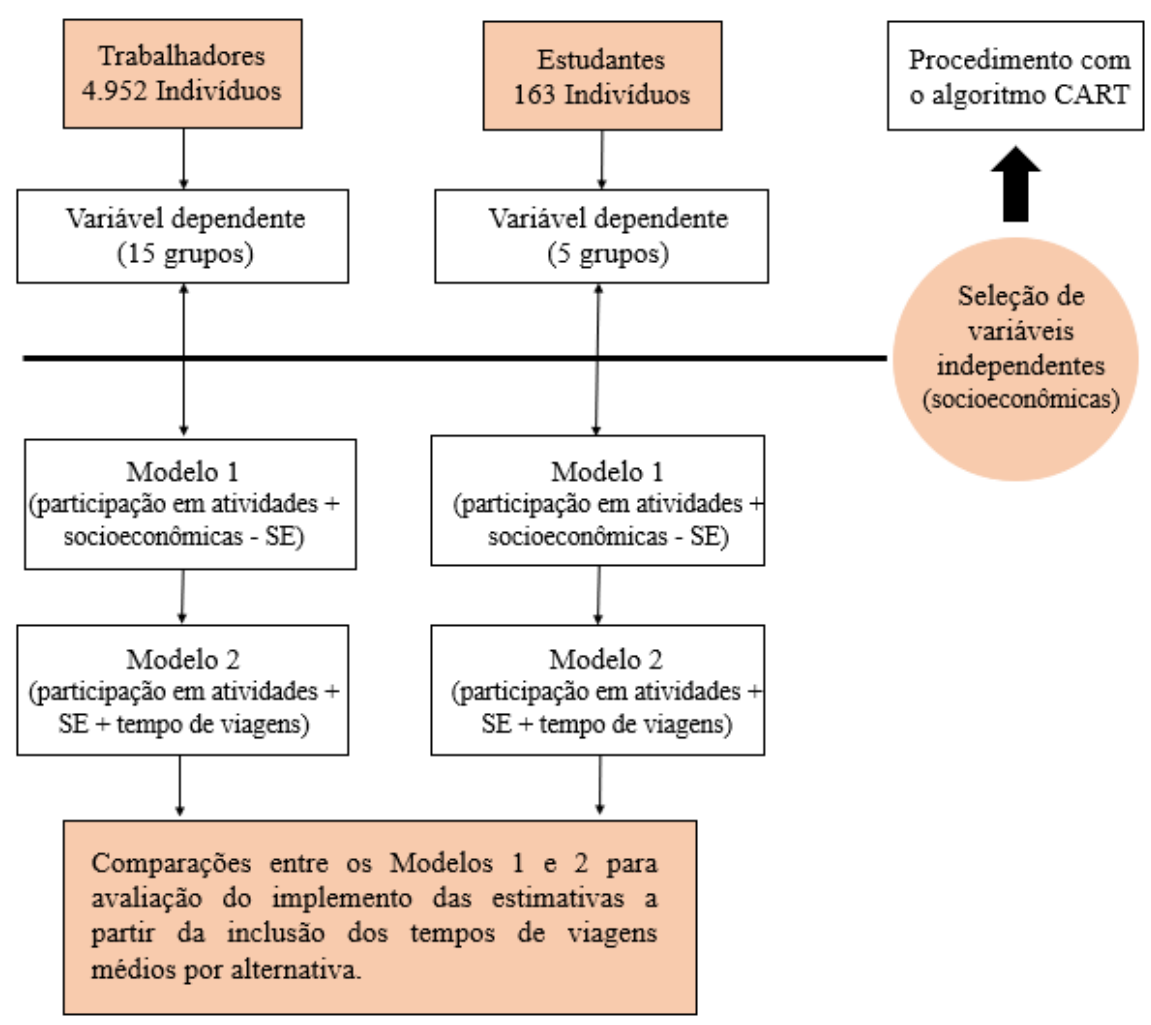




\subsection{IDENTIFICAÇÃO DAS VARIÁVEIS IMPORTANTES PARA COMPOSIÇÃO DAS FUNÇÕES UTILIDADE A PARTIR DE ALGORITMO CART}

Após a obtenção das variáveis dependentes (tanto para amostra de trabalhadores quanto para amostra de estudantes), através do agrupamento de padrões de viagens similares, descrito no Capítulo 6, ocorreu a formulação das funções utilidade com um auxílio de um procedimento aqui proposto.

Esta etapa metodológica está diretamente relacionada ao objetivo específico 3, relativo à proposta de um critério para formulação do Modelo Logit Multinomial e redução de parâmetros a serem estimados. Assim, realizando as etapas metodológicas descritas na Subseção 4.3.4, através do algoritmo CART (Classification And Regression Tree), são identificadas variáveis importantes ou não para composição das funções utilidade. Os resultados estão apresentados na Tabela 7.1 e na Tabela 7.2 e são referentes à amostra de estudantes e de trabalhadores, respectivamente.

As variáveis indicadas na cor vermelha são aquelas que não foram incluídas naquela função utilidade. Na cor verde estão representadas as variáveis a serem incluídas na etapa de modelagem paramétrica. Para a amostra de estudantes, considerando as variáveis independentes inseridas na $\mathrm{AD}$, somente duas variáveis não foram apontadas como importantes para o modelo sendo elas: "número de moradores" para a função utilidade 4 e "quantidade de motocicletas na residência" para a função utilidade 5. A utilidade 4 está associada ao padrão de viagem SH11 (Indivíduos vão para a escola e retornam para casa usando o modo privado motorizado individual), enquanto a utilidade 5 está associada ao padrão de viagem SH33 (Indivíduos vão para a escola e retornam para casa utilizando modo não motorizado). Assim, pelos resultados encontrados, observa-se que o tamanho da família não afeta a sequência de atividades e o uso de automóvel para realização de tais viagens. Também se observa que a quantidade de motocicletas no domicílio não afeta a escolha de uma sequência de modos de transporte ativos. 
Tabela 7.1 - Variáveis importantes na explicação do comportamento.

(Amostra de Estudantes)

\begin{tabular}{|c|c|c|c|c|c|}
\hline \multirow{2}{*}{ Variáveis } & \multicolumn{5}{|c|}{ Funções Utilidade } \\
\hline & 1 & 2 & 3 & 4 & 5 \\
\hline \multicolumn{6}{|l|}{ Situação na família } \\
\hline \multicolumn{6}{|l|}{ Estuda } \\
\hline \multicolumn{6}{|l|}{ Tipo de escola } \\
\hline Número de moradores & & & & $\mathrm{X}$ & \\
\hline Quantidade de motocicletas & & & & & $\mathrm{X}$ \\
\hline \multicolumn{6}{|l|}{ Quantidade de automóveis } \\
\hline \multicolumn{6}{|l|}{ Quantidade de bicicletas } \\
\hline \multicolumn{6}{|l|}{ Renda familiar } \\
\hline \multicolumn{6}{|l|}{ Idade } \\
\hline \multicolumn{6}{|l|}{ Sexo } \\
\hline \multicolumn{6}{|l|}{ Grau de instrução } \\
\hline
\end{tabular}

Situação na família (1 - responsável; 0 - outro); Estuda (1 - Sim; 0 - Não); Tipo de escola (1 - Pública; 2 Particular); Número de moradores (1-11); Quantidade de motocicletas (0 - 1), Quantidade de automóveis (0 - 7); Quantidade de bicicletas ( 0 - 4); Renda Familiar (1 - Renda $\leq \mathrm{R} \$ 2.856,00 ; 2$ - R $\$ 2.856,01<$ Renda $\leq \mathrm{R} \$$ 4.110,00; 3 - R \$ 4.110,01 < Renda $\leq \mathrm{R} \$ 9.000,00 ; 4$ - > R \$ 9.000,01); Idade ( 1 - até 11 anos; 2 - de 12 a 20 anos; 3 - de 21 a 59 anos); Sexo ( 1 - Feminino); Grau de Instrução (1 - não alfabetizado -Primário incompleto; 2 Primário completo - Fundamental incompleto; 3 - Fundamental completo - Ensino Médio incompleto; 4 - Ensino Médio completo - Superior incompleto; 5 - Superior completo); Cluster 1(Utilidade 1) - Vai para a escola e volta para casa. Usa o modo público; Cluster 2 (Utilidade 2) - Outras atividades. Usa o mesmo modo para fazer as viagens; Cluster 3 (Utilidade 3) - Escola encadeada com outras atividades. Usa várias combinações dos modos; Cluster 4 (Utilidade 4) - Vai para a escola e volta para casa. Usa o modo privado motorizado; Cluster 5 (Utilidade 5) - Vai para a escola e volta para casa. Usa o modo não motorizado.

No caso da amostra de trabalhadores, pode-se observar que houve uma boa redução do número de variáveis independentes utilizando o algoritmo CART (Tabela 7.2).

Tabela 7.2 - Variáveis importantes na explicação do comportamento.

(Amostra de Trabalhadores)

\begin{tabular}{|c|c|c|c|c|c|c|c|c|c|c|c|c|c|c|c|}
\hline \multirow{2}{*}{ Variáveis } & \multicolumn{15}{|c|}{ Funções Utilidade } \\
\hline & 1 & 2 & 3 & 4 & 5 & 6 & 7 & 8 & 9 & 10 & 11 & 12 & 13 & 14 & 15 \\
\hline Número de moradores & & & & & $\mathrm{X}$ & & & $\mathrm{X}$ & $\mathrm{X}$ & $\mathrm{X}$ & $\mathrm{X}$ & $\mathrm{X}$ & $\mathrm{X}$ & $\mathrm{X}$ & \\
\hline Situação na família & & & & & & $\mathrm{X}$ & & $\mathrm{X}$ & & $\mathrm{X}$ & & $\mathrm{X}$ & & & \\
\hline Quantidade de motocicletas & & & & & & & $\mathrm{X}$ & $\mathrm{X}$ & & X & & X & $X$ & $X$ & \\
\hline Quantidade de automóveis & & & $\mathrm{X}$ & $\mathrm{X}$ & $\mathrm{X}$ & & $\mathrm{X}$ & $\mathrm{X}$ & & & & & $\mathrm{X}$ & & $\mathrm{X}$ \\
\hline Quantidade de bicicletas & & & & $\mathrm{X}$ & & & $\mathrm{X}$ & $\mathrm{X}$ & $\mathrm{X}$ & & & $\mathrm{X}$ & $\mathrm{X}$ & $\mathrm{X}$ & $\mathrm{X}$ \\
\hline Estuda & & & & & & & & $\mathrm{X}$ & & & & & & & $\mathrm{X}$ \\
\hline Renda familiar & & & & $\mathrm{X}$ & & & $\mathrm{X}$ & $\mathrm{X}$ & & & & & & & $X$ \\
\hline Idade & & & & & $\mathrm{X}$ & & & $\mathrm{X}$ & & $\mathrm{X}$ & & & $\mathrm{X}$ & $\mathrm{X}$ & $\mathrm{X}$ \\
\hline Sexo & & & & & $\mathrm{X}$ & & $\mathrm{X}$ & $\mathrm{X}$ & $\mathrm{X}$ & $\mathrm{X}$ & $\mathrm{X}$ & $\mathrm{X}$ & & $\mathrm{X}$ & $\mathrm{X}$ \\
\hline Grau de instrução & & & & & & & & $\mathrm{X}$ & & & & & $\mathrm{X}$ & & \\
\hline
\end{tabular}




\begin{tabular}{|c|c|c|c|c|c|c|c|c|c|c|c|c|c|c|c|}
\hline \multicolumn{16}{|l|}{ Conclusão } \\
\hline \multirow{2}{*}{ Variáveis } & \multicolumn{15}{|c|}{ Funções Utilidade } \\
\hline & 1 & 2 & 3 & 4 & 5 & 6 & 7 & 8 & 9 & 10 & 11 & 12 & 13 & 14 & 15 \\
\hline Assalariado com carteira & & & & $\mathrm{X}$ & & & & & & $\mathrm{X}$ & $\mathrm{X}$ & $\mathrm{X}$ & & & $\mathrm{X}$ \\
\hline Assalariado sem carteira & & & $X$ & $X$ & & & & $X$ & $\mathrm{X}$ & $\mathrm{X}$ & & $\mathrm{X}$ & $X$ & $X$ & $\mathrm{X}$ \\
\hline Funcionário público & & & & & $\mathrm{X}$ & $\mathrm{X}$ & & $X$ & $X$ & & $\mathrm{X}$ & $X$ & $X$ & $X$ & \\
\hline Autônomo & & & & $\mathrm{X}$ & & & & & $\mathrm{X}$ & $\bar{X}$ & $\mathrm{X}$ & $\mathrm{X}$ & $\mathrm{X}$ & $\mathrm{X}$ & $\mathrm{X}$ \\
\hline Empregador & & & & $\mathrm{X}$ & $\mathrm{X}$ & & & $\mathrm{X}$ & & & $\mathrm{X}$ & $\mathrm{X}$ & & & $\mathrm{X}$ \\
\hline Profissional liberal & & & & $\mathrm{X}$ & $\mathrm{X}$ & & $\mathrm{X}$ & & & $\mathrm{X}$ & & $\mathrm{X}$ & & & $\mathrm{X}$ \\
\hline Dono de negócio familiar & & $\mathrm{X}$ & & & & & $\mathrm{X}$ & $\bar{X}$ & & $\mathrm{X}$ & $\bar{X}$ & $\mathrm{X}$ & $\bar{X}$ & $\bar{X}$ & $\mathrm{X}$ \\
\hline Trabalhador familiar & & & & $\mathrm{X}$ & & & & & & & & & & & \\
\hline Tem outro trabalho & & & & $\mathrm{X}$ & & & & $\mathrm{X}$ & & $\mathrm{X}$ & & $\mathrm{X}$ & & & \\
\hline
\end{tabular}

Variáveis incluídas nas funções utilidade

Variáveis excluídas das funções utilidade

Número de moradores (1-14); Situação na família (1 - responsável; 0 - outro); Quantidade de moto (0 - 9), Quantidade de automóvel (0 - 6); Quantidade de bicicleta ( 0 - 9); Renda Familiar $(0-\leq \mathrm{R} \$ 2.502,00 ; 1$ - > R\$ 2.502,00); Idade ( 1 - até 11 anos; 2 - de 12 a 20 anos; 3 - de 21 a 59 anos; 4 - $\geq 60$ anos); Sexo ( 1 - Feminino); Grau de Instrução (1 - não alfabetizado-Primário incompleto; 2 - Primário completo - Fundamental incompleto; 3 - Fundamental completo - Ensino Médio incompleto; 4 - Ensino Médio completo - Superior incompleto; 5 Superior completo); Variáveis associadas à participação em atividades - Todas binárias com valor 1 correspondente ao "Sim" (Estuda; Assalariado com carteira; Assalariado sem carteira; Funcionário público; Autônomo; Empregador; Profissional liberal; Dono de negócio familiar; Trabalhador familiar; Tem outro trabalho); Cluster 1 (Utilidade 1) - Vai para o trabalho e volta para casa. Usa o modo público; Cluster 2 (Utilidade 2) - Vai para o trabalho e volta para casa. Predominantemente utilizam o modo não motorizado; Cluster 3 (Utilidade 3) - Outras atividades ou escola. Predominantemente utiliza o mesmo modo para fazer as duas viagens; Cluster 4 (Utilidade 4) - Outras atividades encadeadas com trabalho. Predominantemente utiliza o mesmo modo para fazer todas as viagens; Cluster 5 (Utilidade 5) - Tem dois trabalhos. Predominantemente utiliza o modo motorizado para fazer as viagens; Cluster 6 (Utilidade 6) - Vai para o trabalho e volta para casa. Usa o modo privado motorizado; Cluster 7 (Utilidade 7) - Outras atividades, trabalho e escola encadeadas. Predominantemente utiliza o mesmo modo para fazer todas as viagens; Cluster 8 (Utilidade 8) - Outras atividades. Predominantemente utiliza o modo motorizado; Cluster 9 (Utilidade 9) - Trabalho intercalado com residência. Utiliza o modo privado motorizado para realizar as quatro viagens; Cluster 10 (Utilidade 10) - Trabalho intercalado com residência. Utiliza o modo não motorizado para realizar as quatro viagens; Cluster 11 (Utilidade 11) - Outras atividades, escola e trabalho sempre intercaladas com casa. Utiliza o mesmo modo motorizado para realizar as quatro viagens; Cluster 12 (Utilidade 12) - Outras atividades, escola e trabalho sempre intercaladas com casa. Utiliza o modo não motorizado para realizar as quatro viagens; Cluster 13 (Utilidade 13) - Outras atividade, escola e trabalho sempre intercaladas com casa. Predominantemente utiliza o modo motorizado para realizar as quatro viagens; Cluster 14 (Utilidade 14) - Outras atividades, escola e trabalho encadeadas. Utiliza o mesmo modo para realizar as quatro viagens; Cluster 15 (Utilidade 15) - Outras atividades, escola e trabalho encadeadas. Predominantemente utiliza o modo não motorizado.

Para a amostra de trabalhadores, tomando como exemplo, a variável "número de moradores", foi apontada como não sendo importante nas funções utilidade 5, 8, 9, 10, 11, 12, 13 e 14. A função Utilidade 5, por exemplo, está associada aos padrões de viagem WWH222, WWH111, WWH221 (Indivíduos que têm dois trabalhos e predominantemente utilizam o modo motorizado para realizar as viagens). Como a Utilidade 5 trata de viagens com motivo trabalho e ainda está associada a grupos de indivíduos com mais de um trabalho/emprego, 
possivelmente, a quantidade de "número de moradores" não tem influência neste grupo (que realiza viagens obrigatórias a diferentes locais de trabalho. Neste caso, é provável que outros membros do domicílio realizem as atividades de "assistência e manutenção" do domicílio (sobretudo para o caso de domicílios com crianças, por exemplo), sendo o motivo "Outras atividades".

\subsection{MODELAGEM LOGIT MULTINOMIAL}

Os resultados dessa etapa estão organizados a partir das duas modelagens, associadas a cada uma das amostras:

A. Modelagem 1 (Variáveis Socioeconômicas + Participação em atividades)

a. Amostra de estudantes

b. Amostra de trabalhadores

B. Modelagem 2 (Variáveis Socioeconômicas, participação em atividades e tempos de viagem)

a. Amostra de Estudantes

b. Amostra de Trabalhadores

\subsubsection{Modelagem 1}

\subsubsection{Amostra de estudantes}

Para a amostra de estudantes, na modelagem 1, foram obtidos os seguintes resultados: Rho-quadrado ajustado igual a 0,170 e Critério de informação Akaike de 304,48. Com a amostra de validação, foram calculadas as seguintes medidas: Taxa de acertos de 36,73\%, valor de verossimilhança $L=3,35 \times 10-28$ e $\log (L)=-63,26$.

As Equações 7.1, 7.2, 7.3, 7.4 e 7.5 são as funções utilidade calibradas para os cincos grupos de estudantes, com os parâmetros estimados que foram significativos para um nível de confiança de $95 \%$.

$$
\begin{aligned}
& \mathrm{V}_{1}=0 \\
& \mathrm{~V}_{2}=-8.12+1.74 * \text { grau_ins } \\
& \mathrm{V}_{3}=-0.73+1.19 * \text { sit_fam }
\end{aligned}
$$




$$
\begin{aligned}
& \mathrm{V}_{4}=-1.97+0.73 * \text { qt_auto } \\
& \mathrm{V}_{5}=2.77-1.81 * \text { tipo_esc }
\end{aligned}
$$

GRAU_INS (grau de instrução); SIT_FAM (situação na família); QT_AUTO (quantidade de automóvel no domicílio); TIPO_ESC (tipo de escola). Os padrões associados às funções utilidade da amostra de estudantes são: $\mathrm{V}_{1}: \mathrm{SH} 22 ; \mathrm{V}_{2}$ : AH11, AH22, AH33; V $:$ SHAH1221, ASH223, SHSH3333; V4: SH11; V $:$ SH33.

A análise da modelagem 1, pode-se observar:

- $\quad$ Na Utilidade 2 (associada aos padrões de viagens AH11, AH22, AH33) observa-se a influência positiva da variável "grau de instrução" na realização de viagens encadeadas com motivos predominantemente de atividades não obrigatórias. Não é possível fazer inferências associadas a tal resultado, considerando que há apenas 9 observações relativas a tal função utilidade;

- A Utilidade 3 correspondente às cadeias de viagens mais complexas SHAH1221; ASH223; SHSH3333. É observada a influência positiva da variável "Situação Familiar (0: Não Responsável ;1: Responsável). Este fato ressalta vários achados da literatura que afirmam a relação entre responsáveis familiares e cadeias mais complexas de padrões de viagens (BIANCO; LAWSON, 1998; MCGUCKIN; MURAKAMI, 1999).

- $\quad \mathrm{Na}$ Utilidade 4, relacionada ao uso de transporte individual motorizado (SH11), verifica-se a influência positiva da variável posse de automóveis. Tais relações estão estritamente vinculadas à escolha modal e são tradicionalmente encontradas na literatura (BARFF et al., 1982; HARTGEN, 1974; PITOMBO et al., 2011).

- $\quad$ Finalmente, a Utilidade 5 relaciona-se a padrões de viagens com motivo estudo e modo de transporte não motorizado (SH33). Observa-se um resultado bem interessante na calibração desta função. Verifica-se a influência negativa da variável "Tipo de Escola" (1: Pública; 2: Particular). Este resultado demonstra que crianças, provenientes de escola pública, estão mais propensas a ir a pé para as escolas. Este resultado condiz com a política nacional do Ministério da Educação que assegura vaga nas escolas públicas de educação infantil e de ensino fundamental, mais próxima do domicílio (BRASIL, 2008; PITOMBO, 2007). 


\subsubsection{Amostra de trabalhadores}

A modelagem 1, para a amostra de trabalhadores, teve como resultado final: Rhoquadrado ajustado igual a 0,25 e Critério de informação Akaike de 14.109,94. Com a amostra de validação, foram calculadas as seguintes medidas: Taxa de acertos de 46,54\%, valor de verossimilhança $L=9,97 \times 10-16$ e $\log (L)=-34,54$.

As Equações de 7.6 a 7.20 são as funções utilidade calibradas para os quinze grupos de trabalhadores, com os parâmetros estimados que foram significativos para um nível de confiança de $95 \%$. Foi utilizada uma função Utilidade de referência $\left(U_{15}\right)$ a fim de reduzir o número de parâmetros a serem estimados.

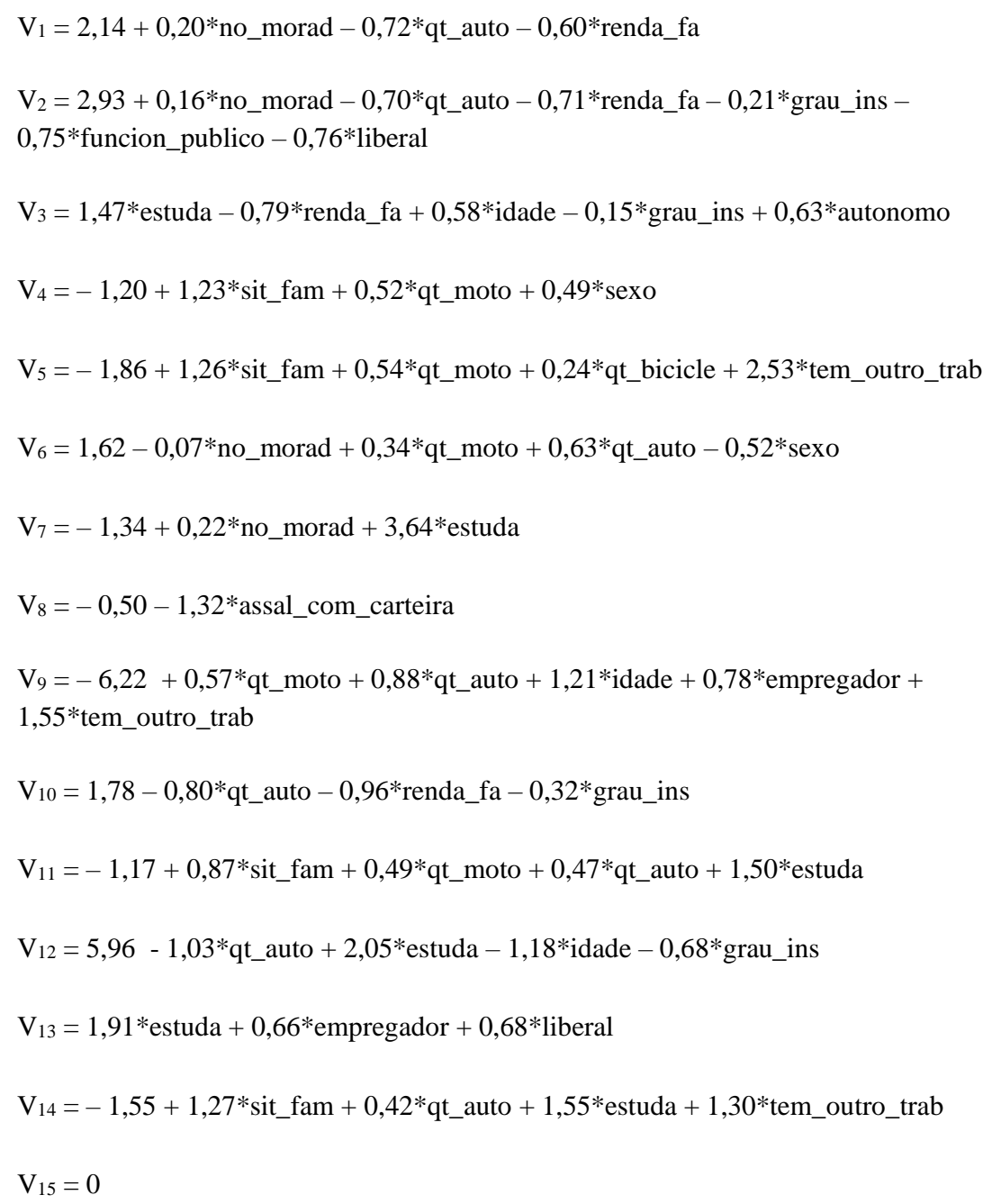

NO_MORAD (número de moradores no domicílio); QT_AUTO (quantidade de automóvel no domicílio); RENDA_FA (renda familiar); GRAU_INS (grau de instrução); FUNCION_PUBLICO (funcionário público); LIBERAL (profissional liberal); ESTUDA (se estuda); IDADE (idade); AUTONOMO (autônomo); SIT_FAM (situação na família); QT_MOTO (quantidade de moto no domicílio); SEXO (sexo); QT_BICICLE (quantidade de bicicleta no domicílio); TEM_OUTRO_TRAB (tem outro trabalho); ASSAL_COM_CARTEIRA (assalariado 
com carteira); EMPREGADOR (empregador). Os padrões associados às funções utilidade da amostra de trabalhadores são: $\mathrm{V}_{1}$ : WH22; $\mathrm{V}_{2}$ : WH23, WH13, WH33; $\mathrm{V}_{3}$ : AH11, AH33, SH22; $\mathrm{V}_{4}$ : WAH111, AWH222, AWH333; V5: WWH222, WWH111, WWH221; V6: WH11; V7: SWH111, WSH222, SAH111; V8: AAH111, AAH222, AAH333; $\mathrm{V}_{9}$ : WHWH1111; $\mathrm{V}_{10}$ : WHWH3333; $\mathrm{V}_{11}$ : WHAH1111, AHWH2222, WHSH1111; $\mathrm{V}_{12}$ : SHSH3333, SHWH3333, WHAH3333; V 13 : WHAH2211, WHWH1122, WHAH3111; V 14 : WAWH3333, WWAH1111, WAWH2222; V15: WAWH1331, AAAH3331, WAAH2333.

$\mathrm{Na}$ análise da modelagem 1, para amostra composta por trabalhadores, observa-se que:

(1) Na Utilidade V1 (associada ao cluster 1 - WH22) há uma influência positiva da variável "número de moradores", indicando que pessoas pertencentes a grupos familiares maiores estariam dentro desse cluster e teriam uma maior propensão a realizar as viagens identificadas neste grupo, o qual corresponde aos indivíduos que realizam o padrão Residência - Trabalho - Residência por transporte público (WH22). Além disso, observase influência negativa das variáveis "quantidade de automóveis no domicílio" e "renda familiar". Tais relações estão estritamente vinculadas à escolha modal. Tradicionalmente, na literatura, corroboram-se tais relações (BARFF et al., 1982; HARTGEN, 1974; ICHIKAWA et al., 2002; PITOMBO et al., 2011).

(2) A Utilidade $V_{2}$ (associada ao cluster 2 - WH23; WH13 e WH33) apresenta relações similares às encontradas na Utilidade 1, associada ao cluster 1, incluindo a influência negativa das variáveis "grau de instrução", "funcionário público" e "profissional liberal”;

(3) A Utilidade 3 (cluster 3 - padrões AH11; AH33 e SH22) está associada aos indivíduos que estudam, mais velhos, com menor renda, com menor grau de instrução e com uma maior propensão para pessoas que trabalham como autônomos. As relações encontradas nessa função utilidade, através dos parâmetros estimados, sobretudo no que diz respeito à participação em atividades de estudo e à classe de trabalhadores autônomos, são coerentes com os padrões de viagens predominantes a este grupo de indivíduos;

(4) A Utilidade $\mathbf{V}_{4}$ representa o grupo de indivíduos que realiza três viagens, encadeando o motivo "outras atividades" ao motivo "trabalho" (WAH; AWH; AWH). Assim, observase relações importantes entre a situação familiar, a quantidade de motocicletas e o gênero. Pode-se afirmar, através desses resultados, que mulheres chefes de domicílios estão mais propensas a realizar os padrões de viagens que compõem o cluster 4. Na literatura encontram-se relações similares associadas ao gênero, à situação familiar e às viagens encadeadas (GORDON et al., 1989; MCGUCKIN; MURAKAMI, 1999).

(5) A Utilidade V 5 (predominância dos padrões WH222; WWH111; WWH221) apresenta relações similares às encontradas na $\mathrm{V}_{4}$, com exceção da variável "sexo", que não está 
indicada nessa utilidade, e pela presença positiva das variáveis "quantidade de bicicleta no domicílio" e "tem outro trabalho", indicando a presença de indivíduos que possuem mais de um trabalho. O coeficiente da variável "tem outro trabalho" é positivo e fortemente relacionado à maior propensão de pertencimento a este grupo de viajantes, que realiza viagens consecutivas com motivo trabalho e para diferentes locais.

(6) Na Utilidade $V_{6}$ (associada ao cluster 6 - WH11) existe uma influência negativa da variável "número de moradores", indicando que pessoas pertencentes a grupos familiares menores estariam dentro desse cluster. Além disso, observa-se influência positiva para gênero masculino, assim como para pessoas com maior número de automóveis e motos no domicílio. As relações aqui encontradas estão associadas, essencialmente, à escolha do automóvel, do gênero, do tamanho do domicílio e da posse de automóveis (BARFF et al.,1982; HARTGEN, 1974; TRAIN; MCFADDEN, 1978).

(7) A Utilidade $V_{7}$ aponta que o cluster 7 é composto por indivíduos pertencentes a grupos familiares maiores e que estão estudando. Tais relações explicam padrões de viagens encadeadas entre atividades de trabalho e escola (SWH111; WSH222, SAH111).

(8) Os parâmetros estimados na função Utilidade 8, são bastante coerentes com o esperado em relação ao comportamento relativo a viagens. A modelagem mostra que as pessoas que trabalham com carteira assinada têm menor propensão a realizar as viagens caracterizadas no cluster 8 (tais viagens possuem motivos diferentes de "trabalho" AAH111; AAH222; AAH333).

(9) A calibração da Utilidade V9 destaca padrões com duas viagens ao trabalho, intercalados com o motivo residência (WHWH). Pelo fato deste grupo ser composto por sequência de uso do automóvel, observa-se relação positiva das variáveis “quantidade de automóveis", por exemplo.

(10)A Utilidade 10 é composta pela mesma sequência de atividades anterior, variando a sequência de modos de transporte para modos não motorizados. Reconhecem-se relações tradicionais, encontradas na literatura, relativas à escolha modal. Assim, observa-se relações entre o modo de transporte não motorizado e baixa renda, menor grau de instrução e menor número de automóveis no domicílio (todos os parâmetros associados a tais variáveis são negativos).

(11) A Utilidade V11 caracteriza indivíduos que realizam quatro viagens, intercalando o motivo "trabalho" com "outras atividades" ou "estudo" (WHAH1111; AHWH2222 e WHSH1111). Nesse grupo, observa-se que indivíduos responsáveis pelo domicílio estão mais propensos para realizar tais padrões de cadeia de viagens. Observam-se, também, 
influência da posse veicular.

(12) A modelagem aponta, através da calibração da Utilidade $\mathbf{V}_{12}$, que as pessoas que estudam, com menor idade e grau de instrução e que possuem poucos automóveis no domicílio têm maior propensão de realizar as viagens descritas no cluster 12 (SHSH3333; SHWH333; WHAH333);

(13) Os coeficientes estimados na Utilidade $V_{13}$ indicam uma maior propensão das pessoas que realizam quatro viagens encadeadas para outras atividades, escola e trabalho, sempre intercaladas à residência e com uso do modo motorizado (WHAH2211; WHWH1122; WHAH3111), serem pessoas que estudam e que atuam como empregadores ou profissionais liberais;

(14)Finalmente, a calibração da Utilidade V14 indica uma maior propensão das pessoas que realizam quatro viagens encadeadas para outras atividades, escola e trabalho, sempre fazendo uso do mesmo modo de transporte (WAWH3333; WWAH1111; WAWH2222), serem pessoas que são chefes de família, que estudam, que possuem um número maior de automóveis no domicílio e que atuam em pelo menos dois trabalhos diferentes.

Em síntese, boa parte das relações encontradas na primeira etapa da modelagem, associadas à participação em atividades, às características socioeconômicas e aos grupos de comportamentos individuais relativos a viagens encadeadas (Modelagem 1), é corroborada em diversos trabalhos da literatura. Alguns autores já chegaram a resultados similares, ao longo de décadas. Segundo estudo desenvolvido por Blumenberg e Pierce (2014), por exemplo, os americanos de baixa renda são menos multimodais do que aqueles com renda mais alta $\left(\mathrm{V}_{1}, \mathrm{~V}_{2}\right.$, $\mathrm{V}_{3}$ e V9). Barff et al. (1982), Hartgen (1974) e Train e McFadden (1978) já comprovaram as relações entre variáveis socioeconômicas e escolha modal, como uma maior propensão ao uso do automóvel $\left(\mathrm{V}_{6}\right)$ para o gênero masculino, assim como para pessoas com maior idade $\left(\mathrm{V}_{3}\right.$, $\left.\mathrm{V}_{6}, \mathrm{~V}_{9}\right)$, maior grau de instrução e maior número de automóveis no domicílio $\left(\mathrm{V}_{6}, \mathrm{~V}_{11}\right)$. Strathman et al. (1994) mostraram que a estrutura familiar afeta o comportamento do encadeamento da viagem $\left(\mathrm{V}_{4}, \mathrm{~V}_{5}, \mathrm{~V}_{11}, \mathrm{~V}_{14}\right)$.

\subsubsection{Modelagem 2}

$\mathrm{Na}$ modelagem 2, incorporou-se aos modelos os tempos de viagens das cinco alternativas modais (1) privado motorizado, (2) ônibus, (3) metro e trem, (4) bicicleta e (5) a pé. Utilizou-se coeficientes específicos associados aos tempos de viagem dos modos usados por cada um dos grupos (clusters). 


\subsubsection{Amostra de estudantes}

Para a amostra de estudantes, os parâmetros significativos para um nível de confiança de 95\%, estão apresentados nas Equações 7.21, 7.22, 7.23, 7.24 e 7.25. Para essa amostra verificou-se um Rho-quadrado ajustado igual a 0.287 e Critério de informação Akaike de 261,63. Com a amostra de validação, foram calculadas as seguintes medidas: Taxa de acertos de 56,06\%, valor de verossimilhança $L=2,05 \times 10-21$ e $\log (L)=-47,64$.

$\mathrm{Na}$ amostra de estudantes verificou-se a melhoria global da modelagem através do aumento da métrica Rho-quadrado ajustado e redução do Critério de informação Akaike. Na validação, o aprimoramento do modelo pode ser verificado através do aumento de L, da diminuição (em módulo) de Log (L) e do aumento da taxa de acertos.

$$
\begin{aligned}
& \mathrm{V}_{1}=0 \\
& \mathrm{~V}_{2}=-7,86+1,67 * \text { grau_ins } \\
& \mathrm{V}_{3}=-0,72+1,15 * \text { sit_fam } \\
& \mathrm{V}_{4}=-1,94+0,69 * \mathrm{qt} \_ \text {auto } \\
& \mathrm{V}_{5}=7,50-1,95 * \text { tipo_esc }-0,21 *+5 \_ \text {pe }
\end{aligned}
$$

GRAU_INS (grau de instrução); SIT_FAM (situação na família); QT_AUTO (quantidade de automóvel no domicílio); TIPO_ESC (tipo de escola); t5_pe (tempo de viagem a pé). Os padrões associados às funções utilidade da amostra de estudantes são: $\mathrm{V}_{1}$ : SH22; $\mathrm{V}_{2}$ : AH11, AH22, AH33; $\mathrm{V}_{3}$ : SHAH1221, ASH223, SHSH3333; V4: $\mathrm{SH} 11 ; \mathrm{V}_{5}: \mathrm{SH} 33$.

$\mathrm{Na}$ modelagem 2, para a amostra de estudantes, no que se refere às variáveis socioeconômicas, as mesmas relações anteriores foram verificadas. No que diz respeito ao tempo de viagem, o que se espera é que o aumento do tempo de viagem de determinada alternativa modal contribua de forma negativa para a sua função utilidade (BEN-AKIVA; MORIKAWA, 1990). Para essa amostra, apenas o tempo do modo a pé para a Utilidade 5 foi significativo, o que já foi suficiente para melhorar as métricas do modelo. Observou-se a relação negativa entre o tempo de viagem por modo a pé e uma sequência de viagens com motivo estudo, por modo a pé, através do valor negativo do parâmetro estimado.

Pode-se destacar que trabalhos anteriores de modelagens desagregadas para escolha modal, valores e Rho-quadrado ajustado em torno de 0,20 e 0,40 são os mais usualmente encontrados na literatura (BEKHOR; SHIFTAN, 2010; BEN-AKIVA; MORIKAWA, 1990; SOUTHWORTH, 1981). 


\subsubsection{Amostra de trabalhadores}

Para um nível de confiança de $95 \%$, os parâmetros significativos para o modelo 2 da amostra de trabalhadores estão indicados nas equações abaixo (entre a Equação 7.26 e Equação 7.40). Para essa amostra verificou-se um Rho-quadrado ajustado igual a 0,298 e Critério de informação Akaike de 13.171,62. Com a amostra de validação, foram calculadas as seguintes medidas: Taxa de acertos de 56\%, valor de verossimilhança $\mathrm{L}=1,78 \times 10-14$ e $\log (\mathrm{L})=-$ 31,66 .

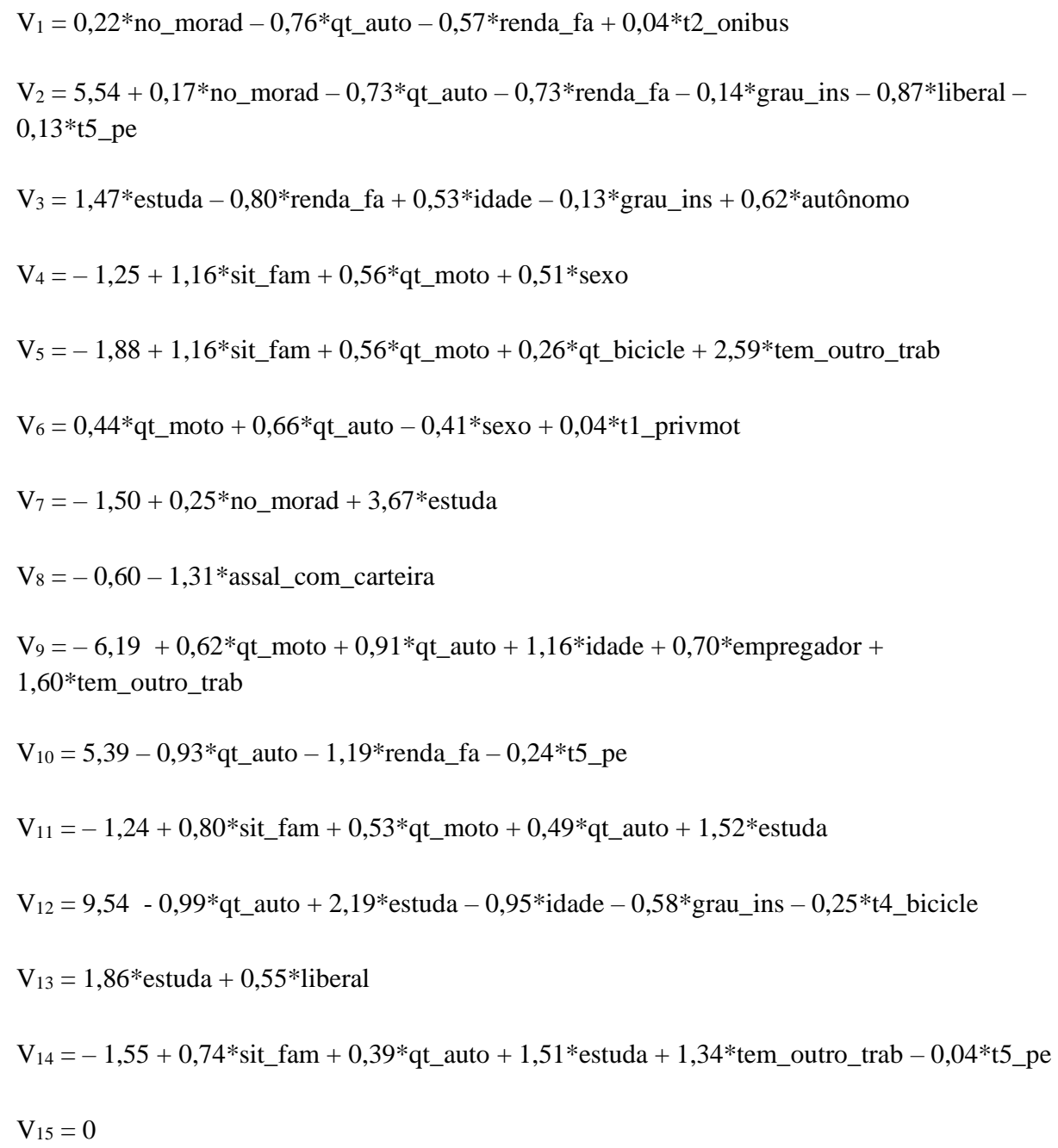

NO_MORAD (número de moradores no domicílio); QT_AUTO (quantidade de automóvel no domicílio); RENDA_FA (renda familiar); GRAU_INS (grau de instrução); FUNCION_PUBLICO (funcionário público); LIBERAL (profissional liberal); ESTUDA (se estuda); IDADE (idade); AUTONOMO (autônomo); SIT_FAM (situação na família); QT_MOTO (quantidade de moto no domicílio); SEXO (sexo); QT_BICICLE (quantidade de bicicleta no domicílio); TEM_OUTRO_TRAB (tem outro trabalho); ASSAL_COM_CARTEIRA (assalariado com carteira); EMPREGADOR (empregador). Os padrões associados às funções utilidade da amostra de 
trabalhadores são: $\mathrm{V}_{1}$ : WH22; $\mathrm{V}_{2}$ : WH23, WH13, WH33; $\mathrm{V}_{3}$ : AH11, AH33, SH22; V AWH333; V : WWH222, WWH111, WWH221; V6: WH11; V7: SWH111, WSH222, SAH111; V: AAH111, AAH222, AAH333; $\mathrm{V}_{9}$ : WHWH1111; $\mathrm{V}_{10}$ : WHWH3333; $\mathrm{V}_{11}$ : WHAH1111, AHWH2222, WHSH1111; V 12 : SHSH3333, SHWH3333, WHAH3333; V13: WHAH2211, WHWH1122, WHAH3111; V 14 : WAWH3333, WWAH1111, WAWH2222; V15: WAWH1331, AAAH3331, WAAH2333.

Verificou-se uma melhoria global do modelo com a inserção dos tempos de viagem agregados. Como citado, a expectativa era que o aumento do tempo de viagem de determinada alternativa modal contribua negativamente para a utilidade da mesma, o que se deu no Cluster 2 (tempo de viagem a pé), Cluster 10 (tempo de viagem a pé), Cluster 12 (tempo de viagem de bicicleta) e Cluster 14 (tempo de viagem a pé). No entanto, verificou-se que na função Utilidade $\mathrm{V}_{1}$, relativa ao Cluster 1 (WH22) - padrão associado ao transporte público - houve um coeficiente com baixo valor e positivo associado à duração do tempo de ônibus e na função Utilidade $\mathrm{V}_{6}$, relativa ao Cluster 6 também estimou-se um coeficiente com baixo valor e positivo associado, nesse caso, ao tempo do modo privado motorizado.

Realizando-se uma análise comparativa entre os Modelos 1 e 2, verificou-se o incremento da acurácia a partir da inclusão de características das alternativas. No caso desse trabalho, seriam os tempos de viagens agregados, provenientes de uma pesquisa de Preferência Revelada. O Quadro 7.1 sintetiza os principais resultados relativos à investigação do comportamento associado a viagens encadeadas para amostra de trabalhadores e estudantes.

Quadro 7.1 - Síntese dos resultados, provenientes da etapa paramétrica, encontrados neste trabalho

(Gomes et al., 2021)

\section{Para amostra de trabalhadores}

\begin{tabular}{|c|c|}
\hline Sequência de Modos de Transporte & $\begin{array}{c}\text { Número de automóveis no domicílio } \\
\text { Renda Familiar } \\
\text { Grau de Instrução } \\
\text { Gênero }\end{array}$ \\
\hline $\begin{array}{l}\text { Variação de escolha modal na sequência de } \\
\text { viagens realizadas ao longo do dia }\end{array}$ & $\begin{array}{l}\text { Funcionário Público } \\
\text { Profissional liberal }\end{array}$ \\
\hline $\begin{array}{c}\text { Sequência de viagens incluindo motivos } \\
\text { diferentes de "Trabalho" }\end{array}$ & $\begin{array}{c}\text { Estudantes } \\
\text { Profissionais Autônomos } \\
\text { Profissionais com carteira assinada } \\
\text { Profissionais liberais }\end{array}$ \\
\hline
\end{tabular}




\begin{tabular}{c|c}
\hline $\begin{array}{c}\text { Cadeias de viagens mais complexas, intercalando } \\
\text { outras atividades ao trabalho }\end{array}$ & Mulheres \\
Chefes de Família \\
\hline $\begin{array}{c}\text { Cadeias com viagens consecutivas com motivo } \\
\text { "Trabalho" }\end{array}$ & Indivíduo possui dois trabalhos diferentes \\
\hline Maior número de viagens & Renda Familiar \\
\hline Sequência de modos de viagens & Tempos de viagens por modo de transporte \\
\hline
\end{tabular}

\section{Para amostra de estudantes}

\begin{tabular}{c|c}
\hline $\begin{array}{c}\text { Cadeias de viagens mais complexas, intercalando } \\
\text { outras atividades ao estudo }\end{array}$ & Chefes de Família \\
\hline Sequência de Modos de Transporte & Número de automóveis no domicílio \\
Tipo de escola (Pública ou Particular)
\end{tabular}

\subsubsection{Comparação entre os modelos}

A Tabela 7.3 apresenta um resumo dos resultados das modelagens e as medidas de erro observadas na validação.

Tabela 7.3 - Resumo dos resultados das modelagens.

\begin{tabular}{lcccccc}
\hline \multirow{2}{*}{ AMOSTRAS E MODELOS } & $\begin{array}{c}\text { Rho- } \\
\text { quadrado } \\
\text { ajustado }\end{array}$ & Akaike & $\begin{array}{c}\text { Taxa } \\
\text { de } \\
\text { acertos }\end{array}$ & $\begin{array}{c}\text { Verossimilhança } \\
(\mathbf{L})\end{array}$ & $\begin{array}{c}\text { Log } \\
(\mathbf{L})\end{array}$ \\
\hline \multirow{2}{*}{ ESTUDANTES } & Modelo 1 & 0,170 & 304,483 & $37 \%$ & $3,35 \times 10^{-28}$ & $-63,26$ \\
\cline { 2 - 7 } & Modelo 2 & 0,267 & 268,909 & $55 \%$ & $2,05 \times 10^{-21}$ & $-47,64$ \\
\hline \multirow{2}{*}{ TRABALHADORES } & Modelo 1 & 0,248 & $14.109,94$ & $47 \%$ & $9,97 \times 10^{-16}$ & $-34,54$ \\
\cline { 2 - 7 } & Modelo 2 & 0,298 & $13.171,62$ & $56 \%$ & $1,78 \times 10^{-14}$ & $-31,66$ \\
\hline
\end{tabular}

Realizando-se a comparação entre os modelos 1 e 2, para cada uma das amostras, verificou-se um aprimoramento dos modelos a partir da inserção dos tempos de viagem dos modos de transporte. 
Os modelos de escolha discreta têm uma base teórica consistente (BRADLEY; DALY, 1994; CASCETTA et al., 2013), que proporcionam uma ligação com valores associados pelo indivíduo das diferentes variáveis, no processo de escolha. Percebe-se que a inserção do atributo referente à alternativa trouxe uma melhoria no grau de previsibilidade dos modelos, apresentando uma maior taxa de acertos.

Pode-se aferir que a inclusão da variável "tempo de viagem" ampliou a compreensão dos efeitos relativos ao ambiente de escolha e sobretudo sobre o comportamento de escolha (SWAIT; ADAMOWICZ, 1997). Percebeu-se que a incorporação dos tempos de viagem das demais alternativas ao Modelo 1 possibilitou incorporar um dado que está diretamente relacionado ao conjunto de atributos das escolhas individuais e dessa forma fornecer uma melhoria das especificações dos dados.

A caracterização do conjunto de escolhas, sobretudo em experimentos com uso de dados de Preferência Revelada, é um desafio enfrentado por pesquisadores (SWAIT; BEN AKIVA, 1988) e o método apresentado neste estudo traz uma alternativa simples para essa caracterização, que pode ser aplicada em outras variáveis que descrevem as alternativas.

Dados de Preferência Revelada e de Preferência Declarada têm sido amplamente aplicados em estudos de planejamento de transportes. A Tabela 7.4 relaciona os resultados de trabalhos que utilizaram dados combinados de PR e PD e os resultados mostraram que a combinação melhora a confiabilidade e previsibilidade dos modelos, já que se torna possível a caracterização do decisor e também do conjunto de alternativas, através de diferentes cenários. 
Tabela 7.4 - Trabalhos que utilizaram combinação de dados de PR e PD.

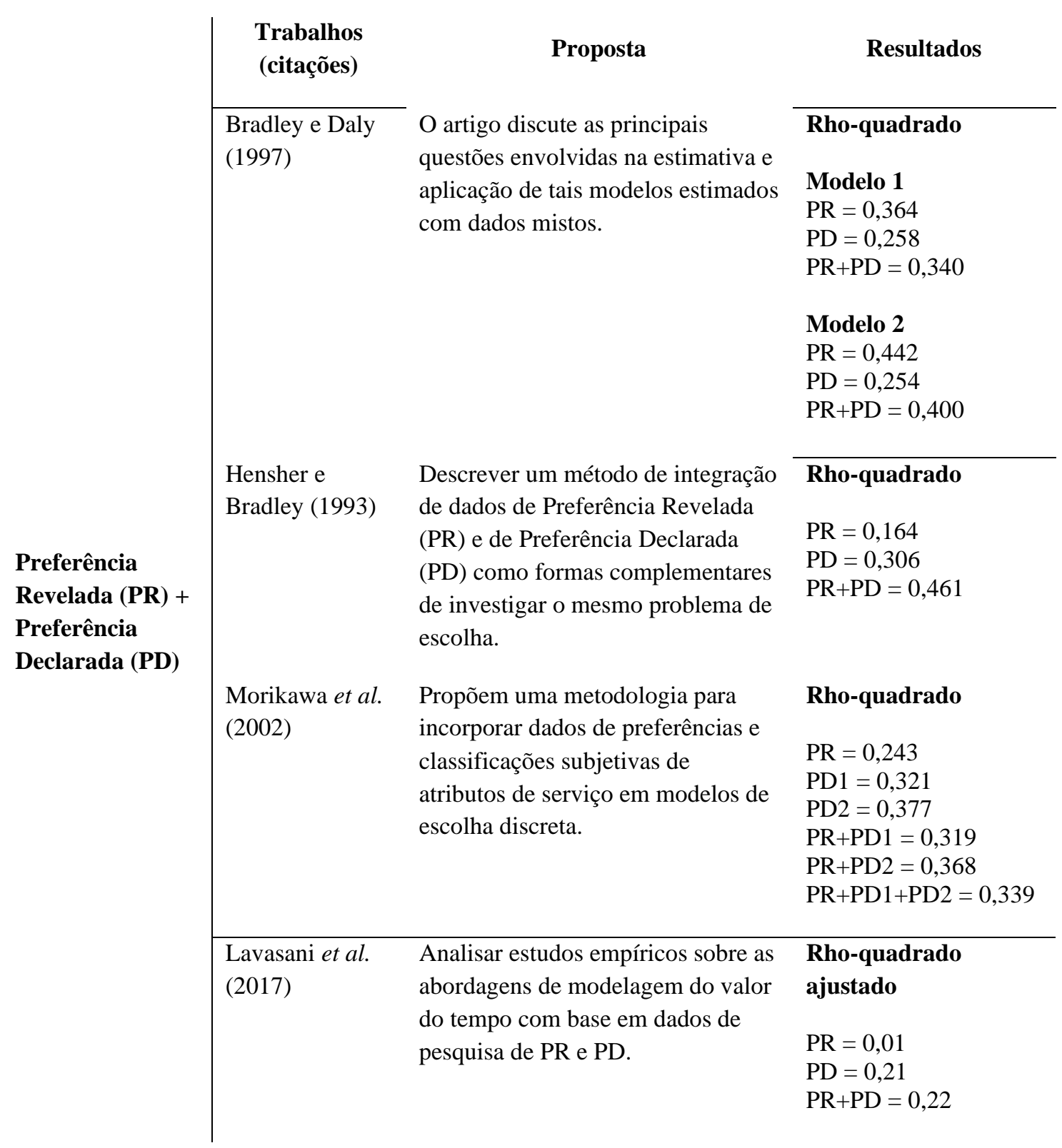




\section{Capítulo}

\section{CONSIDERAÇÕES \\ FINAIS, CONTRIBUIÇÕES E RECOMENDAÇÕES PARA TRABALHOS FUTUROS}

Este último capítulo descreve as principais conclusões deste trabalho. Inicia-se com a sintese do estudo apresentado, as hipóteses de pesquisa, as questões que incentivaram a pesquisa, os objetivos e, em seguida, são apresentadas as conclusões e contribuições. Finalmente, são propostas algumas sugestões para futuros trabalhos.

\subsection{SÍNTESE DO TRABALHO: OBJETIVOS, HIPÓTESES E LACUNAS DE PESQUISA}

O presente estudo foi conduzido a partir de dois problemas de pesquisa:

1. A necessidade de melhor representação do comportamento individual relativo a viagens com o uso da abordagem de viagens baseadas em atividades; e

2. Restrições da aplicação de modelo Logit Multinomial associadas ao uso de dados de Preferência Revelada no que se refere à ausência de dados que caracterizem o conjunto de alternativas e com relação à abordagem, a qual possui algumas restrições relativas a grandes conjuntos de alternativas.

Com isso, este estudo teve como objetivo principal analisar o comportamento relativo a viagens encadeadas para duas amostras de indivíduos, sendo uma amostra de trabalhadores e outra de estudantes. O objetivo geral deste trabalho, está estritamente vinculado ao problema de pesquisa 1 e às seguintes lacunas e hipóteses de pesquisa, respectivamente:

- Lacuna de pesquisa 1: Necessidade de melhor representação comportamental, associada aos deslocamentos, através de análise de viagens baseadas em atividades

- Hipótese de pesquisa 1: A análise de viagens baseadas em atividades permite um entendimento mais preciso do comportamento. 
Após a realização de um conjunto de procedimentos metodológicos, assume-se que tanto a primeira lacuna de pesquisa foi explorada quanto a primeira hipótese pôde ser comprovada, haja vista que, a partir da cadeia de viagens, o comportamento relativo a viagens pode ser representado de forma mais complexa, considerando a interdependência entre todas as viagens realizadas pelo mesmo indivíduo, bem como aspectos importantes das escolhas dos deslocamentos, como a sequência de motivos e modos de viagem.

A fim de se alcançar esse objetivo geral, foram propostos quatro objetivos específicos, associados a lacunas e hipóteses de pesquisas, explicitadas no início desta tese de doutoramento.

\subsubsection{Objetivo específico 1: Classificar os indivíduos em grupos que apresentem similares padrões de viagens encadeadas, utilizando-se as sequências de motivos e modos de viagem (Variável dependente)}

Além de ser um objetivo específico, é uma etapa metodológica importante, já que a classificação dos indivíduos em grupos de padrões de viagens encadeadas similares gera a variável dependente para a modelagem paramétrica posterior.

Utilizando o algoritmo Two-Step Cluster e, após diversos testes, foi obtido um total de cinco grupos para a amostra composta por estudantes e quinze grupos para a amostra composta por trabalhadores.

Para o caso dos estudantes, três grupos representavam padrões de ida e volta da escola, variando-se a sequência de modos de transportes. Os demais grupos eram compostos por indivíduos que faziam outra atividade (diferente de educação) e três ou quatro viagens, respectivamente.

Para o caso dos trabalhadores, houve quatro grupos de indivíduos que realizam duas viagens diárias, observando-se a predominância do padrão Residência - Trabalho - Residência -WH. Também foram obtidos quatro grupos de indivíduos que realizam três viagens, identificando-se variação da atividade "trabalho" com "estudo" e "outras atividades", além de viagens consecutivas com motivo "trabalho". Finalmente, foram obtidos sete grupos de indivíduos que realizaram quatro viagens no dia anterior à entrevista. Tanto para amostra de trabalhadores, como para amostra de estudantes, os grupos foram nomeados segundo padrões de viagens encadeadas similares. A partir de tal agrupamento, construiu-se o conjunto de alternativas para os modelos paramétricos. As probabilidades, posteriormente obtidas, 
correspondem à possibilidade de determinados indivíduos pertencerem a uma classificação de comportamento relativo a viagens encadeadas.

\subsubsection{Objetivo específico 2: Caracterizar, de forma agregada, as alternativas modais} a partir de dados de PR. O segundo objetivo específico deste trabalho está associado ao segundo problema de pesquisa, descrito anteriormente, além de estar relacionado às seguintes lacunas e hipóteses de pesquisa, respectivamente.

- Lacuna de pesquisa 2: Ausência de dados relativos às alternativas em pesquisas de Preferência Revelada (PR);

- Lacuna de pesquisa 3: Inadequação de modelos de escolha discreta, unicamente baseados em característica dos indivíduos;

- Hipótese de pesquisa 2: A utilização de algoritmos de Árvore de Decisão (AD) é adequada para obtenção de características agregadas das alternativas, com uso de dados de pesquisa de Preferência Revelada.

Através da aplicação de algoritmo de AD, foi possível caracterizar, de forma agregada, as alternativas modais disponíveis na área de estudo e assim estimar o tempo de viagem dos modos não utilizados.

As viagens foram agrupadas, segundo variáveis independentes selecionadas pelos algoritmos, e foram obtidos valores médios de tempos de viagens para as cinco alternativas modais: modo motorizado privado (1), ônibus (2), metrô ou trem (3), bicicleta (4) e a pé (5).

Foram utilizados dados desagregados por viagens, a variável dependente corresponde à duração das viagens e as variáveis independentes foram "zona de origem", "zona de destino", "motivo na origem", "motivo no destino", "hora de saída", "duração da viagem", "modo principal" e "distância".

As viagens foram agrupadas, segundo variáveis independentes selecionadas pelos algoritmos em 29 nós terminais, que são os 29 grupos de viagens similares formados pelo algoritmo CART.

A validação dessa etapa do método foi realizada fazendo a comparação dos tempos de viagem estimados com os valores das durações de viagens declarados na pesquisa de PR. A 
amostra foi dividida aleatoriamente em treinamento $(70 \%)$ e teste $(30 \%)$ e, em seguida, calculou-se as medidas de erros e de correlação considerando a amostra de teste.

A partir dos resultados, sucintamente descritos, pode-se verificar que a segunda hipótese de pesquisa pode ser corroborada, considerando a eficiência do método proposto para a obtenção das características agregadas das alternativas.

\subsubsection{Objetivo específico 3: Propor um critério para formulação do Modelo Logit Multinomial e redução de parâmetros a serem estimados}

Este objetivo relaciona-se estritamente às seguintes lacunas e hipóteses de pesquisa, respectivamente.

- Lacuna de Pesquisa 4: Ausência de critério para formulação das funções utilidade em caso de um alto número de alternativas e parâmetros a serem estimados.

- Hipótese de Pesquisa 3: Algoritmos de AD podem ser adequados no auxílio à formulação de funções utilidade para o conjunto vasto de alternativas.

Através dos procedimentos realizados, foi possível reduzir o número de parâmetros a serem estimados. Para isso, utilizou-se o algoritmo CART a fim de identificar as variáveis potencialmente não relevantes em cada função utilidade e dessa forma excluí-las.

As árvores geradas foram bivariadas (com apenas uma variável independente). A variável dependente foi o agrupamento dos indivíduos segundo padrões de viagens ( 5 e 15 grupos) e as variáveis independentes, geradas individualmente, foram as características socioeconômicas e de participação em atividades dos trabalhadores: "situação na família", "tipo de escola", "número de moradores", "quantidade de moto", "quantidade de automóvel", "quantidade de bicicleta", "renda familiar", "idade", "sexo", "grau de instrução" e as variáveis associadas à participação em atividades, "estuda”, "assalariado com carteira”, "assalariado sem carteira", "funcionário público", "autônomo", “empregador”, "profissional liberal”, "dono de negócio familiar", "trabalhador familiar", "tem outro trabalho".

Foram geradas 19 árvores bivariadas, com apenas uma divisão do conjunto total dos dados. O objetivo foi identificar, para cada variável independente, altas variações entre os nós filhos (mais de 10\%) de categorias da variável dependente, que apontam uma relevância de determinada variável explicativa na utilidade de uma alternativa específica. 
$\mathrm{Na}$ amostra de estudantes foram excluídos 2 parâmetros e na amostra de trabalhadores, 112 parâmetros. Em decorrência dessa redução, foi possível calibrar os modelos Logit Multinomial pois especialmente a amostra de trabalhadores era composta com grande número de variáveis explicativas.

Baseando-se nos resultados encontrados, pode-se afirmar que o procedimento proposto funciona bem para um caso de modelagem de um conjunto grande de alternativas. No entanto, tal procedimento deve ser mais bem aprofundado, no futuro, a fim de determinar qual a variação ideal da variável dependente deve ser considerada para determinação das variáveis explicativas a serem incluídas nas funções utilidade.

\subsubsection{Objetivo específico 4: Incorporar as variáveis agregadas, obtidas em (2), e mensurar} o aprimoramento nas estimativas através de Modelo Logit Multinomial.

Finalmente, este último objetivo associa-se à seguinte hipótese de pesquisa.

- Hipótese de pesquisa 4: A modelagem do comportamento individual associado a viagens encadeadas, pode ser aprimorada, a partir da inclusão de características agregadas de alternativas modais, estimadas a partir de dados de PR.

A proposta desta etapa do trabalho foi testar o aprimoramento do modelo a partir da inclusão de variáveis que caracterizam as alternativas. Para isso, foi definido um Modelo 1, para estudantes e trabalhadores. Os modelos iniciais continham apenas variáveis socioeconômicas e participação em atividades, enquanto o Modelo 2, para ambas as amostras, incorporava as variáveis agregadas de tempos de viagem.

No que se refere à investigação do comportamento associado a viagens encadeadas para a amostra de estudantes, verificou-se que as cadeias de viagens mais complexas, intercalando outras atividades com a atividade de estudo estão diretamente relacionadas aos responsáveis pela família; a sequência de modos de transporte depende do número de automóveis no domicílio e do tipo de escola, se é pública ou particular e a sequência de viagens a pé está relacionada aos tempos de viagens por modo de transporte (a pé). 
Para a amostra de trabalhadores, sobre o comportamento associado a viagens encadeadas, observou-se que:

- A sequência de modos de transporte para essa amostra está diretamente relacionada ao número de automóveis no domicílio, à renda familiar, ao grau de instrução e ao gênero;

- A variação da escolha modal na sequência de viagens realizadas ao longo do dia depende das atividades de funcionário Público e profissional liberal;

- A sequência de viagens incluindo motivos diferentes de "Trabalho" está relacionado às atividades de estudante, profissional autônomo, com carteira assinada e liberal;

- As cadeias de viagens mais complexas, intercalando outras atividades ao trabalho estão diretamente relacionadas às mulheres e aos chefes de família;

- As cadeias com viagens consecutivas com motivo "Trabalho" estão relacionadas aos indivíduos que possuem dois trabalhos diferentes;

- O maior número de viagens se dá por indivíduos com maior renda familiar;

- A sequência de modos de viagens está relacionada aos tempos de viagens por modo de transporte.

As medidas de erro observadas na validação dos modelos (Modelos 1 e Modelos 2), tanto da amostra de estudantes, como de trabalhadores, apontaram o aumento da acurácia a partir da inclusão de variável que caracteriza as alternativas (tempos de viagens agregados).

Os resultados obtidos foram satisfatórios com a proposta de investigar o comportamento relativo a viagens encadeadas através da abordagem baseada em atividades que permite uma análise mais detalhada do comportamento individual e da sequência de viagens realizadas.

Finalmente, a Figura 8.1, ilustra sucintamente a relação entre os objetivos deste trabalho, lacunas e hipóteses de pesquisa. 
Figura 8.1 - Relação entre os objetivos, lacunas e hipóteses de pesquisa.

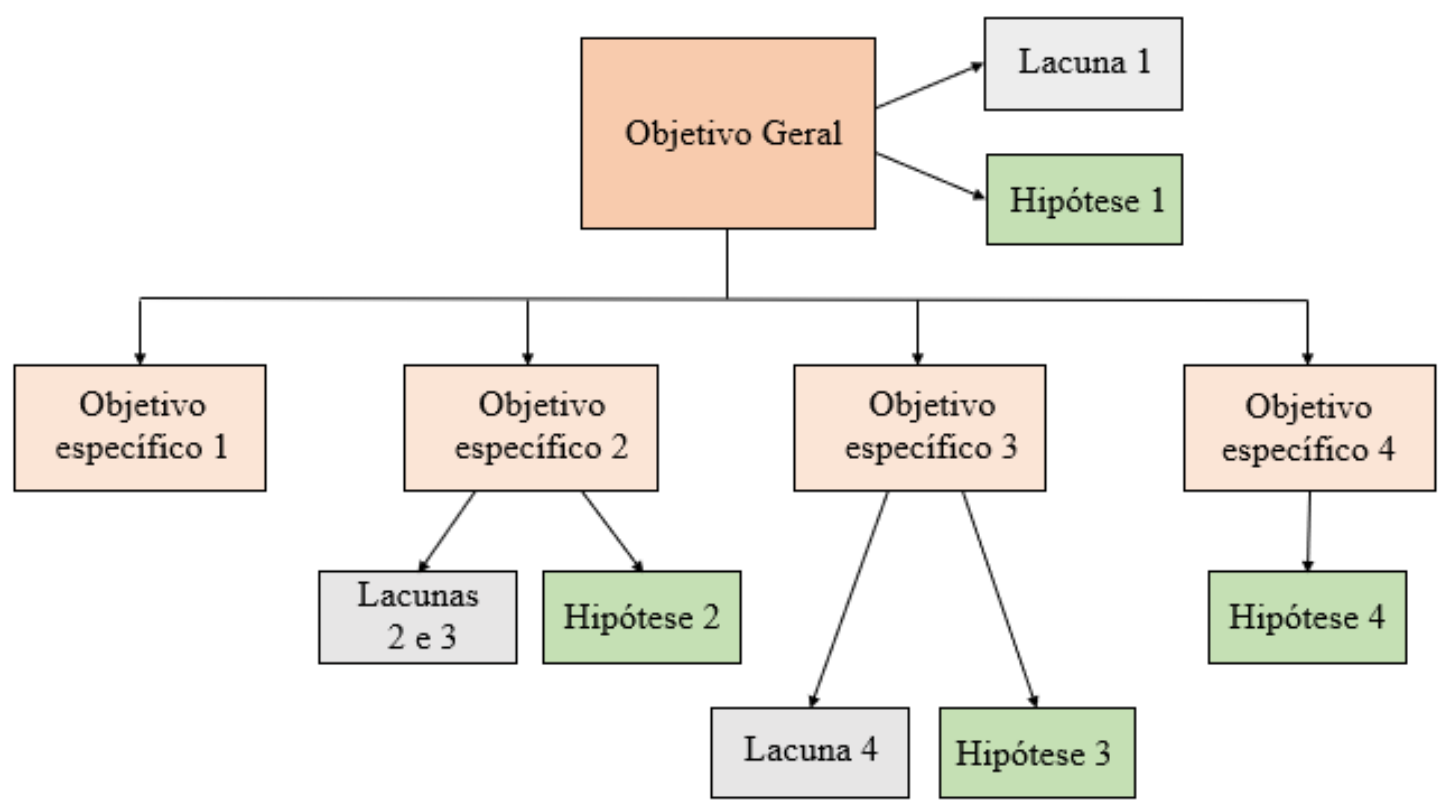

\subsection{CONCLUSÕES E CONTRIBUIÇÕES}

As conclusões extraídas dos resultados são descritas a seguir a partir das hipóteses que foram levantadas anteriormente.

\subsubsection{Viagens baseadas em atividades}

Este trabalho, através do emprego sequencial de técnicas de Análise Multivariada de dados, investigou o comportamento individual relativo a viagens, considerando a abordagem de viagens baseada em atividades.

Levando-se em conta a Hipótese 1 observou-se que os resultados obtidos foram satisfatórios e que as escolhas das atividades ao longo do dia não são escolhas desvinculadas, ou seja, a escolha de uma determinada atividade está associada à atividade anterior e à posterior, criando-se um encadeamento de viagens correlacionadas. Essa análise não seria possível, através de modelos baseados em viagens. A formulação considerou implicitamente as escolhas individuais de participação nas atividades e modos de transporte, como transporte privado, transporte público e não motorizado. 
Os resultados obtidos na fase de modelagem, mostraram que os aspectos estruturais considerados na definição dos modelos foram satisfatórios. A separação dos grupos de estudantes e trabalhadores foi fundamental para se conseguir fazer a caracterização dos grupos.

\subsubsection{Caracterização agregada das alternativas}

Buscando testar a Hipótese 2 deste trabalho, para obtenção da característica agregada das alternativas, foi utilizado um conjunto de variáveis associadas às viagens e proposto um critério, baseado em algoritmo não paramétrico (CART), para obtenção de valores médios de variáveis que caracterizem as alternativas.

O algoritmo baseia-se na formação de grupos homogêneos, a partir da variável dependente, e otimização dos grupos considerando a escolha das variáveis independentes (assim como valores de corte) que tornam as divisões de classes homogêneas.

Considerando que a pesquisa OD é a pesquisa mais utilizada como fonte de dados para os trabalhos na área de planejamento de transportes e que o fato de não apresentar informações relativas às alternativas que não foram efetivamente utilizadas pelo entrevistado é um fator limitante a estudos que envolvem modelagem, o procedimento apresentou contribuições importantes para a caracterização dessas alternativas e, dessa forma, melhorar o poder preditivo dos modelos.

Outros trabalhos, encontrados na literatura, propuseram a caracterização agregada das alternativas a partir de critérios empíricos (FEZZI et al., 2014; KATO et al., 2013; SOUZA et $a l ., 2017)$. Neste estudo foi proposto um critério, com a aplicação de algoritmo não paramétrico, para o agrupamento de viagens e obtenção de valores médios de variáveis que caracterizem alternativas (determinados pelos nós terminais), sendo um método mais robusto.

O algoritmo apresentou bons resultados de acordo com as validações realizadas e o método pode ser replicado para qualquer outra variável que caracterize as alternativas modais, sendo uma técnica de fácil aplicação, sem restrições relacionadas a tipos de variáveis ou distribuições populacionais. 


\subsubsection{Redução de parâmetros a serem estimados}

A combinação de diferentes aspectos da demanda em múltiplas viagens em sequência ocasionou um grande conjunto de alternativas, que implica em muitos parâmetros a serem estimados, sobretudo para modelos específicos, como é o caso deste trabalho, criando a necessidade da utilização de ferramentas computacionais robustas e onerosas para viabilizar a calibração.

Neste estudo, a principal restrição associada ao uso do modelo Logit Multinomial estava associada ao grande conjunto de alternativas. Dessa forma, a aplicação do algoritmo CART como ferramenta auxiliar na modelagem paramétrica foi fundamental nessa formulação apontando as variáveis importantes a partir da $\mathrm{AD}$ e corroborando a Hipótese 3 deste estudo associada ao critério para formulação do Modelo Logit Multinomial e redução de parâmetros a serem estimados.

O procedimento proposto foi aplicado visando auxiliar a formulação do modelo Logit Multinomial a partir da redução da quantidade de parâmetros a serem estimados e consiste em uma contribuição importante para qualquer problema de pesquisa com um grande conjunto de alternativas, uma vez que há restrições operacionais importantes devido ao alto número de parâmetros a serem estimados nesses casos.

Vale ratificar que o procedimento aplicado é simplificado e que pode ser objeto de validações futuras, de forma a aferir se as variáveis retiradas das funções utilidade são realmente associadas à estimação de parâmetros não significativos, para um nível de confiança de 95\%.

\subsubsection{Aprimoramento do modelo}

Na Hipótese 4 pretendeu-se verificar se a modelagem do comportamento individual associado a viagens encadeadas, pode ser aprimorada, a partir da inclusão de características agregadas de alternativas modais, estimadas a partir de dados de PR.

O conjunto de alternativas do Modelo Logit Multinomial, utilizado nesta tese, refere-se aos 5 e 15 clusters que identificam padrões de viagens encadeadas semelhantes referentes aos grupos de estudantes e de trabalhadores, respectivamente. Neste trabalho, todas as viagens encadeadas, realizadas por um indivíduo ao longo do dia, são representadas através de um único bloco (representação alfanumérica) do número de viagens, da sequência de motivos e modos de transporte que identificam os diferentes padrões de viagem. 
A partir da análise comparativa entre os Modelos 1 e 2, verificou-se o incremento na acurácia a partir da inclusão de características das alternativas (tempos médios de viagem). Ocorreu o aumento do valor do rho quadrado ajustado, diminuição do valor do Critério Akaike, além do aumento na taxa de acertos e do valor da verossimilhança, indicando melhorias do Modelo 2 em relação ao Modelo 1, corroborando a Hipótese 4 deste estudo.

\subsubsection{Investigação do comportamento relativo a viagens encadeadas}

Finalmente, os resultados obtidos foram satisfatórios considerando o objetivo principal desta tese, que foi a proposta de investigar o comportamento relativo a viagens encadeadas para duas amostras de indivíduos, sendo uma amostra de trabalhadores e outra de estudantes.

A investigação se deu através da participação em atividades, das variáveis socioeconômicas e a inclusão de características modais agregadas, obtidas através do algoritmo CART e da Pesquisa OD realizada na Região Metropolitana de São Paulo em 2007. A partir da observação dos parâmetros estimados nos modelos foi possível identificar relações coerentes, corroboradas pela literatura, descritas no Capítulo 7.

Esta pesquisa tem suas maiores contribuições associadas ao procedimento metodológico. Apresentou-se uma sequência metodológica que pode ser replicada em outros trabalhos para a investigação de comportamentos de viagens encadeadas referentes a outros grupos ou segmentos populacionais.

\subsection{RECOMENDAÇÕES PARA TRABALHOS FUTUROS}

Os modelos desenvolvidos deste estudo são derivados dos dados da pesquisa OD, que são dados desagregados referentes a um dia do entrevistado. Recomenda-se, para trabalhos futuros, a utilização de diários de atividades ou dados em painel com a aplicação de tecnologia GPS (Global Positioning System), que caracterizassem mais dias da semana, e dados de final de semana com o intuito de uma melhor caracterização das variações intrapessoais no tempo e no espaço dos comportamentos relativos à viagem.

A etapa do método utilizado para fazer a caracterização agregada das alternativas modais com utilização de dados de Preferência Revelada é de fácil aplicação e sem restrições relacionadas a tipos de variáveis ou distribuições populacionais. Logo pode ser replicada para 
qualquer outra variável que caracterize as alternativas modais, como custo de viagem, por exemplo.

Também pode ser um potencial trabalho futuro, a comparação das características das alternativas, obtidas a partir do procedimento proposto, com dados (como duração de viagens) extraídos através de apps modernos e de fácil utilização, considerando as origens e destinos e horários do dia.

Pode-se citar também a necessidade de aprimoramento da estratégia incialmente aqui proposta para redução de parâmetros a serem utilizados nos modelos Logit Multinomiais, para um grande conjunto de alternativas. É necessário se fazer uma análise de sensibilidade para determinar o quanto a exclusão de determinadas variáveis explicativas pode prejudicar a acurácia de tais modelos.

Finalmente, sugere-se inclusão de covariáveis espaciais, a fim de investigar o quanto a dependência espacial pode influenciar o comportamento relativo a viagens encadeadas. 


\section{REFERÊNCIAS}

ABDEL-ATY, M.; KITAMURA, R.; JOVANIS, P. Using stated preferences data for studying the effect of advanced traffic information on drivers' route choice. Transportation Research Part C, v. 5, n. 1, p. 39-50, 1997.

ADLER, T.; BEN-AKIVA, M. A Theoretical and empirical model of trip-chaining behavior, Transportation Research, 13B, p. 243-257, 1979.

ALEX, A. P.; SARASWATHY, M. V.; ISAAC, K. P. Latent variable enriched mode choice model for work activity in multi modal condition prevalent in India. International Journal for Traffic and Transport Engineering, v. 6, n. 4, p. 378-389, 2016.

ANDERBERG, M. R. Cluster analysis for applications. New York: Academic Press, 1973.

ANTONINI, G.; BIERLAIRE, M.; WEBER, M. Discrete choice models of pedestrian walking behavior. Transportation Research Part B, v. 40, p. 667-687, 2006.

ANTONIOU, C.; MATSOUKIS, E.; ROUSSI, P. A Methodology for the estimation of valueof-time using state-of-the-art econometric models. Journal of Public Transportation, v. 10, n. 3, p. 1-20, 2007.

ARRUDA, F. S. Aplicação de um modelo baseado em atividades para análise da relação uso do solo e transportes no contexto brasileiro - Doutorado, 2005 - Engenharia de São Carlos da Universidade de São Paulo.

ASSIRATI, L. Análise da influência da vizinhança no comportamento individual relativo a viagens através de dados em painel. 2018. Tese (Doutorado) - Escola de Engenharia de São Carlos, Universidade de São Paulo, São Carlos, 2018.

ASSIRATI, L.; PITOMBO, C. S. Classificação de indivíduos segundo comportamento individual relativo a viagens a partir de dados em painel obtidos por smartphones.

Transportes, Rio de Janeiro, v. 27, p. 165-181, 2019.

BAJWA, S.; BEKHOR, S.; KUWAHARA, M.; CHUNG, E. Discrete choice modeling of combined mode and departure time. In: INTERNATIONAL CONFERENCE ON TRAVEL BEHAVIOUR RESEARCH, 11., 2008, Kyoto. Paper presented [...]. Kyoto, 2008.

BARFF, R.; MACKAY, D.; OLSHAVSKY, R. W. A Selective review of travel-mode choice models. Journal of Consumer Research, v. 8, n. 4, p. 370-380, Mar. 1982.

DOI: https://doi.org/10.1086/208877.

BEKHOR, S., SHIFTAN, Y. Specification and Estimation of Mode Choice Model Capturing Similarity between Mixed Auto and Transit Alternatives. Journal of Choice Modelling, v. 3, n. 2, p. 29-49, 2010.

BEN-AKIVA M.; BOWMAN J. L. Travel demand model system architecture with daily activity schedules, M.I.T. Internal Report. 1994.

BEN-AKIVA M.E.; MORIKAWA T. Estimation of switching models from revealed preferences and stated intentions. Transportation Research, v. 24A, n. 6, p. 485-495, 1990. 
BEN-AKIVA, M.; BIERLAIRE, M. Discrete choice models with applications to departure time and route choice. In: HALL, R.W. (ed.). The Handbook of transportation science. $2^{\text {nd }}$ ed. Oxford: Kluwer Academic, 2003. p. 7-38.

BEN-AKIVA, M.; LERMAN, S. R. Discrete choice analysis: theory and application to travel demand. Cambridge: MIT Press, 1985. (MIT Press Series in Transportation Studies, 9).

BEN-AKIVA, M.; LITINAS, N.; TSUNOKAWA, K. Continuous spatial choice: the continuous logit model and distributions of trips and urban densities. Transportation Research Part A: general, v. 19, n. 2, 119-154, Mar. 1985.

BEN-AKIVA, M.; MORIKAWA, T. Estimation of switching models from revealed preferences and stated intentions. Transportation Research Part A: General, v. 24, p. $485-$ 495, 1990a.

BEN-AKIVA, M.; T. MORIKAWA. Estimation of travel demand models from multiple data sources. In: THE INTERNATIONAL SYMPOSIUM ON TRANSPORTATION AND TRAFFIC THEORY, 11., Yokohama. Proceedings[...]. Yokohama, $1990 \mathrm{~b}$.

BEN-AKIVA, M.E.; BOWMAN, J.L. Activity based travel demand model systems. In: MARCOTTE, P.; NGUYEN, S. (ed.). Equilibrium and advanced transportation modelling [Online]. Boston: Springer, 1998. p. 27-46. Disponível em: http://link.springer.com/10.1007/978-1-4615-5757-9_2. 1998. Acesso em: 5 out. 2020.

BHAT, C. A Heteroskedastic extreme value model of intercity travel mode choice. Transportation Research B, v. 29, p. 471-483, 1995.

BHAT, C. Incorporating observed and unobserved heterogeneity in urban work travel mode choice modeling. Transportation Science, v. 34, n. 2, p. 228-238, May 2000.

BHAT, C. R.; KOPPELMAN, F. S. Activity-based modeling of travel demand. In: HALL, R. W. Handbook of transportation science. Boston: Springer, 2003. p. 39-65.

BHAT, C. R.; KOPPELMAN, F.S. A Conceptual framework of individual activity program generation. Transportation Research Part A, v. 27, p. 433-446, 1991.

BHAT, C. R.; STEED, J. L. A Continuous-time model of departure time choice for urban shopping trips. Transportation Research B, v. 36, p. 207-224. 2002.

BHAT, C.R. Work travel mode choice and number of non-work commute stops, Transportation Research, v. 31B, p. 41-54. 1997.

BHAT, C.R.; GOSSEN, R. A Mixed multinomial logit model analysis of weekend recreational episode type choice. Transportation Research Part B, v. 38, p. 767-787, 2004.

BHAT, C.R.; GUO, J.Y.; SRINIVASAN, S.; SIVAKUMAR, A. A Comprehensive econometric micro-simulator for daily activitytravel patterns. Transportation Research Record, v. 1894, n. 1, p. 57-66, Jan. 2004.

BHAT, C.R.; KOPPELMAN, F.S. Activity-based modeling of travel demand. In: HALL, R.W. (ed.). Handbook of transportation science. Boston: Springer, 1999. v. 23. (International 
Series in Operations Research \& Management Science). DOI: https://doi.org/10.1007/978-14615-5203-1_3.

BIANCO, M.; LAWSON, C. Trip chaining, childcare, and personal safety. In: WOMEN'S TRAVEL ISSUES, PROCEEDINGS FROM THE SECOND NATIONAL CONFERENCE. Department of Transportation, 1998. (Report FHWA-PL-97-024. FHWA, U.S.)

BIERLAIRE, M. A Short introduction to pandas biogeme: technical report TRANSP-OR 200605: Transport and Mobility Laboratory. ENAC, EPFL, Jun. 2020.

BIFULCO, G. N.; CARTENÌ, A.; PAPOLA, A. An Activity-based approach for complex travel behavior modeling. European Transport Research Review, v. 2, n. 4, p. 209-221, 2010.

BORDLEY, R. Discrete choice with large choice sets. Economics Letters 118(1), 2013, 13 15. https://doi.org/10.1016/j.econlet.2012.05.010.

BORDLEY, R. Discrete choice with large choice sets. Economics Letters 118(1), 2013, 1315. https://doi.org/10.1016/j.econlet.2012.05.010.

BOWMAN, J. L. Activity based travel demand model systemwith daily activity schedules. 1995. Thesis (Master - Departament of Civil and Environmental Engineering) Massachusetts Institute of Technology, 1995.

BOWMAN, J. L., BEN-AKIVA, M. E. Activity-based disaggregate travel demand model system with activity schedules, Transportation Research Part A: Policy and Practice 35(1), 2001, 1-28. https://doi.org/10.1016/S0965-8564(99)00043-9.

BOWMAN, J.L.; BEN-AKIVA, M.E. Activity-Based Travel Forecasting. In: Activity-Based Travel Forecasting Conference, June 2-5, 1996: Summary, recommendations and Compendium of Papers, New Orleans, Louisiana, USA, 1997, USDOT report\#DOT-t-9717.32p.

BRADLEY, M. A.; DALY, A. J. Estimation of logit choice models using mixed stated preference and revealed preference information. In: STOPHER, P.R.; LEE-GOSSELIN, M. (ed.). Understanding travel behaviour in an era of change. Oxford: Pergamon, 1997. p. 209232.

BRADLEY, M.; BOWMAN, J.L., GRIESENBECK, B. SACSIM: an applied activity-based model system with fine-level spatial and temporal resolution. Journal of Choice Modelling, v. 3, n. 1, p. 5-31, 2010.

BRADLEY, M.; DALY, A. Use of the logit scaling approach to test for rank-order and fatigue effects in stated preference data. Transportation, v. 21, n. 2, p. 167-184, 1994.

BRASIL. Lei $n^{o} 11.700$, de 13 de junho de 2008. Acrescenta inciso X ao caput do art. 40 da Lei n. 9.394, de 20 de dezembro de 1996. Congresso Nacional. Disponível em: https://www6g.senado.leg.br/buscacongresso/?q=Lei+n\%C2\%BA+11.700+de+13+de+Junho+de+2008. Acesso em: 22 ago. 2020.

BREIMAN, L.; FRIEDMAN, J.; CHARLES, J.; STONE, R. A.; OLSHEN, R. A. Classification and regression trees. Belmont: Wadsworth International Group, 1984. 
BRICKA, S. Trip chaining: linking the influences and implications. Austin: University of Texas at Austin, 2008.

BROCK, W. A.; DURLAUF; S. N. Discrete choice with social interactions. Review of Economic Studies, v. 68, n. 2, p. 236-260, 2001.

BUEHLER, R.; HAMRE, A. The Multimodal majority? Driving, walking, cycling, and public transportation use among american adults. Transportation, v. 42, n. 6, p. 1081-1101, 2015. DOI:10.1007/s11116-014-9556-z.

CAN, V. V. Estimation of travel mode choice for domestic tourists to Nha Trang using the multinomial probit model. Transportation Research Part A: policy and practice, v. 49, p. 149-159, 2013.

CARDELL N.; DUNBAR F. Measuring the societal impacts of automobile downsizing. Transportation Research 14A, n. 5-6, p. 423-434, 1980.

CASCETTA, E., CARTENİ, A.; MONTANINO, M. A New measure of accessibility based on perceived opportunities. Procedia - Social and Behavioral Sciences, v. 87, p. 117-132, 2013.

CERVEIRA, C.F.; GOMES, V.A.; PITOMBO, C.S. Proposta de critério para caracterização agregada das alternativas modais a partir de dados de preferência revelada. In: CONGRESSO DA ANPET, 32., Gramado, RS., 2018. Anais [...]. Gramado: Anpet, 2018.

CHAKRAVATI, D.; SINHA, A. R.; JAEWHAN, K. Choice research: a wealth of perspectives. Marketing Letters, v. 16, n. 3-4, p. 173-182, Dec. 2005.

CHAPIN JR., F.S. Free-time activities and the quality of urban life, Journal of the American Institute of Planners, v. 37, p. 411-417, 1971.

CHEN, L., DUANN, W. HU. The estimation of discrete choice models with large choice-set. Journal of the Eastern Asia Society for Transportation Studies 6, 2005, 1724-1739. https://doi.org/10.11175/easts.6.1724.

CHEN, L., DUANN, W. Hu. The estimation of discrete choice models with large choice-set. Journal of the Eastern Asia Society for Transportation Studies 6, 2005, 1724-1739. https://doi.org/10.11175/easts.6.1724

CHIKARAISHI, M.; ZHANG, J.; FUJIWARA, A.; AXHAUSEN, K.W. Identifying variations and co-variations in discrete choice models. Transportation, v. 38, n. 6, p. 993-1016, 2011.

CHIU, T.; FANG, D.; CHEN, J.; WANG, Y.; JERIS, C. A Robust and scalable clustering algorithm for mixed type attributes in large database environment. In: ACM SIGKDD INTERNATIONAL CONFERENCE ON KNOWLEDGE DISCOVERY AND DATA MINING, 70., San Francisco. Proceedings [...]. San Francisco: ACM, 2001. p. 263-268.

CHOW, J.Y.J.; DJAVADIAN, S. Activity-based market equilibrium for capacitated multimodal transport systems. Transportation Research Part C: emerging technologies, n. 59, p. 2-18. DOI:10.1016/j.trc.2015.04.028. 2015. 
CIRILLO, C.; AXHAUSEN, K.W. Comparing urban activity travel behaviour. Zurich: Swiss Federal Institute of Technology, Institute of Transportation, Traffic, Highway and RailwayEngineering. 2001.

CLARKE, M.I. Activity modeling: a research tool or a practical planning technique? In: BEHAVIORAL research for transport policy. Noordwijk: VNU Sciences, 1986.

CULLEN, I.; V. GODSON. Urban networks: the structure of activity patterns. Progress in Planning, v. 4, part 1, p. 1-96, 1975.

DAISY, N. S.; LIU, L.; MILLWARD, H. Trip chaining propensity and tour mode choice of out-of-home workers: Evidence from a mid-sized Canadian city. Transportation, n. 2, p. 1-30, 2018a. [Google Scholar].

DAISY, N. S.; MILLWARD, H.; LIU, L. Trip chaining and tour mode choice of non-workers grouped by daily activity patterns. Journal of Transport Geography, v. 69, p. 150-162, 2018b. DOI:10.1016/j.jtrangeo.2018.04.016. [Crossref], [Google Scholar].

DAMM, D. Interdependencies in activity behavior. Transportation Research Record 750, p. 33-40, 1980.

DAVIDSON, W.; DONNELLY, R.; VOVSHA, P.; FREEDMAN, J.; RUEGG, S.; HICKS, J.; CASTIGLIONE, J.; PICADO, R. Synthesis of first practices and operational research approaches in activity-based travel demand modelling, Transportation Research Part A, v. 41, p. 464-488, 2007.

DE LAPPARENT, M. Attitude toward risk of time loss in travel activity and air route choices. Journal of Intelligent Transportation Systems., v. 14, p. 166-178, 2010.

DHIBI, M.; BELKACEM, L. The Sampling effect on the value of travel-time savings: estimation by discrete choice models on Tunisian data. Advances in Transportation Studies, p. 29, Apr. 2013

DING, L.; ZHANG, N. A Travel mode choice model using individual grouping based on cluster analysis. Procedia Engineering, v. 137, p. 786-795, 2016.

Disponível em: http://www.escholarship.org/uc/item/0r75311t. Acesso em: 6 out. 2020.

DOMECICH, T. A., MCFADDEN, D. Urban travel demand: A behavioral analysis, North Holland Publishing Co., NY, USA, 1975.

DOMECICH, T. A.; MCFADDEN, D. Urban travel demand: a behavioral analysis. Transportation Research, 1975. DOI: 10.1016/0041-1647(76)90063-0.

ELURU, N.; CHAKOUR, V.; EL-GENEIDY, A. Travel mode choice and transit route choice behavior in Montreal: insights from Mcgill University members commute patterns. Public Transport, v. 4, n. 2, p. 129-149, 2012.

ETTEMA, D. Activity-based travel demand modeling. Thesis (Doctoral) - Technische Universiteit Eindhoven, Holanda, 1996. 
ETTEMA, D.; BORGERS, A.W.J.; TIMMERMANS, H.J.P. Simulation model of activity scheduling behavior. Transportation Research Record, v. 1413, p. 1-11, 1993.

FEZZI, C.; FERRINI, S. BATEMAN, I. J. Using revealed preferences to estimate the value of travel time to recreation sites. Journalof Environmental Economics Management, v. 67, p. 58-70, 2014. DOI:10.1016/j.jeem.2013.10.003.

FORINASH, C.V.; KOPPELMAN, F.S. Application and interpretation of nested logit models of intercity mode choice. Innovations in travel behaviour analysis, demand forecasting, and modeling networks. Transportation Research Record 1413, p. 98-106, 1993.

FOSGERAU, M.; RANJAN, A. A Note on identification in discrete choice models with partial observability. Theory and Decision, v. 83, n. 2, p. 283-292, 2017.

FREJINGER, E. Route choice analysis: data, models, algorithms and applications. France: École Polytechnique Fédérale de Lausanne, 2008.

FREJINGER, E.; BIERLAIRE, M. Capturing correlation with subnetworks in route choice models. Transportation Research Part B: methodological, v. 41, n. 3, p. 363-378, 2007.

GAO, S.; FREJINGER, E.; BEN-AKIVA, M. E. Adaptive route choice models in stochastic time-dependent networks. Transportation Research Record: journal of the transportation research board, Washington, D.C., n. 2085, p. 136-143, 2008.

GÄRLING, T.; SCHUITEMA, G. Travel demand management targeting reduced private car use: effectiveness, public acceptability and political feasibility. Journal of Social Issues, v. 63, n. 1, p. 139-153, 2007. DOI:10.1111/j.1540-4560.2007.00500.x.

GAUDRY, M.; LAPPARENT, M. Attitudes to distance, time and cost in logit transport choice models. ReseachGate, 2015. Publication AJD-146, Agora Jules Dupuit, Université de Montréal and Report TRANSP-OR 150113 of the Transport and Mobility Laboratory, École Polytechnique Fédérale de Lausanne 10 pages.

GOETZKE F.; ANDRADE, P. M. Walkability as a summary measure in a spatially autoregressive mode choice model: an instrumental variable approach. Advances in Spatial Sciences, p. 217-229, Sept. 2009.

GOMES, V.A.; CALDAS, M.U.C; PITOMBO, C.S. An investigation of trip-chaining behaviour based on activity participation, socioeconomic variables and aggregated characteristics of modal alternatives. Revista Transportes, vol 29, número 1, pp 21-41, 2021. 10.14295/transportes.v29i1.2302

GORDON, P.; KUMAR, A.; RICHARDSON, H. Gender differences in metropolitan travel behavior. Regional Studies, v. 23, p. 499-510, 1989.

GREENWALD, M. J. The Relationship between land use and intrazonal trip making behaviors: Evidence and implications. Transportation Research Part D: transport and environment, v. 11, n. 6, p. 432-446, 2006.

GUEVARA, C.; BEN-AKIVA M. Endogeneity in residential location choice models. Transportation Research Record, v. 77, p. 60-66, 2006. 
GUEVARA, C.; BEN-AKIVA, M. Change of scale and forecasting with the control-function method in logit models. Transportation Science, v. 46, n. 3, p. 425-437, 2012.

DOI: $10.1287 /$ trsc. 1110.0404 .

GUN, V.D.; PEL, J.A.; AREM, B.V. A General activity-based methodology for simulating multimodal. Transportation networks during emergencies. European Journal of Transport and Infrastructure Research, v. 16, 2, n. 3, 2016.

HÄGERSTRAND, T. Tidsanvändning och omgivningsstruktur, Urbanisering i Sverige: en geografisk samhällsanalys. Stockholm: Statens Offentliga Utredningar, Allmänna Förlaget, 1970. v.14.

HAIR JUNIOR, J. F.; BLACK, W. C.; BABIN, B. J.; ANDERSON, R. E.; TATHAN, R. L. Análise multivariada de dados. 6.ed. Porto Alegre: Bookman, 2009.

HAO, J.; HATZOPOULOU, M.; MILLER, E. Integrating an activity based travel demand model with dynamic traffic assignment and emission models. Transportation Research Record: journal of the transportation research board, v. 2176, n. 1, p. 1-13, 2010.

HARTGEN, D. T. Attitudinal and situational variables influencing urban mode choice: some empirical findings. Transportation, v. 3, p. 377-392, Dec. 1974.

DOI: https://doi.org/10.1007/BF00167967 .

HARTIGAN, J. A. Clustering algorithms. New York: John Wiley, 1975.

HEINEN, E. Identity and travel behavior: a cross-sectional study on commute mode choice and intention to change. Transportation Research Part F: traffic psychology and behaviour, v. 43, p. 238-253, 2016.

HENSHER, D.; BRADLEY, M. Using stated response data to enrich revealed preference discrete choice models. Marketing Letters, v. 4, p. 39-152, 1993.

HENSHER, D.; LOUVIERE, J.; SWAIT, J. Combining sources of preference data. Journal of Econometrics, v. 87, p. 97-221, 1999.

HESS, S. Modelling air travel choice behaviour. In: FORSYTH, P.; GILLEN, D.; MULLER, J.; NIEMEIER, H. (ed.). Airport competition: the european experience. Burlington: Ashgate, 2010. p. 151-175.

HESS, S.; POLAK, J.; DALY, A.J. On The Performance of the shuffled Halton sequence in the estimation of discrete choice models. In: EUROPEAN TRANSPORT CONFERENCE. Paper presented [...], 2003.

HESS, S.; QUDDUS, M.; RIESER-SCHÜSSLER, N.; DALY, A. Developing advanced route choice models for heavy goods vehicles using GPS data. Transportation Research Part E: logistics and transportation review, v. 77, p. 29-44, 2015.

HIRSH, M.; PRASHKER, J. N.; BEN-AKIVA, M. E. Dynamic model of weekly activity pattern. Transportation Science, v. 20, p. 24-36, 1986.

HOLGUÍN-VERAS, J.; THORSON, E. Modeling commercial vehicle empty trips with a first order trip chain model. Transportation Research B, v. 37, n. 2, p. 129-148, 2003. 
IBM. IBM SPSS Statistics 22 Algorithms. Chicago: Author, 2012.

ICHIKAWA, S. M.; PITOMBO, C.S.; KAWAMOTO, E. Aplicação de minerador de dados na obtenção de relações entre padrões de viagens encadeadas e características socioeconômicas. In: TRANSPORTE em transformação VII. 2003.

ICHIKAWA, S.M.; PITOMBO, C.S.; KAWAMOTO, E. Aplicação de minerador de dados na obtenção de relações entre padrões de viagens encadeadas e características socioeconômicas. Panorama Nacional de Pesquisa em Transportes. In:CONGRESSO DE PESQUISA E ENSINO EM TRANSPORTES, 16., 2002. [Trabalhos apresentados...]. Anpet, 2002, v. 2. p. 175-186.

JÁNOŠÍIOVÁ, L.; SLAVÍK, J.; KOHÁNI, M. Estimation of a route choice model for urban public transport using smart card data. Transportation Planning and Technology, v. 37, n. 7, p. 1-11, 2014.

JARA-DÍAZ, S. R.; GÁLVEZ, T.; VERGARA, C. Social valuation of road accident reductions using subjective perceptions. Journal of Transport Economics and Policy, v. 34, p. 215-232, 2000.

JARA-DÍAZ, S. R.; ORTÚZAR J. D. Introducing the expenditure rate in the estimation of mode choice models. Journal of Transport Economics and Policy, v. 23, p. 293-308, 1989.

JARA-DÍAZ, S.R.; VIDELA, J. Detection of income effect in mode choice: theory and application. Transportation Research 23B, p. 393-400, 1989.

JOHANSSON, M. V.; HELDT, T.; JOHANSSON, P. The Effects of attitudes and personality traits on mode choice. Transportation Research Part A: policy and practice, v. 40, n. 6, p. 507-525, 2006.

JONES, P. M. The Practical application of activity-based approaches in transport planning: an assessment: In: CARPENTER, S.; JONES, P. (ed.). Recent advances in travel demand analysis. Hanst: Gower, 1983.

JONES. P.; KOPPELMAN. F.; ORFUEIL. J. P. Activity analysis: State-of-the-art and future directions. In: JONES, P. M. (ed.). Developmentes in dynamic and activity-based approaches to travel analysis. Brookfield: Gower, 1990.

JONNALAGADDA, N.; FREEDMAN J.; DAVIDSON W.A.; HUNT J.D. Development of microsimulation activity-based model for San Francisco: destination and mode choice models. Transportation Research Recor, v. 1777, p. 25-35, 2001.

KADDOURA, I.; KRÖGER, L.; NAGEL, K. An Activity-based and dynamic approach to calculate road traffic noise damages. 2015. (VSP Working Paper 15-05). Disponível em: https://svn.vsp.tu-berlin.de/repos/public-svn/publications/vspwp/2015/1505/KaddouraKroegerNagel2015NoiseDamages.pdf . Acesso em: 6 out. 2020.

KASS, G.V. An Exploratory technique for investigating large quantities of categorical data. Applied Staistics., v. 29, p. 119-127, 1980. DOI: http://dx.doi.org/10.2307/2986296. 
KATO, H.; ODA, T.; SAKASHITA, A. Valuation of travel time saving with revealed preference data in Japan: further analysis. In: WCT, 13., Rio de Janeiro, Brasil. Select proceendings [...] Rio de Janeiro, 2013.

KATO, H.; SAKASHITA, A.; TSUCHIYA, T.; ODA, T.; TANISHITA, M. Estimating value of travel time savings by using large-scale household survey data from Japan. Transportation Research Record: journal of the transportation research board, v. 2231, p. 85-92, 2011.

KAUFMAN, L.; ROUSSEEUW, P. J. Finding groups in data: an introduction to cluster analysis. New York: John Wiley, 1990.

KEANE, M. P., WASI, N. Estimation of Discrete Choice Models with Many Alternatives Using Random Subsets of the Full Choice Set: With an Application to Demand for Frozen Pizza, Economics Papers, 2012-W13, Economics Group, Nuffield College, University of Oxford.

KIM, S.; ULFARSSON, G. Travel mode choice of the elderly: effects of personal, household, neighborhood, and trip characteristics. Transportation Research Record, v. 1894, p. 117-126, 2004.

KITAMURA R. Applications of models of activity behavior for activity based demand forecasting. In: TEXAS TRANSPORTATION INSTITUTE (ed.). activity-based travel forecasting conference (USDOT), 1996. Summary, Recommendations, and Compendium of Papers, Travel Model Improvement Program, US Department of Transportation, US Environmental Protection Agency. USDOT, 1997. p. 119-150.

KITAMURA, R. A Sequential, history dependent approach to trip chaining behavior, Transportation Research Record, v. 944, p. 13-22, 1983.

KITAMURA, R. Incorporating trip chaining into analysis of destination choice. Transportation Research B18, p. 67-81, 1984.

KOPPELMAN, F.; SETHI, V. Closed-form discrete-choice models. In: HENSHER, D. A.; BUTTON, K. J. (ed.). Handbook of transport modelling. Oxford: Pergamon Press, 2000. v. 1, p. 211-222. (Handbooks in Transport).

KRIZEK, K.; WADDELL, P. Analysis of lifestyle choices: neighborhood type, travel patterns and activity participation. Transportation Research Record, v. 1807, p. 119-128, 2002.

KURANI, K.S.; LEE-GOSSELIN, M. E. H. (1996). Synthesis of past activity analysis applications. In: TRAVEL MODEL IMPROVEMENT PROGRAM (TMIP) CONFERENCE ON ACTIVITY-BASED TRAVEL FORECASTING. New Orleans, 1996. Presented [...]. New Orleans, 1996.

KWAN, M. Interactive revisualization of activity-travel patterns using three-dimensional geographical information systems: a methodological exploration with a large data set. Transportation Research Part. C, v. 8, p. 185-203, 2000.

LABBÉ, M.; LAPORTE, G.; TANCZOS, K.; TOINT, P. L. Transportation modeling and operations research: a fruitful connection. In: LABBE, M.; LAPORTE, G.; TANCZOS, K.; TOINT, P. (ed.). Operations research and decision aid methodologies in traffic and transportation management. New York: Springer-Verlag, 1998. v. 166, p. 1-27. 
LAVASANI, M.; HOSSAN, M. S.; ASGARI, H.; JIN, X. Examining methodological issues on combined RP and SP data. Transportation Research Procedia, v. 25, p. 2335-2348, 2017.

LEE, J.; HE, S. Y.; SOHN, D.W. Potential of converting short car trips to active trips: the role of the built environment in tour-based travel. Journal of Transport \& Health, v. 7, p. 134148, 2017. DOI: https://doi.org/10.1016/j.jth.2017.08.008.

LEE, M.; MCNALLY, M. G. An Empirical investigation on the dynamic processes of activity scheduling and trip chaining. Transportation, v. 33, n. 6, p. 553-565, 2006.

LEE, Y.; HICKMAN, M.; WAHINGTON, S. Household type and structure, time-use pattern, and trip-chaining behavior. Transportation Research Part A, p. 1004-1020, 2007.

LEVINSON, D.; KUMAR, A. A Multimodal trip distribution model: structure and application. Transportation Research Record, Washington, D. C., v. 1446, 1995.

LEWE, J. H.; HIVIN, L. F.; MAVRIS, D. N. A Multi-paradigm approach to system dynamics modeling of intercity transportation. Transportation Research E, v. 71, p. 188-202, 2014.

LI, G. Intercity travel demand: a utility consistent simultaneous trip generation and mode choice model. 2003. Dissertation (Doctoral. Interdisciplinary Program in Transportation) New Jersey Institute of Technology, Newark, 2003.

LI, J.; WENG, J.; SHAO, C.; GUO, H. Cluster-based logistic regression model for holiday travel mode choice. Procedia Engineering, v. 137, p. 729-737, 2016.

LI, P.; ZHAO, P.; BRAND, C. Future energy use and CO2 emissions of urban passenger transport in China: a travel behavior and urban form based approach. Applied Energy, v. 211, p. 820-42, 2018. DOI:10.1016/j.apenergy.2017.11.022.

LINDNER, A.; PITOMBO, C. S.; CUNHA, A. L. Estimating motorized travel mode choice using classifiers: an application for high-dimensional multicollinear data. Travel Behaviour and Society, v. 6, p. 100-109, 2017.

LOUVIERE, J. J.; HENSHER, D. A.; SWAIT, J. D. Stated choice methods analysis and application. Cambridge: Cambridge University Press, 2000.

LU, X.; PAS, E. I. Socio-demographics, activity participation and travel behavior. Transportation Research Part A: policy and practice, v. 33, n. 1, p. 1-18, 1999. Disponível em: http://linkinghub.elsevier.com/retrieve/pii/ S0965856498000202. Acesso em: 6 out. 2020.

LU, Y.; KAWAMURA, K. Data-mining approach to work trip mode choice analysis in Chicago, Illinois, area. Transportation Research Record: Journal of the Transportation Research Board, v. 2156, p. 73-80, 2010. DOI: 10.3141/2156-09.

LUCE, R. D.; SUPPES, P. Preference, utility, and subjective probability. In: LUTE, R. D.; BUSH, R. R.; GALANTER, E. (ed.). Handbook of mathematical psychology. New York: Wiley, 1965. v. 111. p. 249-410.

MACNALLY, M. An activity-based microsimulation model for travel demand forecasting. Irvine CA: ITS Working Paper UCI-ITS-AS-WP-96-1, 1996. 
MADAN, D.B.; GROENHOUT, R. Modelling travel mode choices for the Sydney work trip. Journal of Transport Economics and Policy, v. 21, p. 135-149, 1987.

MANOJ, M.; VERMA. Activity-travel behaviour of non-workers belonging to different income group households in Bangalore, India. Journal of Transport Geography, v. 49, p. 99-109, Dec. 2015.

MATHWORKS. MatLab v. 6.5: user's guide. mathworks Inc. Massachusetts, U.S. 2002.

MCCAFFERTY, D.; HALL, F. L. The Use of multinomial logit analysis to model the choice of time of travel. Economic Geography., v. 58, n. 3, p. 236-246, 1982.

MCFADDEN, D. Conditional logit analysis of qualitative choice behavior. In: ZAREMBKA, P. Frontiers of econometrics. New York: Academic Press, 1973.

MCFADDEN, D. L. Quantitative Methods for Analyzing Travel Behaviour of Individuals: Some Recent Developments, in D. Hensher and P. Stopher (Eds.), Behavioural Travel Modelling, Croom Helm London: London, 1978, pp. 279-318.

MCFADDEN, D. Modeling the choice of residential location. In: KARLQVIST, A. et al. (ed.). Spatial interaction theory and residential location. North-Holland; [s.n.], 1978. p. 7596.

MCFADDEN, D. The Measurement of urban travel demand. Journal of Public Economics, v. 3, n. 4, p. 303-328, 1974.

MCGUCKIN, N.; MURAKAMI, E. Examining trip-chaining behavior: comparison of travel by men and women. Transportation Research Record: journal of the transportation research board, v. 1693, p. 79-85, 1999.

MCNALLY, M.G. The Four-step model. In: HENSHER, D. A.; BUTTON, K. J. (ed.). Handbook of transport modeling [Online]. Bingley: Emerald Insight, 2008. p. 35-53.

METRÔ. Companhia de Trem Metropolitano de São Paulo. Resultados da pesquisa origemdestino 2007. 2008. Disponível em: http://www.metro.sp.gov.br/pesquisaod/arquivos/OD_2007_Sumario_de_Dados.pdf. Acesso em: 19 jun. 2019.

MILLER E. J.; ROORDA M. J.; CARRASCO, J.A. A Tour-based model of travel mode choice. Transportation, v. 32, n. 4, p. 399-422, 2005.

MILLWARDA, H.; HAFEZIB, M. H.; DAISY, N. S. Activity travel of population segments grouped by daily time-use: GPS tracking in Halifax. Canada: Elsevier, 2019. p. 161-170.

MISHRA, S.; YANLI, W.; XIAOYU, Z.; ROLF, M.; SUBRAT, M. Comparison between gravity and destination choice models for trip distribution in Maryland. Transportation Research Board, p. 1-22, 2013.

MISKEEN, M. A. A. B.; ALHODAIRI, A. M.; RAHMAT, R. Modeling of intercity travel mode choice behavior for non-business trips within Libya. Research Journal of Applied Sciences, Engineering and Technology, v. 7, n. 3, p. 442-453, 2014. 
MOLLOY, J. Development of a destination choice model for ontario. Master's Thesis, Technical University of Munich. Munich, Germany, 2017.

MONZÓN, A.; RODRÍGUEZ-DAPENA, A. Choice of mode of transport for long-distance trips: solving the problem of sparse data. Transportation Research Part A, v. 40, p. 587-601, 2006.

MORIKAWA, T. Incorporating stated preference data in travel demand analysis. Dissertation. (Department of Civil Engineering) - MIT, 1989.

MORIKAWA, T.; BEN-AKIVA, M.; MCFADDEN, D. Discrete choice models incorporating revealed preferences and psychometric data. In: FRANSES, P.H.; MONTGOMERY, A.L. (ed.). Econometric models in marketing. Advances in econometrics. $16^{\text {th }}$ ed. Amsterdam: Elsevier, 2002. v. 16, p. 29-55.

MORIKAWA, T.; BEN-AKIVA, M.; YAMADA, K. Forecasting intercity rail ridership using revealed preference and stated preference data. Transportation Research Record, v. 1328, p. 30-35, 1991.

MURO-RODRÍGUEZ, A.; PEREZ-JIMÉNEZ, I.; GUTIÉRREZ-BRONCANO, S. Consumer behavior in the choice of mode of transport: a case study in the Toledo Madrid Corridor. Frontiers in Psychology, v. 8, 2017.

MYUNG, I. J. "Tutorial on Maximum Likelihood Estimation". Journal of Mathematical Psychology, 2003, 47 (1): 90-100. doi:10.1016/S0022-2496(02)00028-7.

NAZARI, F.; SEYEDABRISHAMI, S.; MAMDOOHI, A. R. A Direct demand model of departure time and mode for intercity passenger trips. International Journal of Transportation Engineering, v. 3, n. 2, p. 125-141, 2015.

NISHII, K.; KONDO, K.; KITAMURA, R. Empirical analysis of trip-chaining behavior. Transportation Research Record, v. 1203, p. 48-59, 1988.

ORTÚZAR, J. D.; GONZÁLEZ, R. M. Inter-island travel demand response with discrete choice models: functional form, forecasts and elasticities. Journal of Transport Economics and Policy, v. 36, 2002 (in press).

ORTÚZAR, J. D.; WILLUMSEN, L. G. Modelling Transport. $4^{\text {th }}$ ed. Londres: Wiley, 2011.

PALMA, A.; PICARD, N. Route choice behavior with risk averse users. In: NIJKAMP, P.; REGGIANI, A. (ed.). Spatial evolution and modeling. Cheltenham: Elgar, 2006. p. 129-178.

PAPACOSTAS, C. S.; PREVEDOUROS, P. D. transportation engineering and planning. Englewood Cliffs: Prentice Hall, 1993.

PAS, E. I. Weekly travel-activity behavior. Transportation, v. 15, p. 89-109, 1988.

PAULSSEN, M.; TEMME, D.; VIJ, A.; WALKER, J. L. Values, attitudes and travel behaviour: a hierarchical latent variable mixed logit model of travel mode choice. Transportation, v. 41, p. 873-888, 2014. 
PEETA, S.; PAZ, A.; DELAURENTIS, D. Stated preference analysis of a new very light jet based on-demand air service. Transportation Research Part A: policy and practice, v. 42, p. 629-645, 2008.

PINJARI, A.R.; BHAT, C.R. Activity-based travel demand analysis. In: PALMA, A.; LINDSEY, R.; QUINET, E.; VICKERMAN, R. (ed.). A Handbook Transport economics. [S.1.]: Edward Elgar, 2011. n. 1, p. 1-36.

PITOMBO, C. S. Estudo de relações entre variáveis socioeconônicas, de uso do solo, participação em atividades e padrões de viagens encadeadas urbanas. Tese (Doutorado em Engenharia de Transportes) - Escola de Engenharia de São Carlos, Universidade de São Paulo, São Carlos, 2007.

PITOMBO, C. S.; KAWAMOTO, E.; SOÚSA, A. J. An Exploratory analysis of relationships between socioeconomic, land úse, activity participation variables and travel patterns. Transport Policy, v. 18, n. 2, p. 347-357, 2011.

PITOMBO, C. S.; SALGUEIRO, A. R.; COSTA, A.S.G.; ISLER, C. A. A Two-step method for mode choice estimation with socioeconomic and spatial information. Spatial Statistics, v. 11, p. 45-64, 2015.

PITOMBO, C. S.; SOUZA, A. D.; LINDNER, A. Comparing decision tree algorithms to estimate intercity trip distribution. Transportation Research Part $C$ : emerging technologies, v. 77, p. 16-32, 2017. DOI: 10.1016/j.trc.2017.01.009.

PUCHER, J. Urban passenger transport in the united states and europe: a comparative analysis of public policies. Transport Reviews, v. 15, n. 2, p. 99-117, 1995.

QUINLAN, R. Learning efficient classification procedures and their application to chess end-games. Tioga, Palo Alto: Machine Learning: An Artificial Intelligence Approach, 1983. p. 463-482.

RANJAN, A.; FOSGERAU, M. A Note on identification in discrete choice models with partial observability. Theory and Decision, v. 83, p. 283-292, 2017.

RECKER, W. W.; MCNALLY, M.G.; ROOT, G. S. A Model of complex travel behavior: part i: theoretical development. Transportation Research, v. 20A, p. 307-318, 1986.

ROBERT, L.T. “Quem pertence à família?”. Psychometrika, 1953, 18(4): 267-276. doi :10.1007 / BF02289263

ROMA, A. D. S.; PITOMBO, C. S.; GUIMARÃES, H. S.; COSTA, L. H. M. Análise de desempenho de algoritmos de aprendizagem de máquinas para análise desagregada de viagens intermunicipais. Transportes, v. 26, p. 159-175, 2018. DOI: 10.14295/transportes. v26i3.1614.

RUAN, M.; LIN, J.; KAWAMURA, K. Modeling urban commercial vehicle daily tour chaining. Transportation Research Part E: logistics and transportation review, v. 48, p. 1169-1184, 2012. doi:10.1016/j.tre.2012.06.003. 
SARKAR, P.P., MALLIKARJUNA, C. Effect of perception and attitudinal variables on mode choice behavior: a case study of Indian city, Agartala. Travel Behavior and Society, v. 12, p. 108-114, 2018.

SCHEINER, J., HOLZ-RAU, C. Women's complex daily lives: a gendered look at trip chaining and activity pattern entropy in Germany. Transportation, v. 44, p. 117-138, 2017.

SCHLOSSBERG, M.; GREENE, J.; PHILLIPS, P. P.; JOHNSON, B., PARKER, B. School trips: effects of urban form and distance on travel mode. Journal of the American Planning Association, v. 72, p. 337-46, 2006.

SCHWANEN, T.; DIJST, M.; DIELEMAN, F. M. Policies for urban form and their impact on travel: the Netherlands experience. Urban Study. 41, p. 579-603, 2004.

SHREWSBURY, J. S. Calibration of trip distribution by generalised linear models. New Zealand Transport Agency Research Report, 473, 2012.

SHUKLA, N.; MA, J.; WICKRAMASURIYA, R.; HUYNH, N. N. Data-driven modelling and analysis of household travel mode choice. In: INTERNATIONAL CONGRESS ON MODELLING AND SIMULATION, 20., Adelaide, 2013a. p. 92-98.

SHUKLA, N.; MA, J.; WICKRAMASURIYA, R.; HUYNH, N. N.; PEREZ, P.. Tour-based travel mode choice estimation based on data mining and fuzzy techniques. In: DOLAN, T.; COLLINS, B. S. (ed.). International Symposium For Next Generation Infrastructure. United Kingdom: University College London (UCL), 2015. p. 215-220.

SHUKLA, N.; MUNOZ, A.; MA, J.; HUYNH, N. Hybrid agent based simulation with adaptive learning of travel mode choices for university commuters. In: WORKSHOP ON MODEL-DRIVEN APPROACHES FOR SIMULATION ENGINEERING, SYMPOSIUM ON THEORY EOF MODELING AND SIMULATION, SCS SPRINGSIM CONFERENCE. Paper presented [...]. San Diego, CA, 2013b.

SILVA, F. G. F. Modelando valor de tempo de viagem para modos concorrentes por diferentes modelos Logit: o que se ganha e o que se perde? Tese (Doutorado) - Universidade Federal do Ceará, Fortaleza 2015.

SIRIPIROTE, T.; SUMALEE, A.; Ho, H.W.; LAM, W. H. K. Statistical approach for activity-based model calibration based on plate scanning and traffic counts data. Transportation Research Part B, v. 78, p. 280-300, 2015.

SOCORRO, M. P.; VIECENS, M. F. The Effects of airline and high-speed train integration. Transportation Research Part A: policy and practice, v. 49, p. 160-177, 2013.

SOUTHWORTH, F. Calibration of multinomial logit models of mode and destination choice. Transportation Research Part A, v. 15, n. 4, p. 315-325, 1981. Disponível em: https://doi.org/10.1016/0191-2607(81)90013-3. Acesso em: 6 out. 2020.

SOUZA, H. H. H.; SOUSA, F.F.L.M.; OLIVEIRA NETO, F.M.; FREIRE, R.M.C.; LOUREIRO, C.F.G. Estimação do valor do tempo com base em pesquisas domiciliares de origem e destino: desafios teóricos e dificuldades práticas. In: CONGRESSO DA ANPET, 31., Recife. Anais [...]. Recife, 2017. 
SPECKMAN, P.; VAUGHN, K. M.; PAS, E. I. A Continuous spatial interaction model: application to-home-work travel in Portland, Oregon. In: ANNUAL TRANSPORTATION RESEARCH BOARD MEETING, 1997, Washington, D.C.

STEED, J. L.; BHAT, C. R. On Modeling departure-time choice for home-based social/recreational and shopping trips. Transportation Research Record: journal of the transportation research board, Washington, D.C., n. 1706, p. 152-159, 2000.

STRATHMAN J. G.; DUEKER, K. J.; DAVIS, J. S. Effects of household structure and selected characteristics on trip chaining. Transportation, v. 21, p. 23-45, 1994.

SWAIT, J. Choice-set generation within the generalized extreme value family of discrete choice models. Transportation Research, v. 35B, p. 643-666, 2001.

SWAIT, J.; ADAMOWICZ, W. The Effect of choice environment and task demands on consumer behavior: discriminating between contribution and confusion. Working paper, Dept. of Rural Economy, University of Alberta, 1997.

SWAIT, J.; BEN-AKIVA, M. Incorporating random constraints in discrete models of choice set generation. Transportation Research B., v. 21B, n. 2, p. 91-102, 1988.

TACO, P. W. G. Redes Neurais Artificiais Aplicadas na Modelagem Individual de Padrões de Viagens Encadeadas a Pé. Tese Doutorado. Escola de Engenharia de São Carlos/USP, EESC, Brasil, 2003.

TAN, P.; STEINBACH, M.; KUMAR, V. Introduction to data mining. Boston: AddisonWesley, 2006.

TENG, J.; WANG, H.; LEI, X. analyzing the effects of public transit information systems based on mobile terminal on choice behavior of travelers on route. Transportation reform. In: COTA INTERNATIONAL CONFERENCE OF TRANSPORTATION PROFESSIONALS, 17., 2017.

TIMMERMANS, H.; ARENTZE, T. A. Transport models and urban planning practice: experiences with Albatross. Transport Reviews, v. 31, n. 2, p. 199-207, 2011.

TINGUELY, L.; DANALET, A.; LAPPARENT, M.; BIERLAIRE, M. Destination choice model including a panel effect using WiFi localization in a pedestrian facility. In: SWISS TRANSPORT RESEARCH CONFERENCE, 15., 2015. Proceedings [...].

TRAIN, K.; MCFADDEN, D. The Goods/leisure tradeoff and disaggregate work trip mode choice models. Transportation Research, v. 12, p. 349-353, 1978.

VAN ACKER, V.V.; WITLOX, F. Commuting trips within tours: how is commuting related to land use? Transportation, v. 38, n. 3, p. 465-486, 2011.

VAN DER HOORN, T. Development of an activity model using a one-week activity-diary data base. In: RECENT advances in travel demand analysis. Aldershot (UK): Gower, 1983. p. 335-349. 
VERPLANKEN, B.; AARTS, H.; VAN KNIPPENBERG, A.; VAN KNIPPENBERG, C. Attitude versus general habit: antecedants of travel mode choice. Journal of Applied Social Psychology, v. 24, p. 285-300, 1994.

VIJ, A.; CARREL, A.; WALKER, J. L. Incorporating the influence of latent modal preferences on travel mode choice behavior. Transportation Research Part A, v. 54, p. 164-178, 2013.

VITON, P. On The Interpretation of income variables in discrete-choice models. Economics Letters, p. 203-206, 1985.

VOVSHA, P.; BRADLEY, M. Hybrid discrete choice departure-time and duration model for scheduling travel tours. Transportation Research Record: Journal of the Transportation Research Board, v. 1894, p. 46-56, 2004.

WALKER, J. L.; EHLERS, E; BANERJEE I, DUGUNDJI ER. Correcting for endogeneity in behavioral choice models with social influence variables. Transportation Research Part A, 2010 .

WANG, K. Y. E, X.; PENDYALA, R. M.; ZOU, Y. On The Development of a seminonparametric generalized multinomial logit model for travel-related choices. PLoS ONE, v. 12, n. 10, 2017, e0186689.

XIAN-YU, J. Travel mode choice analysis using support vector machines. In:

INTERNATIONAL CONFERENCE OF CHINESE TRANSPORTATION

PROFESSIONALS (ICCTP), 11., Nanjing, 2011. p. 360-371. DOI:10.1061/41186(421)37.

YAO, E.; MORIKAWA, T. A Study of an integrated intercity travel demand model.

Transportation Research, v. 39A, p. 367-381, 2005.

YE, X. et al. A Practical method to test the validity of the standard Gumbel distribution in logit-based multinomial choice models of travel behavior. Transportation Research Part B, 2017. DOI: https://doi.org/10.1016/j.trb.2017.10.009.

ZELLNER, M.; MASSEY, D.; SHIFTAN, Y.; LEVINE, J.; ARQUERO, M. Overcoming the last-mile problem with transportation and land-use improvements: an agent-based approach. International Journal of Transportation, v. 4, n. 1, p. 1-26, 2016.

ZHANG, J.Y.; KUWANO, M.; LEE, B.; FUJIWARA, A. Modeling household discrete choice behavior incorporating heterogeneous group decision-making mechanisms.

Transportation Research Part B, v. 43, n. 2, p. 230-250, 2009.

ZHANG, T.; RAMAKRISHNON, R.; LIVNY, M. BIRCH, M. An Efficient data clustering method for very large databases. In: ACM SIGMOD CONFERENCE ON MANAGEMENT OF DATA. Proceedings [...]. Montreal: ACM, 1996. p. 103-114.

ZHU, Z.; XIONG, C.; CHEN, X.; HE, X.; ZHANG, L. Integrating mesoscopic dynamic traffic assignment with agent-based travel behavior models for cumulative land development impact analysis. Transportation Research Part C: emerging technologies, v. 93, p. 446-462, 2018. DOI: 10.1016/j.trc.2018.06.011. 


\section{APÊNDICE A}

RESUMO DOS CLUSTERS - 3 Modos - 20 Clusters

\begin{tabular}{|c|c|c|}
\hline Cluster/Padrão & Repetições & Porcentagem \\
\hline 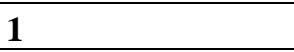 & 211 & $3,01 \%$ \\
\hline WHWH1111 & 88 & $1,25 \%$ \\
\hline AHWH1111 & 18 & $0,26 \%$ \\
\hline WHWH2222 & 12 & $0,17 \%$ \\
\hline WAAH1111 & 11 & $0,16 \%$ \\
\hline SHAH1111 & 10 & $0,14 \%$ \\
\hline WHWH1122 & 6 & $0,09 \%$ \\
\hline 2 & 120 & $1,71 \%$ \\
\hline WHSH2222 & 9 & $0,13 \%$ \\
\hline WWWH2222 & 6 & $0,09 \%$ \\
\hline WHSH3333 & 6 & $0,09 \%$ \\
\hline AHSH2222 & 6 & $0,09 \%$ \\
\hline 3 & 979 & $13,96 \%$ \\
\hline WH22 & 979 & $13,96 \%$ \\
\hline 4 & 196 & $2,79 \%$ \\
\hline AHAH1111 & 86 & $1,23 \%$ \\
\hline AAAH1111 & 29 & $0,41 \%$ \\
\hline SHWH1111 & 16 & $0,23 \%$ \\
\hline WHSH1111 & 14 & $0,20 \%$ \\
\hline SWSH1111 & 12 & $0,17 \%$ \\
\hline SWAH1111 & 9 & $0,13 \%$ \\
\hline AHSH1111 & 8 & $0,11 \%$ \\
\hline SWWH1111 & 6 & $0,09 \%$ \\
\hline 5 & 146 & $2,08 \%$ \\
\hline SHSH1111 & 40 & $0,57 \%$ \\
\hline WWWH1111 & 36 & $0,51 \%$ \\
\hline WAWH1111 & 36 & $0,51 \%$ \\
\hline AWAH1111 & 8 & $0,11 \%$ \\
\hline 6 & 165 & $2,35 \%$ \\
\hline WHAH1111 & 83 & $1,18 \%$ \\
\hline WHAH3311 & 17 & $0,24 \%$ \\
\hline WHAH3333 & 14 & $0,20 \%$ \\
\hline WHAH 2233 & 13 & $0,19 \%$ \\
\hline WHAH2211 & 10 & $0,14 \%$ \\
\hline WHAH1133 & 8 & $0,11 \%$ \\
\hline WHAH3322 & 6 & $0,09 \%$ \\
\hline 7 & 174 & $2,48 \%$ \\
\hline AHAH2222 & 23 & $0,33 \%$ \\
\hline AHAH2233 & 19 & $0,27 \%$ \\
\hline AHAH1133 & 15 & $0,21 \%$ \\
\hline
\end{tabular}




\begin{tabular}{|c|c|c|}
\hline AHAH2211 & 14 & $0,20 \%$ \\
\hline АHAH3311 & 11 & $0,16 \%$ \\
\hline WHSH2233 & 9 & $0,13 \%$ \\
\hline AHAH3322 & 7 & $0,10 \%$ \\
\hline SHSH2222 & 6 & $0,09 \%$ \\
\hline 8 & 223 & $3,18 \%$ \\
\hline WHWH3333 & 92 & $1,31 \%$ \\
\hline SHSH3333 & 57 & $0,81 \%$ \\
\hline AHAH3333 & 42 & $0,60 \%$ \\
\hline SHWH3333 & 8 & $0,11 \%$ \\
\hline SWSH3333 & 7 & $0,10 \%$ \\
\hline SHWH1122 & 6 & $0,09 \%$ \\
\hline 9 & 139 & $1,98 \%$ \\
\hline WAWH 2332 & 56 & $0,80 \%$ \\
\hline WAWH1331 & 46 & $0,66 \%$ \\
\hline WAWH3333 & 11 & $0,16 \%$ \\
\hline 10 & 291 & $4,15 \%$ \\
\hline SH33 & 116 & $1,65 \%$ \\
\hline SH22 & 112 & $1,60 \%$ \\
\hline SH11 & 63 & $0,90 \%$ \\
\hline 11 & 513 & $7,31 \%$ \\
\hline $\mathrm{AH} 22$ & 513 & $7,31 \%$ \\
\hline 12 & 148 & $2,11 \%$ \\
\hline SWH111 & 42 & $0,60 \%$ \\
\hline AWH111 & 35 & $0,50 \%$ \\
\hline WSH111 & 31 & $0,44 \%$ \\
\hline SAH111 & 10 & $0,14 \%$ \\
\hline 13 & 311 & $4,43 \%$ \\
\hline AAH222 & 52 & $0,74 \%$ \\
\hline WSH222 & 45 & $0,64 \%$ \\
\hline AAH333 & 41 & $0,58 \%$ \\
\hline WWH222 & 18 & $0,26 \%$ \\
\hline AAH232 & 12 & $0,17 \%$ \\
\hline AAH223 & 11 & $0,16 \%$ \\
\hline WAH333 & 11 & $0,16 \%$ \\
\hline WSH333 & 8 & $0,11 \%$ \\
\hline SWH222 & 7 & $0,10 \%$ \\
\hline WSH223 & 7 & $0,10 \%$ \\
\hline AAH322 & 6 & $0,09 \%$ \\
\hline 14 & 1334 & $19,02 \%$ \\
\hline WH11 & 1334 & $19,02 \%$ \\
\hline 15 & 651 & $9,28 \%$ \\
\hline WH33 & 651 & $9,28 \%$ \\
\hline
\end{tabular}


RESUMO DOS CLUSTERS - 3 Modos - 30 Clusters

\begin{tabular}{|c|c|c|}
\hline Cluster/Padrão & Repetições & Porcentagem \\
\hline 1 & 131 & $1,87 \%$ \\
\hline WHWH1111 & 88 & $1,25 \%$ \\
\hline WHWH2222 & 12 & $0,17 \%$ \\
\hline WHWH1122 & 6 & $0,09 \%$ \\
\hline WHWH3311 & 5 & $0,07 \%$ \\
\hline WHWH1133 & 5 & $0,07 \%$ \\
\hline 2 & 55 & $0,78 \%$ \\
\hline AAAH3333 & 5 & $0,07 \%$ \\
\hline 3 & 78 & $1,11 \%$ \\
\hline AHWH1111 & 18 & $0,26 \%$ \\
\hline WAAH1111 & 11 & $0,16 \%$ \\
\hline SHAH1111 & 10 & $0,14 \%$ \\
\hline AHWH1133 & 5 & $0,07 \%$ \\
\hline SHAH3322 & 5 & $0,07 \%$ \\
\hline 4 & 63 & $0,90 \%$ \\
\hline WHSH2222 & 9 & $0,13 \%$ \\
\hline WHSH3333 & 6 & $0,09 \%$ \\
\hline AHSH2222 & 6 & $0,09 \%$ \\
\hline WHSH3322 & 5 & $0,07 \%$ \\
\hline 5 & 979 & $13,96 \%$ \\
\hline WH22 & 979 & $13,96 \%$ \\
\hline & & \\
\hline 6 & 110 & $1,57 \%$ \\
\hline AAAH1111 & 29 & $0,41 \%$ \\
\hline SHWH1111 & 16 & $0,23 \%$ \\
\hline WHSH1111 & 14 & $0,20 \%$ \\
\hline SWSH1111 & 12 & $0,17 \%$ \\
\hline SWAH1111 & 9 & $0,13 \%$ \\
\hline AHSH1111 & 8 & $0,11 \%$ \\
\hline SWWH1111 & 6 & $0,09 \%$ \\
\hline 7 & 143 & $2,04 \%$ \\
\hline SHSH1111 & 40 & $0,57 \%$ \\
\hline WAWH1111 & 36 & $0,51 \%$ \\
\hline WWWH1111 & 36 & $0,51 \%$ \\
\hline AWAH1111 & 8 & $0,11 \%$ \\
\hline WWAH1111 & 5 & $0,07 \%$ \\
\hline AAWH1111 & 5 & $0,07 \%$ \\
\hline 8 & 165 & $2,35 \%$ \\
\hline WHAH1111 & 83 & $1,18 \%$ \\
\hline WHAH3311 & 17 & $0,24 \%$ \\
\hline WHAH3333 & 14 & $0,20 \%$ \\
\hline WHAH2233 & 13 & $0,19 \%$ \\
\hline WHAH2211 & 10 & $0,14 \%$ \\
\hline
\end{tabular}




\begin{tabular}{|c|c|c|}
\hline WHAH1133 & 8 & $0,11 \%$ \\
\hline WHAH3322 & 6 & $0,09 \%$ \\
\hline 9 & 102 & $1,45 \%$ \\
\hline AHAH2233 & 19 & $0,27 \%$ \\
\hline AHAH1133 & 15 & $0,21 \%$ \\
\hline AHAH2211 & 14 & $0,20 \%$ \\
\hline WHSH2233 & 9 & $0,13 \%$ \\
\hline AHAH3322 & 7 & $0,10 \%$ \\
\hline AHAH 1122 & 5 & $0,07 \%$ \\
\hline 10 & 132 & $1,88 \%$ \\
\hline SHSH3333 & 57 & $0,81 \%$ \\
\hline AHAH3333 & 42 & $0,60 \%$ \\
\hline SHWH3333 & 8 & $0,11 \%$ \\
\hline SWSH3333 & 7 & $0,10 \%$ \\
\hline SHWH1122 & 6 & $0,09 \%$ \\
\hline 11 & 135 & $1,92 \%$ \\
\hline WAWH2332 & 56 & $0,80 \%$ \\
\hline WAWH1331 & 46 & $0,66 \%$ \\
\hline WAWH3333 & 11 & $0,16 \%$ \\
\hline WAWH2112 & 5 & $0,07 \%$ \\
\hline 12 & 81 & $1,15 \%$ \\
\hline AHAH2222 & 23 & $0,33 \%$ \\
\hline AHAH3311 & 11 & $0,16 \%$ \\
\hline SHSH 2222 & 6 & $0,09 \%$ \\
\hline WWWH2222 & 6 & $0,09 \%$ \\
\hline WHAH2222 & 5 & $0,07 \%$ \\
\hline WAWH2222 & 5 & $0,07 \%$ \\
\hline 13 & 86 & $1,23 \%$ \\
\hline AHAH1111 & 86 & $1,23 \%$ \\
\hline 14 & 93 & $1,33 \%$ \\
\hline WHWH3333 & 92 & $1,31 \%$ \\
\hline 15 & 175 & $2,50 \%$ \\
\hline SH22 & 112 & $1,60 \%$ \\
\hline SH11 & 63 & $0,90 \%$ \\
\hline 16 & 513 & $7,31 \%$ \\
\hline $\mathrm{AH} 22$ & 513 & $7,31 \%$ \\
\hline 17 & 138 & $1,97 \%$ \\
\hline SWH111 & 42 & $0,60 \%$ \\
\hline AWH111 & 35 & $0,50 \%$ \\
\hline WSH111 & 31 & $0,44 \%$ \\
\hline SAH111 & 10 & $0,14 \%$ \\
\hline AWH222 & 5 & $0,07 \%$ \\
\hline
\end{tabular}

